\title{
Ventricular remodeling and arrhythmogenesis in the canine heart : focus on prevention
}

Citation for published version (APA):

Schoenmakers, M. (2004). Ventricular remodeling and arrhythmogenesis in the canine heart : focus on prevention. [Doctoral Thesis, Maastricht University]. Universiteit Maastricht. https://doi.org/10.26481/dis.20040324ms

Document status and date:

Published: 01/01/2004

DOI:

10.26481/dis.20040324ms

Document Version:

Publisher's PDF, also known as Version of record

\section{Please check the document version of this publication:}

- A submitted manuscript is the version of the article upon submission and before peer-review. There can be important differences between the submitted version and the official published version of record.

People interested in the research are advised to contact the author for the final version of the publication, or visit the DOI to the publisher's website.

- The final author version and the galley proof are versions of the publication after peer review.

- The final published version features the final layout of the paper including the volume, issue and page numbers.

Link to publication

\footnotetext{
General rights rights.

- You may freely distribute the URL identifying the publication in the public portal. please follow below link for the End User Agreement:

www.umlib.nl/taverne-license

Take down policy

If you believe that this document breaches copyright please contact us at:

repository@maastrichtuniversity.nl

providing details and we will investigate your claim.
}

Copyright and moral rights for the publications made accessible in the public portal are retained by the authors and/or other copyright owners and it is a condition of accessing publications that users recognise and abide by the legal requirements associated with these

- Users may download and print one copy of any publication from the public portal for the purpose of private study or research.

- You may not further distribute the material or use it for any profit-making activity or commercial gain

If the publication is distributed under the terms of Article $25 \mathrm{fa}$ of the Dutch Copyright Act, indicated by the "Taverne" license above, 
(c) Marieke Schoenmakers, Nijmegen, 2004 ISBN 90-9017823-6

Vormgeving en druk: BENDA drukkers, Nijmegen 


\title{
Ventricular remodeling and arrhythmogenesis in the canine heart Focus on prevention
}

\author{
PROEFSCHRIFT \\ ter verkrijging van de graad van doctor \\ aan de Universiteit Maastricht, \\ op gezag van de Rector Magnificus, \\ Prof.Mr. G.P.M.F Mols, \\ volgens het besluit van het College van Decanen, \\ in het openbaar te verdedigen \\ op woensdag 24 maart 2004 om 12.00 uur
}

door

Marieke Schoenmakers

Geboren op 28 oktober 1973 te Breda 
Promotor:

Prof. Dr. M.A. Vos, Universiteit Utrecht

Beoordelingscommissie:

Prof. Dr. H.J.G.M. Crijns (voorzitter)

Prof. Dr. M.A. Allessie

Dr. M.E. Anderson, Vanderbilt University Medical Center, Verenigde Staten

Dr. K.R. Sipido, Katholieke Universiteit Leuven, België

Prof. Dr. H.J.J. Wellens

The study described in this thesis was supported by the Netherlands Heart Foundation (NHF 98.042)

Financial support by the Netherlands Heart Foundation and the Stichting Hartsvrienden RESCAR for the publication of this thesis is gratefully acknowledged. Additional support was granted by Vitatron Nederland B.V. and St. Jude Medical Nederland B.V. 
Voor mijn papa en mama 


\section{Content}

Chapter 1

Chapter 2

Chapter 3

Chapter 4

Chapter 5

Chapter 6

Summary

Samenvatting

Dankwoord

Curriculum Vitae

In the CAVB dog, maximally attained inotropy is negatively associated with susceptibility to drug-induced torsade de pointes: Inverse relation of electrical remodeling and poststimulus potentiation

Dose-dependent reduction of electrical remodeling and acquired torsade de pointes by carvedilol in the complete AV block dog

General discussion

Publications 
Chapter 1

\section{Introduction}




\section{Background}

Cardiovascular diseases are the leading cause of death in the Netherlands (figure 1 ), which is similar to the situation in other countries of the industrialized world. Cardiovascular mortality is mainly attributed to ischemic heart diseases (34\%), other cardiac diseases (26\%) like heart failure, and cerebrovascular causes (25\%).' Although the clinical symptoms of cardiovascular diseases may vary widely, sudden death is often the first manifestation. ${ }^{2 \cdot-1}$ Sudden cardiac death is defined as the unexpected natural death due to a cardiac cause within a short period of time from the onset of symptoms, in a person without any prior condition that would appear fatal. ${ }^{5,6}$ In the Maastricht area, the mean yearly incidence of this sudden mode of death is 1 in 1000 inhabitants between 20 and 75 years of age, which comprises almost $19 \%$ of total mortality in this age group. ${ }^{23}$ Sudden cardiac death is often attributed to a cardiac arrhythmia, as illustrated by studies in patients where the electrical activity of the heart was recorded just prior to (aborted) death. ${ }^{.11}$

Figure 1: Causes of death in the Netherlands in 2001 as provided by the Central Statistical Office, the Netherlands.

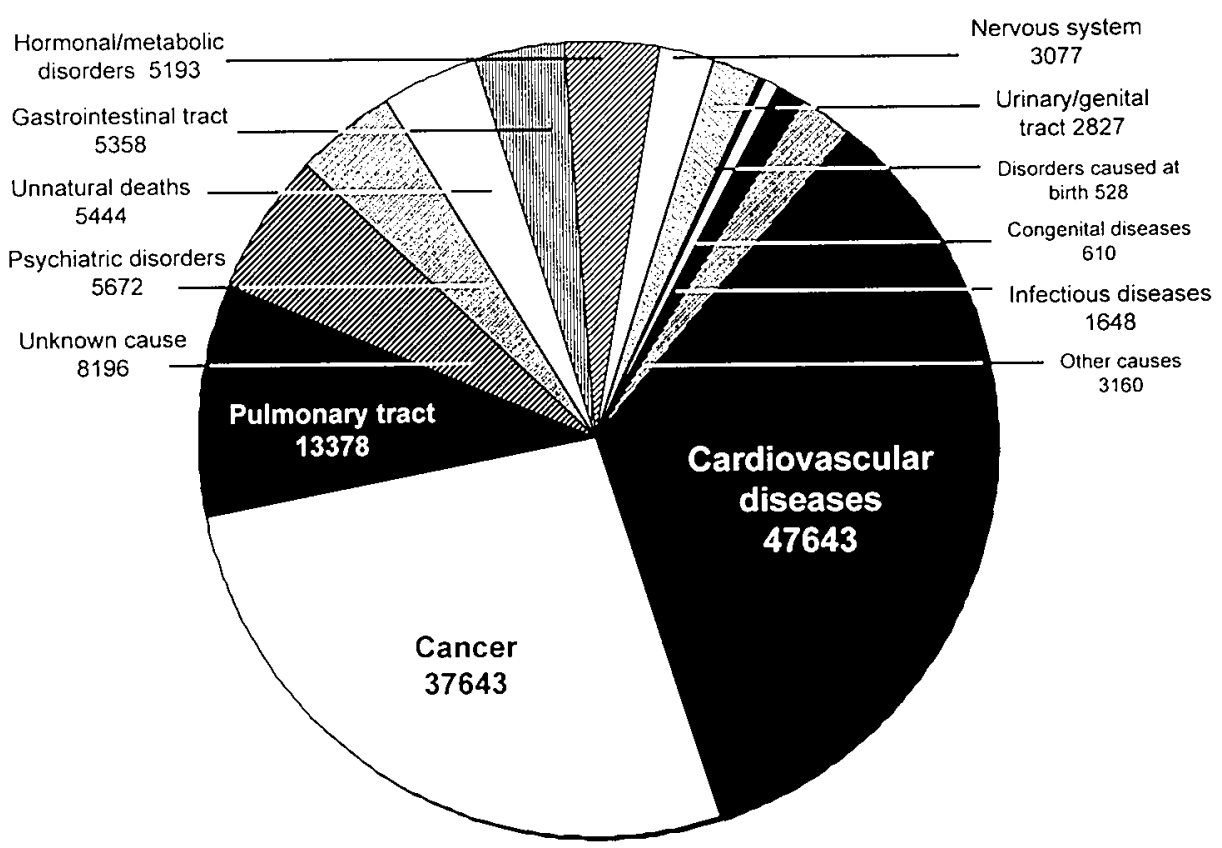

In the year 2001. 140377 people in the Netherlands died. The main causes of death were due to cardiovascular diseases (35\%). cancer $(27 \%)$, or diseases of the pulmonary tract $(10 \%)$. 


\section{Remodeling and ventricular arrhythmias}

Cardiovascular diseases trigger a number of changes in cardiac structure, function, and electrophysiology, which are named remodeling processes. Ventricular structural, contractile, and electrical remodeling are associated with an increased susceptibility to ventricular arrhythmias, as illustrated in figure 2. These remodeling processes are based on changes in the myocyte as well as alterations in the interstitial compartment of the heart.

Figure 2: Relevance of ventricular remodeling for susceptibility to arrhythmias.

\section{Ventricular remodeling}
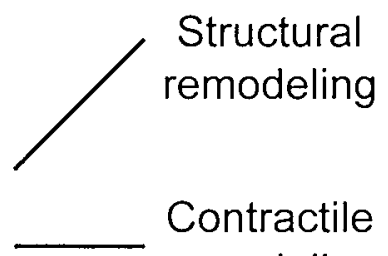

Contractile remodeling

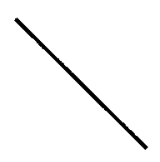

Electrical
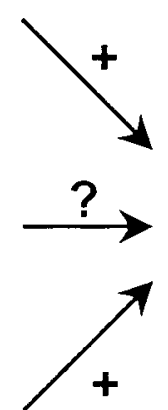

Ventricular arrhythmias

remodeling

Ventricular remodeling consists of changes in structure (structural remodeling), function (contractile remodeling), and electrophysiology (electrical remodeling). Structural and electrical remodeling render the heart susceptible to ventricular arrhythmias, while the role of contractile remodeling seems less clear.

An important expression of structural remodeling is the development of hypertrophy. Left ventricular hypertrophy is an important risk factor for sudden cardiac death and ventricular arrhythmias, and is reported to be present in $10-20 \%$ of the total population in the western world. ${ }^{12-15}$ The development of cardiac hypertrophy is regarded to be an adaptive response to an abnormal global or regional increase in cardiac work, which can be evoked by mechanical overload, e.g. systemic hypertension (pressure overload) or mitral valve regurgitation (volume overload), and myocardial infarction.

Patients with ventricular hypertrophy can have a normal cardiac function at rest and during exercise for years (compensated hypertrophy), but if the stimulus for hypertrophy is sufficiently intense or prolonged ventricular dysfunction and heart failure may ensue. ${ }^{16}$ In heart failure ventricular arrhythmias, either nonsustained or sustained, are frequently observed. ${ }^{417.18}$ Furthermore, the incidence of sudden cardiac death is high, especially in patients with less severe heart failure (NYHA II-III) where more than $50 \%$ die suddenly. ${ }^{18,19}$ However, the exact relevance of contractile 
remodeling (compensated versus decompensated contractile function) for arrhythmias is not yet clear (figure 2).

Susceptibility to ventricular arrhythmias in hypertrophy and heart failure is also associated with electrophysiological remodeling, like slowing of conduction and prolongation of repolarization. Prolongation of ventricular repolarization (increased QT-time) has been attributed to an increased duration of the ventricular action potential based on alterations in ion channels, pumps, and exchangers, which has been studied in patients with end stage heart failure. ledge comes from experiments in animals (table 1) ${ }^{n: t}$

Our insight into remodeling in hypertrophy and heart failure is essential for the development of new treatment strategies, including prevention, for ventricular arrhythmias and sudden cardiac death.

\section{Ventricular remodeling and arrhythmogenesis in animal models}

Numerous animal models of cardiac diseases have been developed in order to study different aspects of remodeling and susceptibility to ventricular arrhythmias. In table 1, emphasis is put on in vivo models of hypertrophy and/or heart failure in which electrical remodeling, cardiac function, and arrhythmogeneity were studied. Ventricular hypertrophy is either induced by volume overload, pressure overload, or myocardial infarction. Volume overload in the models is caused by bradycardia due to complete atrioventricular (AV) block, and pressure overload by aorla banding, or unilateral nephrectomy and contralateral renal artery banding. ${ }^{26 \cdot 30}$ Both left and right ventricles show hypertrophy after chronic complete AV block (CAVB) and longterm aortic insufficiency with aortic constriction, while only the left ventricle is affected in (systemic) pressure overload. Hypertrophy after myocardial infarction is restricted to the noninfarcted area. In the tachypacing dog, however, cardiac hypertrophy seems to be absent."3\%

In most of the models that are mentioned in table 1 , cardiac function has been characterized. ${ }^{26273.2}$ Functional compensation has been reported in the post myocardial infarction rat-model, and has been suggested for the CAVB dog. In the post myocardial infarction rat a temporal relation for contractile function has been described, where in time contractile dysfunction develops. The majority (77\%) of the CAVB rabbit, and all aortic constricted rabbits have heart failure symptoms. Four weeks of fast pacing in the dog results in ventricular dilatation and severe symptoms of heart failure, like apathy, anorexia, tachypnea, and lethargy. This is accompanied by findings of ascites and pleural fluid at autopsy.

In all models, there is electrical remodeling, which is characterized by prolongation of ventricular action potential duration (APD) in most. ventricular APD has been related to remodeling of ion currents, like decreased potassium currents $\left(I_{T_{0}}, l_{k_{1}}, l_{k_{r}}\right.$ and $\left.I_{K_{s}}\right)$, and changes in calcium handling."

Spatial dispersion, either the difference in APD between the ventricles, within the 
Introduction

Table 1: Animal models of hypertrophy and heart failure

\begin{tabular}{|c|c|c|c|c|c|c|}
\hline Model & Hypertrophy & $\mathrm{CHF}$ & Electrical & remodeling & VA & $S C D$ \\
\hline Post MI rat & local LVH & no & $i$ LVAPD & no $\triangle \mathrm{APD}$ & $80 \%$ & $?$ \\
\hline CAVB rabbit & BVH & yes & $\hat{A} \mathrm{APD}$ & $? \triangle A P D$ & $71 \%$ & $100 \%$ \\
\hline$A l+A C$ rabbit & BVH & yes & $\uparrow \mathrm{APD}$ & $? \triangle A P D$ & $90 \%$ & $10 \%$ \\
\hline Aorta banded cat & LVH & ? & $=$ LVAPD & I $\triangle A P D$ & $52 \%$ & $6 \%$ \\
\hline$N+B \operatorname{dog}$ & LVH & ? & $i$ LVAPD & $? \triangle \mathrm{APD}$ & $80 \%$ & ? \\
\hline CAVB dog & BVH & no & $\uparrow \mathrm{APD}$ & $\triangle A P D$ & $60-86 \%$ & $10-15 \%$ \\
\hline Tachypacing dog & $(\mathrm{no})^{* *}$ & yes & $\uparrow \mathrm{APD}$ & $=\uparrow \triangle A P D * *$ & $23-46 \%$ & $24 \%$ \\
\hline
\end{tabular}

CHF: congestive heart failure; VA: ventricular arrhythmias; SCD: sudden cardiac death: post MI: post myocardial infarction; LVH: left ventricular hypertrophy; LV : left ventricular; APD: action potential duration; $\triangle A P D$ : spatial dispersion of APD; ?: has not been studied; CAVB: complete AV block; $B V H$ : biventricular hypertrophy; $\mathrm{Al}+\mathrm{AC}$ : aortic insuffieciency followed by aortic constriction; $\mathrm{N}+\mathrm{B}$ : unilateral nephrectomy and contralateral renal artery banding. " All CAVB rabbits, which are not sacrificed, die suddenly. " Mass of the dilated ventricles is unchanged, but there is myocyte loss. fibrosis, and reactive myocyte hypertrophy. ${ }^{* *}$ Both increased and unchanged $\triangle A P D$ have been reported.

References: $26-30,32,33,40,42-48,50,52,56,57,60,65,73$

same ventricle, or transmurally has been determined in most of the models. In the CAVB dog spatial dispersion is enhanced, while it is only mildly increased in the aorta banded cat, and unchanged after myocardial infarction in the rat. ${ }^{26.28 .30: 47}$ Both increased and unchanged dispersion of repolarization have been described in the tachypacing dog.

Furthermore, the prolongation of repolarization is associated with an increased propensity for early and delayed afterdepolarizations and triggered activity. pacing sequences and/or the administration of (repolarization prolonging) drugs in all models, and are described as polymorphic ventricular tachycardias in the post myocardial infarction rat-model, the CAVB rabbit and dog, and the tachypacing dog. Ventricular tachycardias frequently deteriorate into ventricular fibrillation in the post myocardial infarction rat-model and the tachypacing dog. In the aorta banded cat only ventricular fibrillation is seen. In both the rat and the cat-model susceptibility to ventricular fibrillation has been related to the presence of cardiac 
fibrosis. In some models, polymorphic ventricular tachycardias are even present under baseline circumstances, and have been directly related to sudden cardiac death in the CAVB dog and the tachypacing dog. ${ }^{27.42 .43 .57}$

While the tachypacing dog-model closely resembles severe heart failure in humans, the CAVB dog seems to represent a phase preceding cardiac decompensation, which makes it a suitable model to study (early) development of ventricular remodeling and arrhythmogenesis.

\section{The chronic complete AV block dog}

Almost one decade ago, our group reported a clinically relevant canine model for drug-induced torsade de pointes, in which arrhythmias could be evoked by repolarization prolonging drugs and short-long-short pacing sequences. ${ }^{58.59}$ In the following papers the underlying electrophysiological and ionic alterations, and hypertrophic changes were described. ${ }^{26}$

Several weeks after creation of AV block the QT-time and the ventricular APD have increased, independent of rate. This increase in APD is most pronounced for the left ventricle, which leads to an increase in interventricular dispersion of repolarization. These electrophysiological alterations have been associated with a decrease of $I_{k r}$ and $I_{K_{s}}$, while $I_{T o}$ and $I_{K 1}$ are unaitered. Recently, the reduction of $I_{K s}$ has been related to a decrease in KVLQT1 and MinK transcription. At the same time, CAVB dogs show biventricular eccentric hypertrophy, which is based on an increased myocyte length and unchanged width. The hypertrophy is not accompanied by changes in collagen fraction or capillary-fiber ratio. Moreover, signs of congestive heart failure are absent. Electrical remodeling and hypertrophy are associated with an increased susceptibility to early and delayed afterdepolarizations, triggered ectopic beats, and ventricular tachycardias. In $60-86 \%$ of the dogs, class IIIantiarrhythmic drugs induce torsade de pointes-arrhythmias (figure 3), which are defined as polymorphic ventricular tachycardias with a cycle length of $\leq 300 \mathrm{~ms}$ and consisting of at least 5 beats characterized by an onset with abnormal QT prolongation and/or abnormal TU complexes, a progressively changing ventricular axis, and spontaneous termination with the exception of rare degeneration into ventricular fibrillation. ${ }^{70}$ Some CAVB dogs even show torsade de pointes without the interference of drugs. Moreover, $10-15 \%$ of the dogs die suddenly, presumably from an arrhythmic origin. 
Figure 3: Induction of a torsade de pointes-arrhythmia by dofetilide in a CAVB dog.

\section{Control}

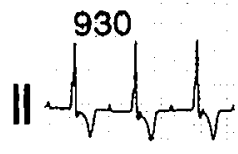

4.10
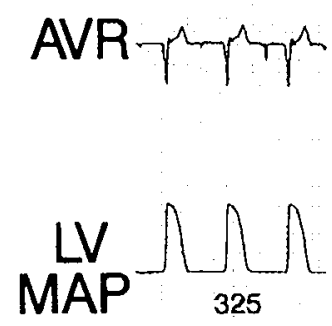

$\triangle 55$

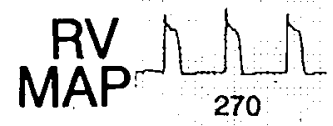

\section{Dofetilide}

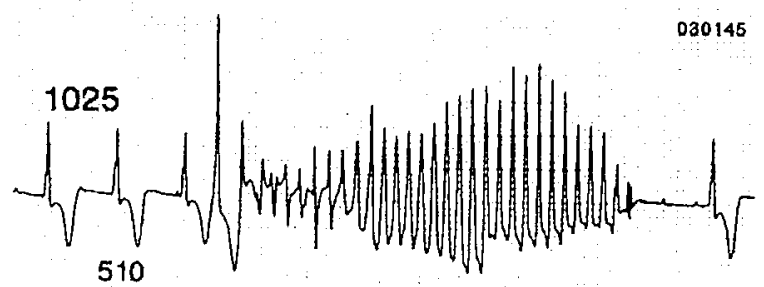

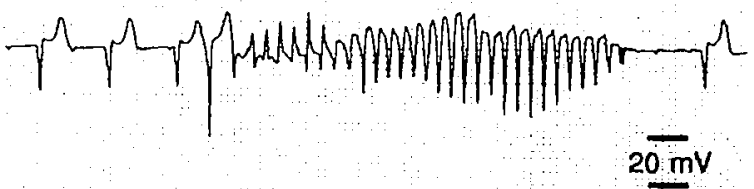

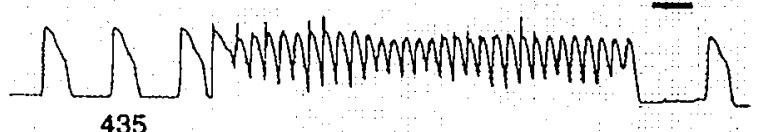

435

$\triangle 95$

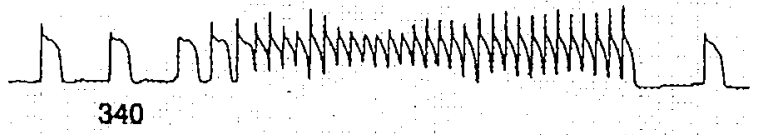

$$
t=4 \mathrm{~min}
$$

Two surface ECG leads, left (LV) and right ventricular (RV) monophasic action potential (MAP) recordings before and 4 minutes after start of dofetilide $\left(0.025 \mathrm{mg} / \mathrm{kg} / 5^{\prime}\right)$ infusion, at a paper speed of $10 \mathrm{~mm} / \mathrm{s}$.

The administration of dofetilide leads to an increase in RR-time, QT-time, and duration of the MAP (MAPD). The prolongation of MAPD is more pronounced for the LV MAPD, which results in an increase in interventricular dispersion of repolarization ( $\triangle M A P D)$. These alterations are associated with the induction of a self-terminating torsade de pointes-arrhythmia.

\section{Aims of the thesis}

The absence of congestive heart failure at chronic, complete AV block in the dog suggests contractile compensation for bradycardia-induced volume overload in the model. ${ }^{20}$ This observation initiated a study concerning the contractile adaptations following creation of AV block (chapter 2). Also, the relevance of contractile alterations for ventricular arrhythmogenesis was investigated (chapter 2 and 4). In the CAVB dog, ventricular hypertrophy, heterogeneous prolongation of repolarization, and susceptibility to torsade de pointes-arrhythmias are present after $\sim 6$ 
weeks AV block. ${ }^{3,463}$ Although the relation between the presence of hypertrophy, electrical remodeling, and arrhythmogeneity seems firm, their temporal behavior has never been studied. Therefore, development of electrical remodeling and hypertrophy up to 5 weeks AV block was investigated in chapter 3 , while the same time phrame for contractile alterations and susceptibility to drug-induced torsade de pointes was studied in chapter 4.

The induction of bradycardia-induced volume overload in the dog has been previously shown to lead to a transient elevation of atrial natriuretic factor in the blood plasma, and activation of the renin-angiotensin system and the adrenergic system, which have all normalized after several weeks of AV block. ${ }^{2 \pi 66}$ At this time, electrical remodeling, biventricular hypertrophy, and susceptibility to dofetilide-induced torsade de pointes are present, which suggests a role of the forementioned systems in the development of ventricular remodeling and arrhythmogenesis. Moreover, both angiotensin II and the adrenoceptors are known to activate transduction pathways leading to hypertrophy. ${ }^{172 ?}$ We hypothesized that by creation of AV block a signal will be transduced through systemic or local factor(s) activating intracellular transduction pathway(s), which leads to altered function and/or expression of specific proteins involved in hypertrophy and electrical remodeling. In chapter 3 , the preventive effects of the angiotensin II type- 1 receptor blocker (irbesartan) on cardiac hypertrophy and electrical remodeling are presented. The results of chronic administration of the non-selective adrenergic blocker carvedilol on development of electrical remodeling, contractile remodeling and susceptibility to (druginduced) torsade de pointes are discussed in chapter 5 . Furthermore, the preventive effects of chronic administration of cyclosporin $A$, a calcineurin inhibitor, on electrical remodeling and arrhythmogenesis are presented. 


\section{References}

1. Koek HL, van Leest LATM, Verschuren WMM. Bots ML. Hart- en vaatziekten in Nederland 2003. cijfers over leefstijl- en risicofactoren. ziekte en sterfte. Den Haag: Nederlandse Hartstichting 2003.

2. de Vreede-Swagemakers JJ, Gorgels AP. Dubois-Arbouw WI, van Ree JW. Daemen MJ, Houben LG. Wellens HJ. Out-of-hospital cardiac arrest in the 1990's: a population-based study in the Maastricht area on incidence, characteristics and survival. J Am Coll Cardiol. 1997;30:1500-5.

3. Gorgels AP, Gijsbers C, de Vreede-Swagemakers JJ, Lousberg A, Wellens HJ. Out-of-hospital cardiac arrest-the relevance of heart failure. The Maastricht Circulatory Arrest Registry. Eur Heart J. 2003:24:1204-1209.

4. Cleland JG, Thygesen K, Uretsky BF, Armstrong P, Horowitz JD, Massie B, Packer M. PooleWilson PA, Ryden L. Cardiovascular critical event pathways for the progression of heart failure; a report from the ATLAS study. Eur Heart J. 2001;22:1601-12.

5. Zipes DP, Wellens HJ. Sudden cardiac death. Circulation. 1998:98:2334-51.

6. Myerburg RJ, Castellanos A. Cardiac arrest and sudden cardiac death. In: Braunwald E, Zipes DP, Libby $P$, ed. Heart disease: a textbook of cardiovascular medicine. New York: WB Saunders Publishing Co. 2001:890.

7. Bayes de Luna A, Coumel P, Leclercq JF. Ambulatory sudden cardiac death: mechanisms of production of fatal arrhythmia on the basis of data from 157 cases. Am Heart J. 1989;117:151-9.

8. Olshausen KV, Witt T, Pop T, Treese N, Bethge KP, Meyer J. Sudden cardiac death while wearing a Holter monitor. Am J Cardiol. 1991;67:381-386.

9. Maron BJ, Shen W, Link MS, Epstein AE, Almquist AK, Daubert JP, Bardy GH, Favale S, Rea RF, Boriani G, Estes III NAM, Spirito P. Efficacy of implantable cardioverter-defibrillators for the prevention of sudden death in patients with hypertrophic cardiomyopathy. $N$ Engl J Med. 2000;342:365-373.

10. Albert CM, Chae CU, Grodstein F, Rose LM, Rexrode KM, Ruskin JN, Stampfer MJ, Manson JE. Prospective study of sudden cardiac death among women in the United States. Circulation. 2003;107:2096-2101.

11. Hinkle JR. LE, Thaler HT. Clinical classification of cardiac deaths. Circulation. 1982;65:457-464.

12. Levy D, Anderson KM. Savage DD, Kannel WB, Christiansen JC, Castelli WP. Echocardiographically detected left ventricular hypertrophy: prevalence and risk factors. The Framingham Heart Study. Ann Intern Med. 1988;108:7-13.

13. Schirmer $H$. Lunde $P$, Rasmussen K. Prevalence of left ventricular hypertrophy in a general population; The Tromso Study. Eur Heart J. 1999;20:429-38.

14. Haider AW, Larson MG, Benjamin EJ, Levy D. Increased left ventricular mass and hypertrophy are associated with increased risk for sudden death. J Am Coll Cardiol. 1998:32:1454-9.

15. Bikkina M. Larson MG. Levy D. Asymptomatic ventricular arrhythmias and mortality risk in subjects with left ventricular hypertrophy. J Am Coll Cardiol. 1993:22:1111-6.

16. Vasan RS. Levy D. The role of hypertension in the pathogenesis of heart failure. A clinical mechanistic overview. Arch Intern Med. 1996:156:1786-1796.

17. Gorgels AP. Vos MA. Smeets JL. Wellens HJ. Ventricular arrhythmias in heart failure. Am J Cardiol. 1992:70:37C-43C. 
18. Kjekshus J. Arrhythmias and mortality in congestive heart failure. Am $J$ Cardiol. $1990 ; 65: 421-481$

19. Effect of metoprolol CR/XL in chronic heart failure: Metoprolol CR/XL Randomised Intervention Trial in Congestive Heart Failure (MERIT-HF). Lancet. 1999;353:2001-7.

20. Gwathmey JK, Copelas L, MacKinnon R. Schoen FJ, Feldman MD, Grossman W, Morgan JP. Abnormal intracellular calcium handling in myocardium from patients with end-stage heart failure. Circ Res. 1987;61:70-76.

21. Beuckelmann DJ, Nabauer M. Erdmann E. Intracellular calcium handling in isolated ventricular myocytes from patients with terminal heart failure. Circulation. 1992;85:1046-1055.

22. Beuckelmann DJ. Nabauer M. Erdmann E. Alterations of $K+$ currents in isolated human ventricular myocytes from patients with terminal heart failure. Circ Res. 1993;73:379-385.

23. Kaab S. Dixon J, Duc J, Ashen D, Nabauer M, Beuckelmann DJ, Steinbeck G, McKinnon D, Tomaselli GF. Molecular basis of transient outward potassium current downregulation in human heart failure: a decrease in Kv4.3 mRNA correlates with a reduction in current density. Circulation. 1998;98:1383-93.

24. Tomaselli GF, Marban E. Electrophysiological remodeling in hypertrophy and heart failure. Cardiovasc Res. 1999;42:270-83.

25. Armoundas AA, Wu R, Juang G. Marban E, Tomaselli GF. Electrical and structural remodeling of the failing ventricle. Pharmacol Ther. 2001;92:213-30.

26. Vos MA, de Groot SH, Verduyn SC, van der Zande J, Leunissen HD, Cleutjens JP, van Bilsen M, Daemen MJ, Schreuder JJ, Allessie MA, Wellens HJ. Enhanced susceptibility for acquired torsade de pointes arrhythmias in the dog with chronic, complete AV block is related to cardiac hypertrophy and electrical remodeling. Circulation. 1998;98:1125-35.

27. Tsuji Y, Opthof T, Yasui K, Inden Y, Takemura H, Niwa N, Lu Z, Lee JK, Honjo H, Kamiya K, Kodama I. lonic mechanisms of acquired QT prolongation and torsades de pointes in rabbits with chronic complete atrioventricular block. Circulation. 2002;106:2012-8.

28. Kowey RC, Friechling TD, Sewter J, Wu U, Sokil A. Paul J, Nocella J. Electrophysiological effects of left ventricular hypertrophy. Effect of calcium and potassium blockade. Circulation. 1991;83:2067-2075.

29. Ben-David J, Zipes DP, Ayers GM, Pride HP. Canine left ventricular hypertrophy predisposes to ventricular tachycardia induction by phase 2 early afterdepolarizations after administration of BAY K 8644. J Am Coll Cardiol. 1992;20:1576-84.

30. Qin D. Zhang ZH, Caref EB, Boutjdir M, Jain P, el-Sherif N. Cellular and ionic basis of arrhythmias in postinfarction remodeled ventricular myocardium. Circ Res. 1996;79:461-73.

31. Weber KT, Pick R, Silver MA, Moe GW, Janicki JS, Zucker IH. Armstrong PW. Fibrillar collagen and remodeling of dilated canine left ventricle. Circulation. 1990;82:1387-401.

32. Kajstura J, Zhang X, Liu Y. Szoke E, Cheng W. Olivetti G. Hintze TH, Anversa P. The cellular basis of pacing-induced dilated cardiomyopathy. Myocyte cell loss and myocyte cellular reactive hypertrophy. Circulation. 1995:92:2306-17.

33. Pfeffer JM, Pfeffer MA. Fletcher PJ, Braunwald E. Progressive ventricular remodeling in rat with myocardial infarction. Am J Physiol. 1991:260:H1406-1414. 
34. Starzl TE, Gaertner RA. Chronic heart block in dogs: a method for producing experimental heart failure. Circulation. 1955:12:259-270.

35. Starzl TE, Gaertner RA, Baker RR. Acute complete heart block in dogs. Circulation. $1955 ; 12: 82-89$.

36. Turina M, Baboti I, Bussmann WD, Krayenbuhl HP. Haemodynamics of acute and chronic atrioventricular block in dogs. Cardiovasc Res. 1969;3:209-17.

37. Wusten B, Flameng W. Schaper W. Cardiac function in the chronically volume-overloaded canine heart. Basic Res Cardiol. 1977;72:172-7.

38. Beazell JW, Adomian GE, Furmanski M, Osborne SL. Complete atrioventricular block in dogs-compensation or decompensation. Am J Pathol. 1984;117:154-7.

39. Belichard P, Savard P, Cardinal R, Nadeau R, Gosselin H, Paradis P, Rouleau JL. Markedly different effects on ventricular remodeling result in a decrease in inducibility of ventricular arrhythmias. J Am Coll Cardiol. 1994;23:505-513.

40. Jones DL, Petrie JP, Li HG. Spontaneous, electrically, and cesium chloride induced arrhythmia and afterdepolarizations in the rapidly paced dog heart. Pacing Clin Electrophysiol. 2001;24:474-85.

41. Komamura K, Shannon RP, Ihara T, Shen YT, Mirsky I, Bishop SP, Vatner SF. Exhaustion of FrankStarling mechanism in conscious dogs with heart failure. Am J Physiol. 1993;265:H1119-31.

42. Pogwizd SM, Qi M, Yuan W, Samarel AM, Bers DM. Upregulation of $\mathrm{Na}(+) / \mathrm{Ca}(2+)$ exchanger expression and function in an arrhythmogenic rabbit model of heart failure. Circ Res. 1999;85:1009-1019.

43. Pak PH, Nuss HB, Tunin RS, Kaab S, Tomaselli GF, Marban E, Kass DA. Repolarization abnormalities, arrhythmia and sudden death in canine tachycardia-induced cardiomyopathy. J Am Coll Cardiol. 1997;30:576-84.

44. Hsieh MH, Chen YJ, Lee SH, Ding YA, Chang MS, Chen SA. Proarrhythmic effects of ibutilide in a canine model of pacing induced cardiomyopathy. Pacing Clin Electrophysiol. 2000;23:149-56.

45. Akar FG, Rosenbaum DS. Transmural electrophysiological heterogeneities underlying arrhythmogenesis in heart failure. Circ Res. 2003;93:638-645.

46. Kaab S, Nuss HB, Chiamvimonvat N, O'Rourke B, Pak PH, Kass DA, Marban E. Tomaselli GF. Ionic mechanism of action potential prolongation in ventricular myocytes from dogs with pacinginduced heart failure. Circ Res. 1996;78:262-73.

47. Volders PG, Sipido KR, Vos MA, Kulcsar A, Verduyn SC, Wellens HJ. Cellular basis of biventricular hypertrophy and arrhythmogenesis in dogs with chronic complete atrioventricular block and acquired torsade de pointes. Circulation. 1998;98:1136-47.

48. Despa S, Islam MA, Weber CR, Pogwizd SM, Bers DM. Intracellular $\mathrm{Na}(+)$ concentration is elevated in heart failure but $\mathrm{Na} / \mathrm{K}$ pump function is unchanged. Circulation. 2002;105:2543-2548.

49. Volders PG, Sipido KR, Vos MA, Spatjens RL, Leunissen JD, Carmeliet E, Wellens HJ. Downregulation of delayed rectifier $\mathrm{K}(+)$ currents in dogs with chronic complete atrioventricular block and acquired torsades de pointes. Circulation. 1999;100:2455-61.

50. Li GR, Lau CP, Ducharme A, Tardif JC, Nattel S. Transmural action potential and ionic current remodeling in ventricles of failing canine hearts. Am J Physiol Heart Circ Physiol. 2002;283:H1031-41. 


\section{Chapter 1}

51. Hobai IA, O'Rourke B. Enhanced $\mathrm{Ca}(2+)$-activated $\mathrm{Na}(+)-\mathrm{Ca}(2+)$ exchange activity in canine pacing-induced heart failure. Circ Res. 2000:87:690-698.

52. Pogwizd SM, Schlothauer K, Li L, Yuan W. Bers DM. Arrhythmogenesis and contractile dysfunction in heart failure: Roles of sodium-calcium exchange, inward rectifier potassium current, and residual beta-adrenergic responsiveness. Circ Res. 2001;88:1159-67.

53. Nuss HB, Kaab S, Kass DA. Tomaselli GF, Marban E. Cellular basis of ventricular arrhythmias and abnormal automaticity in heart failure. Am J Physiol. 1999;277:H80-91.

54. Verduyn SC, Vos MA, Gorgels AP, van der Zande J, Leunissen JD, Wellens HJ. The effect of flunarizine and ryanodine on acquired torsades de pointes arrhythmias in the intact canine heart. J Cardiovasc Electrophysiol. 1995;6:189-200.

55. De Groot SH, Vos MA, Gorgels AP, Leunissen JD, van der Steld BJ, Wellens HJ. Combining monophasic action potential recordings with pacing to demonstrate delayed afterdepolarizations and triggered arrhythmias in the intact heart. Value of diastolic slope. Circulation. 1995;92:2697-704.

56. Li HG, Jones DL, Yee R, Klein GJ. Electrophysiologic substrate associated with pacing-induced heart failure in dogs: potential value of programmed stimulation in predicting sudden death. J Am Coll Cardiol. 1992;19:444-9.

57. Van Opstal JM, Verduyn SC, Leunissen HD, de Groot SH, Wellens HJ, Vos MA. Electrophysiological parameters indicative of sudden cardiac death in the dog with chronic complete AV-block. Cardiovasc Res. 2001;50:354-61.

58. Vos MA, Gorgels AP, Lipcsei GC, De Groot SH, Leunissen JD, Wellens HJ. Mechanism-specific antiarrhythmic effects of the potassium channel activator levcromakalim against repolarizationdependent tachycardias. J Cardiovasc Electrophysiol. 1994;5:731-42.

59. Vos MA, Verduyn SC, Gorgels AP, Lipcsei GC. Wellens HJ. Reproducible induction of early afterdepolarizations and torsade de pointes arrhythmias by $\mathrm{d}$-sotalol and pacing in dogs with chronic atrioventricular block. Circulation. 1995:91:864-72.

60. Verduyn SC. Vos MA, van der Zande J, Kulcsar A, Wellens HJ. Further observations to elucidate the role of interventricular dispersion of repolarization and early afterdepolarizations in the genesis of acquired torsade de pointes arrhythmias: a comparison between almokalant and d-sotalol using the dog as its own control. J Am Coll Cardiol. 1997;30:1575-84.

61. Verduyn SC, Vos MA, van der Zande J, van der Hulst FF, Wellens HJ. Role of interventricular dispersion of repolarization in acquired torsade-de-pointes arrhythmias: reversal by magnesium. Cardiovasc Res. 1997;34:453-63.

62. De Groot SH, Vos MA, Gorgels AP, Leunissen JD, Hermans M, Dohmen LR, Wellens HJ. The dynamic behavior of the diastolic slope of monophasic action potential can be related to the occurrence and maintenance of delayed afterdepolarization dependent arrhythmias. Pacing Clin Electrophysiol. 1999;22:49-59.

63. Vos MA, Gorenek B, Verduyn SC, van der Hulst FF, Leunissen JD, Dohmen L, Wellens HJ. Observations on the onset of Torsade de Pointes arrhythmias in the acquired long QT syndrome. Cardiovasc Res. 2000:48:421-429. 
64. Verduyn SC, van Opstal JM, Leunissen JD, Vos MA. Assessment of the pro-arrhythmic potential of anti-arrhythmic drugs: an experimental approach. J Cardiovasc Pharmacol Ther. 2001:6:89-97.

65. Van Opstal JM, Leunissen JD, Wellens HJ, Vos MA. Azimilide and dofetilide produce similar electrophysiological and proarrhythmic effects in a canine model of Torsade de Pointes arrhythmias. Eur J Pharmacol. 2001:412:67-76.

66. Verduyn SC, Ramakers C. Snoep G, Leunissen JD. Wellens HJ. Vos MA. Time course of structural adaptations in chronic AV block dogs: evidence for differential ventricular remodeling. Am J Physiol Heart Circ Physiol. 2001:280:H2882-90.

67. Vos MA, Van Opstal JM, Leunissen HD, Verduyn SC. Electrophysiologic parameters and predisposing factors in the generation of drug-induced Torsade de Pointes arrhythmias. Pharmacol Ther. 2001:91:1-14.

68. Van Opstal JM, Verduyn SC. Winckels SK, Leerssen HM, Leunissen JD, Wellens HJ, Vos MA. The JT-Area indicates dispersion of repolarization in dogs with atrioventricular block. $J$ Interv Card Electrophysiol. 2002;6:113-120.

69. Ramakers C, Vos MA, Doevendans PA, Schoenmakers M, Wu YS, Scicchitano S, lodice A, Thomas GP. Antzelevitch C. Dumaine R. Coordinated down-regulation of KCNQ1 and KCNE1 expression contributes to reduction of $l(K s)$ in canine hypertrophied hearts. Cardiovasc Res. 2003;57:486-96.

70. Eckardt L, Haverkamp W, Borggrefe M, Breithardt G. Experimental models of torsade de pointes. Cardiovasc Res. 1998;39:178-93.

71. Sugden PH. Clerk A. Cellular mechanisms of cardiac hypertrophy. J Mol Med. 1998;76:725-46.

72. Molkentin JD, Dorn GW. 2nd. Cytoplasmic signaling pathways that regulate cardiac hypertrophy. Annu Rev Physiol. 2001;63:391-426.

73. Rials SJ, Wu Y, Ford N. Pauletto FJ, Abramson SV, Rubin AM, Marinchak RA, Kowey PR. Effect of left ventricular hypertrophy and its regression on ventricular electrophysiology and vulnerability to inducible arrhythmia in the feline heart. Circulation. 1995;91:426-30. 

Chapter 2

\section{Contractile adaptations preserving}

cardiac output predispose the

hypertrophied canine heart to delayed

afterdepolarization-dependent

ventricular arrhythmias

S.H. Marieke de Groot, Marieke Schoenmakers, Mirella M.C. Molenschot, Jet D.M. Leunissen, Hein J.J. Wellens, Marc A. Vos

Department of Cardiology, Cardiovascular Research Institute Maastricht, the Netherlands 


\section{Abstract}

Background: In dogs, chronic complete atrioventricular block (CAVB) results in structural (biventricular hypertrophy) and electrical (delayed repolarization) remodeling, which predisposes the heart to torsade de pointes-arrhythmias. We assessed the contractile alterations in the CAVB dog and tested the hypothesis that these adaptations increase delayed afterdepolarization (DAD)-dependent triggered arrhythmias.

Methods and results: Steady-state and dynamic (fast pacing:1-68 stimuli) left and right ventricular systolic and diastolic parameters were determined by positive and negative inotropic interventions at acute AVB and CAVB. Concomitantly, left and right ventricular endocardial monophasic action potentials were registered. In CAVB, all systolic contractile parameters were markedly increased, resulting in preserved cardiac output. The increase was most pronounced at low heart rates, altering the force-frequency response. At both acute AVB and CAVB, the degree of potentiation of cardiac function with pacing was dependent on the number of stimuli and showed a maximum at 8 to 13 stimuli. With CAVB, this potentiation curve was shifted upward, and it was only then that pacing resulted in DADs (in 8 of 10 dogs) and ectopic beats (EBs, in 6 of 10 dogs). The incidence of EBs in relation to the number of stimuli also had a maximum at 8 to 13 stimuli. Ouabain increased the incidence of DADs and EBs, whereas the negative inotropic interventions prevented them completely.

Conclusions: The alterations responsible for improvement in systolic contractile function in CAVB dogs predispose the hypertrophied heart to DAD-dependent triggered arrhythmias during positive inotropic interventions. 


\section{Introduction}

Delayed afterdepolarization (DAD)-induced triggered arrhythmias (TAs) have been described under conditions of intracellular calcium overload. "Positive inotropic interventions favor their initiation. In anesthetized dogs with chronic complete AV block (CAVB), DAD-dependent ectopic beats (EBs) and ventricular tachycardia (VT) have been observed after the combination of ouabain and pacing. "Also, we have described that CAVB is associated with electrical and structural remodeling, e.g. prolonged repolarization times and biventricular hypertrophy. ". In this study, we tested the hypothesis that contractile alterations increase arrhythmogenic potential in this dog, especially with regard to DAD-dependent TAs. Therefore, using positive and negative inotropic interventions, we related the occurrence of TAs with left and right ventricular (LV and RV) contractile function of the dog in sinus rhythm (SR), directly after AV block (AAVB), and in CAVB under both steadystate and dynamic circumstances. In the accompanying study, ${ }^{\prime}$ the cellular changes underlying these contractile adaptations were assessed.

\section{Methods}

Under aseptic conditions, we performed 50 experiments in 34 anesthetized mongrel dogs of either sex (mean body weight of $28 \pm 5 \mathrm{~kg}$ ). All experiments were performed in accordance with the European directive for the protection of vertebrate animals used for experimental and other scientific purposes. The dogs were tested serially: in SR, at AAVB and at 6 weeks of CAVB in 3 groups : (1) LV and RV steady-state hemodynamic studies were followed by force-frequency (FF) and cardiac output (CO) determinations, (2) LV and RV postextrasystolic potentiation (PESP) and poststimulus potentiation (PSP) assessment, and (3) determination of the relation between the inducibility of EBs to LV PSP with negative and positive interventions. Because of technical difficulties and sudden cardiac death, dogs were added to increase the number at CAVB. For the procedures to induce anesthesia, to create AV block, to place LV electrodes, and for perioperative measures, we refer to our previous publication. "A 6-channel ECG was recorded. Under fluoroscopic guidance, catheters were introduced to register LV and RV monophasic action potentials (MAPs) and pressure curves. " $\mathrm{CO}$ was determined by thermodilution in the pulmonary artery. "All signal were stored at $1 \mathrm{kHz}$.

\section{Pacing protocols, interventions, and data analysis}

At AAVB and CAVB, the FF protocols ( 3 minutes of steady-state) consisted of cycle lengths (CLs) of $300,575 \pm 25$ (equal to SR), 750, 1000, and $1250 \mathrm{~ms}$. The PESP protocol consisted of a basic rhythm of $600 \mathrm{~ms}$, which was interrupted every 20 beats by extrastimuli with decreasing coupling intervals from 550 to $250 \mathrm{~ms}$. The PSP trains were delivered with an interstimulus interval of $300 \mathrm{~ms}$ and 1 to 68 stimuli. Three interventions were performed, after which PSP was repeated: at AAVB 
and CAVB, (1) $20 \mu \mathrm{g} / \mathrm{kg}$ ouabain IV was given $(n=6)$ and (2) fixed rate pacing (FRP) with the SR CL $(520 \pm 40 \mathrm{~ms}, \mathrm{n}=5)$ was performed with constant recovery interval. The third intervention, ryanodine $\left(10 \mu \mathrm{g} / \mathrm{kg} / 10^{\prime}\right)$, was administered only to 4 DADsusceptible CAVB dogs. Pacing was performed from either the LV electrode (FF and PESP) or the RV MAP (PSP). By use of a software program, data were analyzed offline: LV and RV end systolic pressure (ESP), end diastolic pressure (EDP), and $+d P / d t m a x$. From the ECG, CL PP interval, and QT-time were determined. To correlate the functional adaptations with TA, we measured (1) coupling interval of the first beat postpacing, (2) LV and RV action potential duration of the MAP at $100 \%$ repolarization (MAPD), and (3) LV and $\mathrm{RV}+\mathrm{dP} / \mathrm{dt}$ before each pacing train and of beats 1 to 3 postpacing, either spontaneous, ectopic or paced. DADs were defined in the MAP as an afterpotential with a diastolic slope of $\geq 10 \mathrm{mV} / \mathrm{s}$. EBs were defined as ventricular activations with a postpacing interval $<600 \mathrm{~ms}$. VT was defined as $\geq 5$ consecutive EBs. We refer to inducible dogs as those that responded with either EBs or VT.

\section{Heart weight}

We confirmed that the CAVB dogs had (biventricular) hypertrophy: the ratio of heart to body weight was $11.5 \pm 2.1 \mathrm{~g} / \mathrm{kg}$. Slicing the heart in a subset of dogs $(n=6)$ revealed $5.8 \pm 1.2$ and $2.4 \pm 0.3 \mathrm{~g} / \mathrm{kg}$ for the $L V$ and $R V$, respectively.

Table 1. Contractile adaptations at spontaneous rhythm

\begin{tabular}{|c|c|c|c|}
\hline & $S R$ & AAVB & CAVB \\
\hline $\mathrm{CL}, \mathrm{ms}$ & $570 \pm 15$ & $1685 \pm 85^{*}$ & $1580 \pm 120^{*}$ \\
\hline $\mathrm{SV}, \mathrm{mL}$ & $26 \pm 5$ & $44 \pm 4^{*}$ & $55 \pm 7^{\star} \ddot{\circ}$ \\
\hline $\mathrm{CO}, \mathrm{L} / \mathrm{min}$ & $2.7 \pm 0.2$ & $2.0 \pm 0.3^{*}$ & $2.4 \pm 0.5$ \\
\hline LV ESP, mmHg & $98 \pm 4$ & $89 \pm 4$ & $112 \pm 7 \div$ \\
\hline LV EDP, $\mathrm{mmHg}$ & $11 \pm 1$ & $15 \pm 2^{*}$ & $11 \pm 2$ \\
\hline $\mathrm{LV}+\mathrm{dP} / \mathrm{dtmax}, \mathrm{mmHg} / \mathrm{s}$ & $1305 \pm 90$ & $1325 \pm 145$ & $2700 \pm 320 *$ \\
\hline RV ESP, mmHg & $18 \pm 1$ & $22 \pm 2$ & $31 \pm 2 * i$ \\
\hline RV EDP, $\mathrm{mmHg}$ & $3 \pm 1$ & $7 \pm 1$ * & $4 \pm 1$ \\
\hline $\mathrm{RV}+\mathrm{dP} / \mathrm{dtmax}, \mathrm{mmHg} / \mathrm{s}$ & $305 \pm 20$ & $300 \pm 50$ & $620 \pm 45 \cdots$ \\
\hline
\end{tabular}

$S V$ indicates stroke volume. $N=8$. Data are mean $\pm S E M$.

* $p<0.05$ vs SR; $\therefore p<0.05$ vs AAVB. 
Figure 1: FF relation (FFR) and PESP.

LV FFR

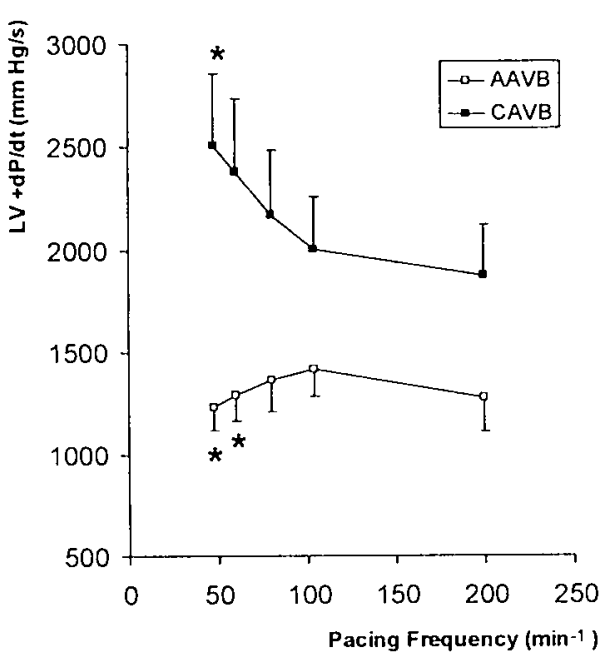

RV FFR

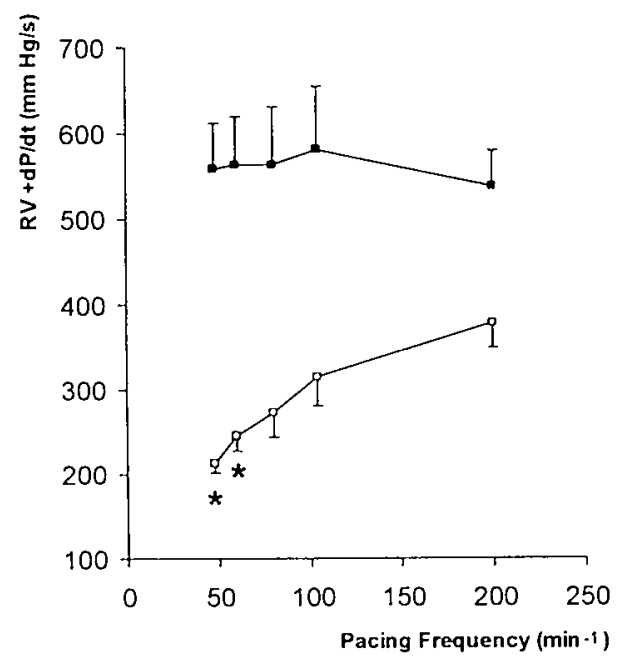

RV PESP

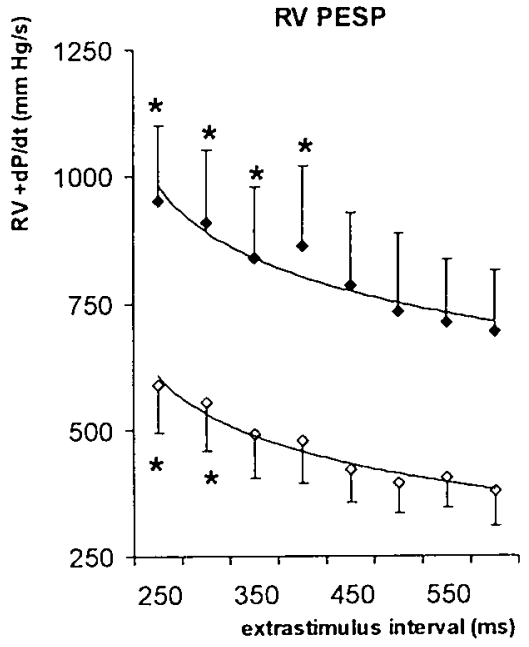

Top, contractile response (+dP/dtmax) of $L V$ (top left) and RV (top right) to increases in heart rate is shown at $A A V B$ and CAVB. Increasing frequency from 48 to $200 \mathrm{bpm}$ ( $x$-axis) leads at AAVB to a positive inotropic response in both ventricles $\left(^{*} p<0.05\right.$ versus 104 beats per min). CAVB values are all significantly higher. Response to pacing, however, is attenuated: LV shows a decrease. wheras RV curve is flat. Bottom, positive inotropic response (PESP) for 2 ventricles when extrastimulus interval is decreased from 550 to $250 \mathrm{~ms}$ ( $x$-axis, " $p<0.05$ versus $600 \mathrm{~ms}$ ) at $A A V B$ and CAVB. Values at CAVB, however, are all significantly higher. 
Chapter 2

\section{Statistics}

Data are presented as mean $\pm S D$, unless otherwise stated. Statistical tests included ( $p \leq 0.05$ ) repeated ANOVA foliowed by Bonferroni's $t$ test, 2 -tailed Student's $t$ test for unpaired events, $\chi^{\prime}$ testing, and logarithmic regression analysis.

\section{Results}

Despite an increase in stroke volume, CO was reduced $(p<0.05)$ when hemodynamics at AAVB were compared with SR (table 1). Both ventricles show an increase in EDP with comparable systolic function (ESP and $+d P / d t m a x$ ). After 6 weeks of CAVB, the LV and RV systolic parameters are significantly increased

\section{Table 2. Electrophysiological and hemodynamic adaptations before and after PSP}

\begin{tabular}{|c|c|c|c|}
\hline & $\mathrm{SR}$ & AAVB & CAVB \\
\hline \multicolumn{4}{|l|}{ Electrophysiology } \\
\hline PP-time & $520 \pm 45$ & $380 \pm 70^{*}$ & $600 \pm 115$ \\
\hline CLIVR & $520 \pm 45$ & $1250 \pm 240^{*}$ & $1290 \pm 150 *$ \\
\hline QT-time & $240 \pm 30$ & $300 \pm 30^{*}$ & $440 \pm 60^{\star}$ \\
\hline LV MAPD & $220 \pm 15$ & $288 \pm 36$ * & $394 \pm 61^{*}$ \\
\hline RV MAPD & $201 \pm 14$ & $256 \pm 22^{*}$ & $316 \pm 38 \cdots$ \\
\hline$\triangle M A P D$ & $18 \pm 6$ & $32 \pm 29$ & $78 \pm 40 \bullet$ \\
\hline $\mathrm{Cl}$ 1st beat postpacing & $585 \pm 75$ & $1200 \pm 280 *$ & $1145 \pm 215^{*}$ \\
\hline \multicolumn{4}{|l|}{ Potentiation } \\
\hline$L V+d P / d t m a x$ pre & $1370 \pm 410$ & $1365 \pm 500$ & $2555 \pm 455^{\star}$ \\
\hline$L V+d P / d t, 1 "$ beat post & $2270 \pm 540$ & $2425 \pm 530$ & $3470 \pm 425 *$ \\
\hline$L V+d P / d t, 2 "$ beat post & $1870 \pm 550 \AA \S$ & $2045 \pm 530 \div \S$ & $3105 \pm 465 * \$ \S$ \\
\hline $\mathrm{LV}+\mathrm{dP} / \mathrm{dt}, 3 "$ beat post & $1675 \pm 545 \AA \S$ & $1825 \pm 520 \div \S$ & $2860 \pm 440 * \S$ \\
\hline$R V+d P / d t m a x$ pre & $360 \pm 100$ & $385 \pm 160$ & $640 \pm 280^{\star}:$ \\
\hline $\mathrm{RV}+\mathrm{dP} / \mathrm{dtmax}, 1$ beat post & $655 \pm 190$ & $690 \pm 195 \%$ & $1090 \pm 325$ \\
\hline $\mathrm{RV}+\mathrm{dP} / \mathrm{dtmax}, 2 "$ beat post & $485 \pm 180 \approx \S$ & $595 \pm 235 \S \S$ & $900 \pm 340 \cdot \mathrm{\S}$ \\
\hline $\mathrm{RV}+\mathrm{dP} / \mathrm{dtmax}, 3^{\prime \prime}$ beat post & $450 \pm 165 \% \S$ & $520 \pm 230 \% \S$ & $790 \pm 305 * \% \S$ \\
\hline
\end{tabular}

IVR indicates idioventrciular rhythm; $\triangle M A P D$, interventricular dispersion of repolarization; $\mathrm{Cl}$, coupling interval. $N=11$. " $p<0.05$ vsSR, $\therefore p<0.05$ vs AAVB, $\therefore p<0.05$ vs $L V$ and $R V+d P / d t$ pre and $\S$ $p<0.05$ vs LV and RV $+d P / d t$ 1" beat. 
Figure 2: Effect of pacing during baseline at AAVB and CAVB in the same dog.

1 ACUTE AV-BLOCK control

100201.3

AVR

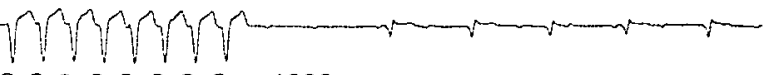

840 S S S S S S S S 1600

MAP
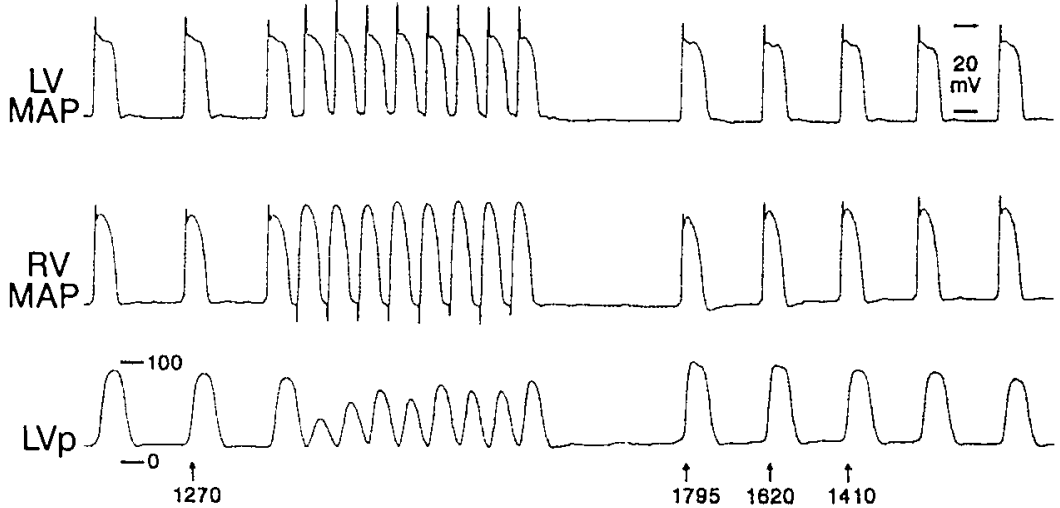

2 CHRONIC COMPLETE AV-BLOCK

control
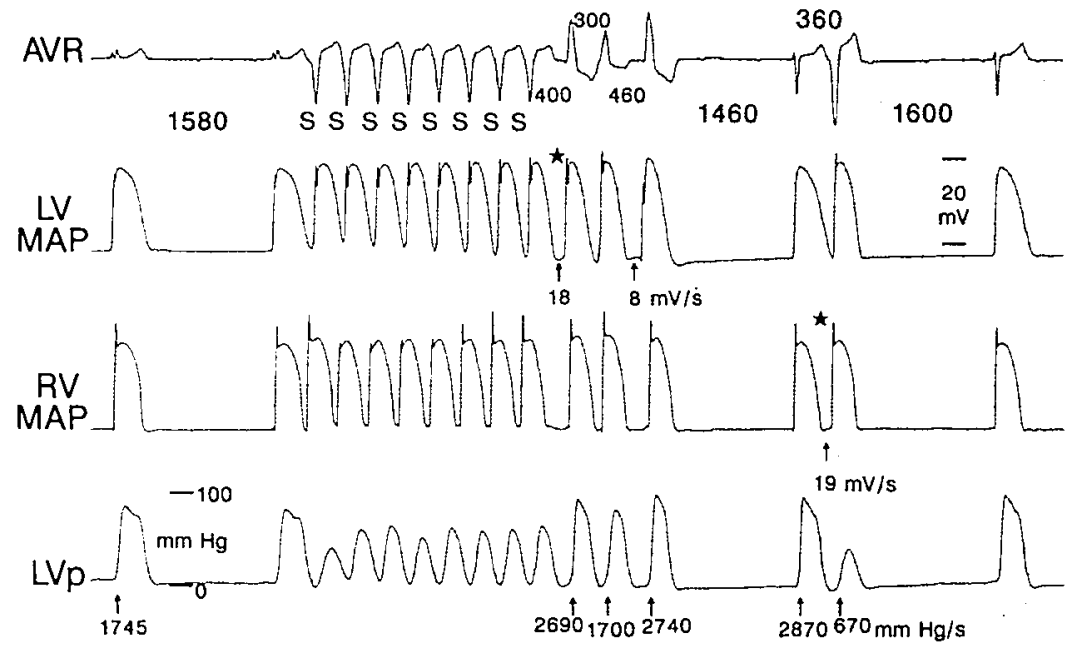

$n(V s)=8 \quad V s-V s=300 m s \quad$ is 1

In each panel, ECG lead aVR, LV and RV MAP, and LV pressure ( $L V p)$ curve are shown at paper speed of $25 \mathrm{~mm} / \mathrm{s}$. Pacing is performed with 8 stimuli (S) with an interstimulus interval (Vs-Vs) of $300 \mathrm{~ms}$. At AAVB (1). pacing clearly increases $+L V$ dP/dt (from 1270 to $1795 \mathrm{~mm} \mathrm{Hg} / \mathrm{s}$ ). but this does not result in DADs or EBs. In the subsequent beats postpacing. the $L V+d P / d t$ declines and returns to prepacing values. At CAVB (2). all inotropic parameters have increased considerably. Pacing now results in induction of 3 EBS, which are related to DADs in LV MAP (asterisk). 
Chapter 2

Figure 3: Effect of number of stimuli ( $n V s)$ on LV and RV PSP.
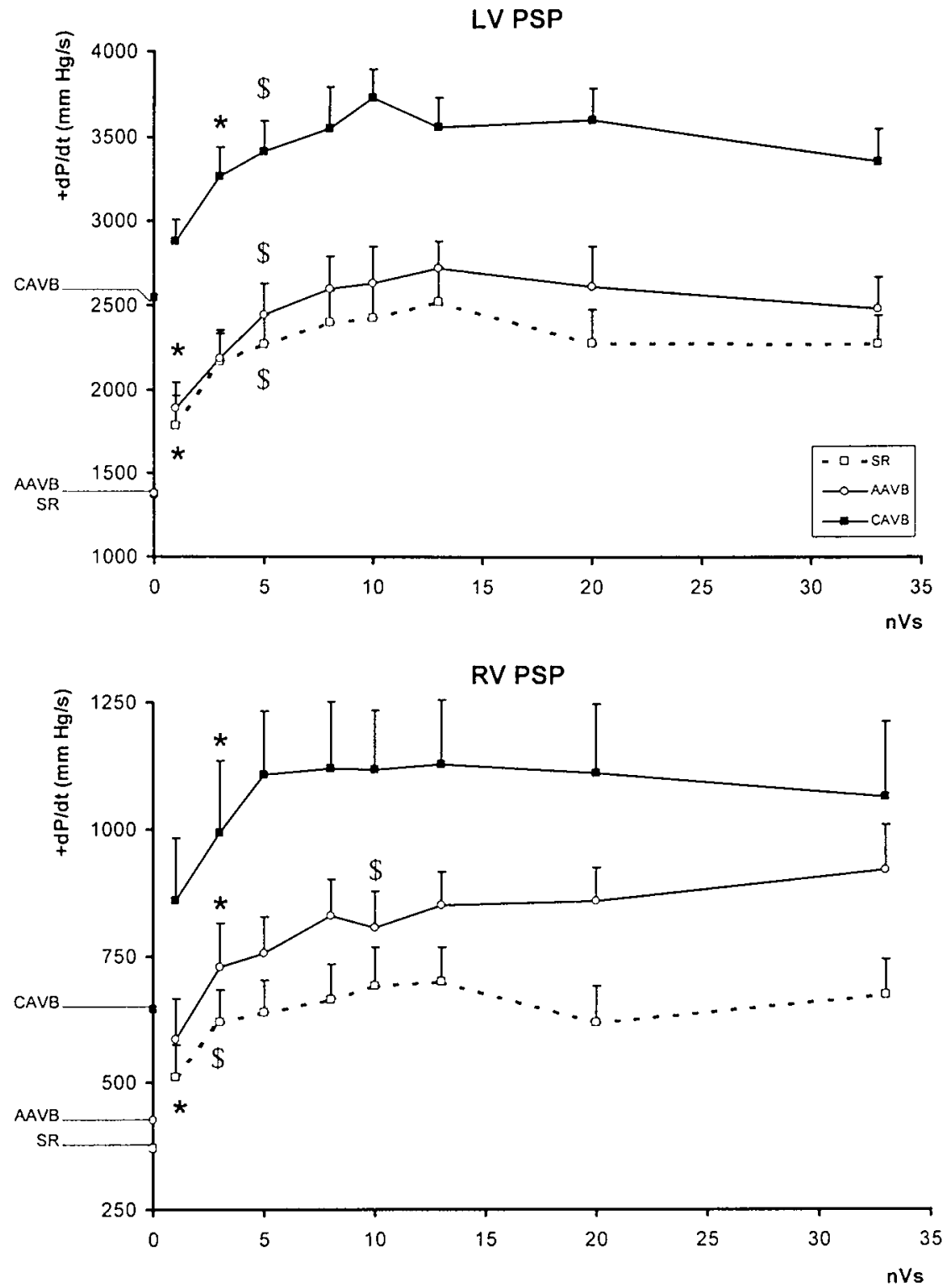

Prepacing inotropic state (+dP/dtmax) is depicted on $y$-axis for SR. AAVB, and CAVB (dotted lines). Pacing induces PSP in LV (top) and RV (bottom). which for all curves reaches significance at the stimulus 1 or $31^{*} p<0.05$ vs prepacing $+d P(d t)$. Absolute values of CAVB curves are significantly higher than $S R$ and $A A V B$. Increasing $n V s$ from 1 to 35 results initially in an increase. with highest values obtained at 8 to 13 stimuli ( $\$ p<0.05$ vs 1 stimulus). 
$(+\mathrm{dP} / \mathrm{dt}:+100 \%)$ resulting in an enhanced stroke volume compared with SR and return of the $\mathrm{CO}$ and EDP values. Steady-state pacing at slow rates showed similar increases for LV and RV $+\mathrm{dP} / \mathrm{dt}$ between AAVB and CAVB (figure 1, top). Increasing the rate resulted in a positive inotropic response at $A A V B$. At CAVB, however, the FF response was attenuated: the LV shows a decrease, whereas the RV curve is flat.

\section{PESP and PSP at baseline}

At AAVB and CAVB, the PESP protocols resulted in an increase in $+d P / d t m a x$ when the extrastimulus interval was decreased. The values obtained were higher at CAVB (figure 1, bottom). At all time points, a fast pacing train resulted in a clear potentiation of cardiac function, which disappeared within 3 to 5 beats (table 2 and figure 2). This PSP was dependent on the number of stimuli: $+\mathrm{dP} / \mathrm{dtmax}$ increased up to a maximum at $\sim 10$ beats (figure 3 ) and declined with a further increase in the stimuli (for details see figure 5). These LV and RV PSP curves were comparable between SR and AAVB but were clearly shifted upward at CAVB.

\section{Triggered ventricular arrhythmias at baseline}

At AAVB, pacing never resulted in the induction of DADs or EBs. In contrast, at CAVB, similar pacing trains induced EBs in 6 of $10(p<0.05)$, and VT in 1 of 10 dogs, which coincided with DADs in the MAPs in 8 of 10 dogs $(p<0.05)$. An example is shown in figure 2. The number of induced EBs also varied depending on the number of stimuli (figures 4 and 5). Most EBs were induced after 5 to 13 stimuli, which corresponded with the highest postpacing $L V+d P / d t$.

\section{Inotropic interventions modulating arrhythmias}

At AAVB, the positive inotropic effect of ouabain or FRP did not result in the induction of DADs or EBs (table 3). At CAVB, in contrast, ouabain increased the induction of arrhythmias (figures 5 and 6), which was accompanied by a sawtooth appearance in the potentiation curve (figure 5, top right). The induction of EBs was broadened when the different numbers of stimuli were compared (bottom right), and the number of EBs were increased (table 3 ), sometimes resulting in $V T$ (figure 6).

At CAVB, the negative inotropic effects of FRP (table 3 ) or ryanodine (data not shown) were accompanied by prevention of all DADs and triggered EBs.

To describe the PSP curve, we determined the postpacing LV $+d P / d t$ of any first postpacing beat, independent of coupling interval or activation sequence. Figure 7 shows PSP of single pacing trains subdivided for AAVB and CAVB and for their response (EB+ and $E B-)$ in relation to the prepacing inotropic values. There was a positive relation $\left(r^{\prime}=0.57\right)$ between potentiation and prepacing $L V+d P / d t$. Importantly, the different arrhythmic responses could not be discriminated on the basis of absolute $L V+d P / d t$ or PSP, suggesting interindividual differences. 
Figure 4: Effect of number of stimuli ( $n V s$ ) on the induction of DAD-dependent EBs.
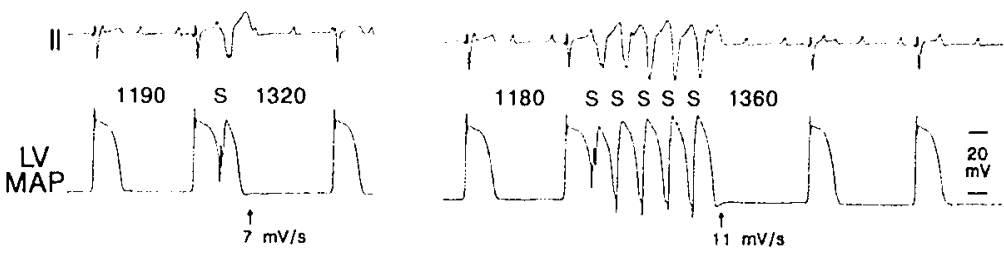

$$
n(V s)=1
$$

$n(V s)=5$

$$
3
$$
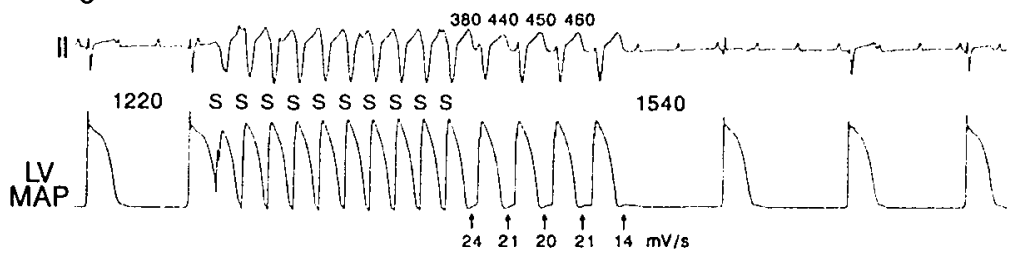

$$
n(V s)=10
$$

4

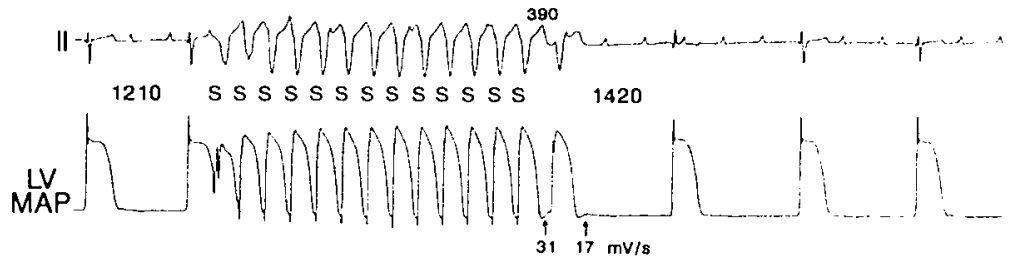

$n(V s)=13$

5
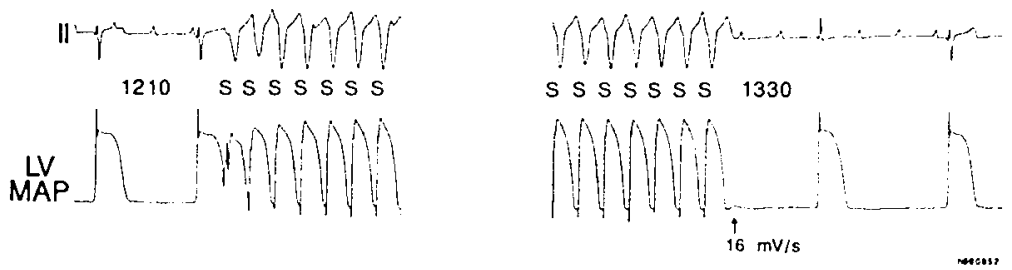

$n(V s)=33$

$\mathrm{Vs}-\mathrm{Vs}=300 \mathrm{~ms}$

I 15 I

In each panel, ECG lead II and LVMAP are shown. Idioventricular rhythm at CAVB is interrupled by pacing with 1 to 33 stimuli (S) with an interstimulus interval (Vs-Vs) of $300 \mathrm{~ms}$. Arrhythmic quantification is based on diastolic slope 3 and appearance of DADs and EBs. (1). Application of 1 stimulus does not lead to an EB and hardly to changes in diastolic slope of DADs ( $7 \mathrm{mV} / \mathrm{s})$. (2). There is an increase in slope after application of 5 stimuli. which remains subthreshold. After 10 stimuli (3). additional increase of slope (>20 $\mathrm{mV} / \mathrm{s})$ is related to occurrence of 4 triggered EBs. A further increase in $n V s$ to 13 (4) and 33 (5) stimuli results in a decreased induction of EBs and in decreased slope of subthreshold DADs. 
Figure 5: Effect of increasing the number of stimuli (nVs) on PSP and inducibility of EBs.

LVPSP
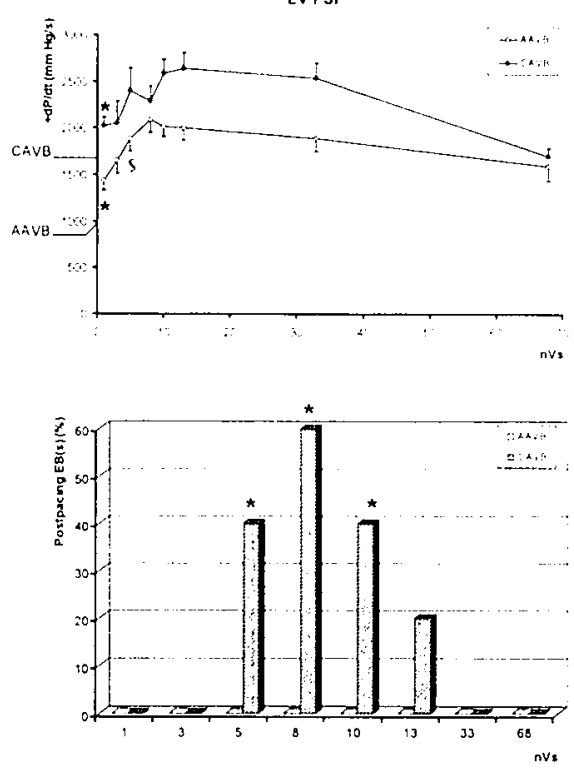

LV PSP
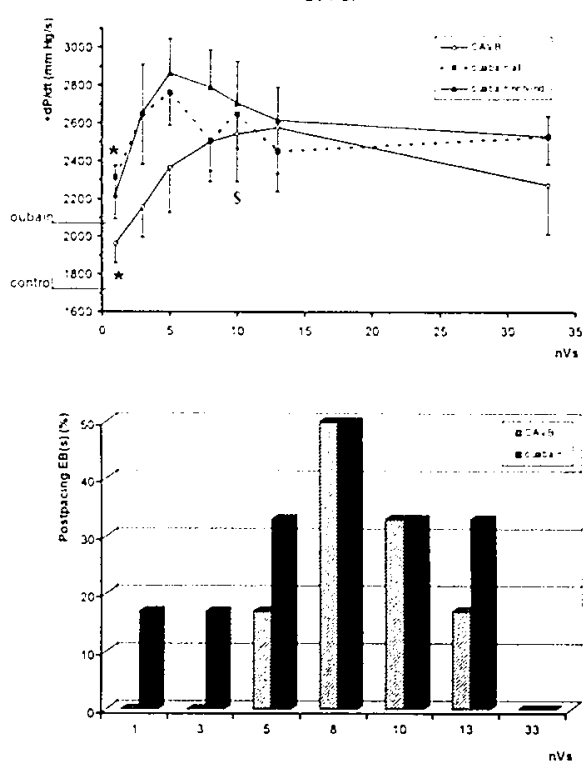

Top left. PSP curves similar to those in figure 3 at AAVB and CAVB are illustrated, but now $n V S$ has been extended to 68. Again. with increasing $n V S$. there is an initial increase in PSP, reaching a maximum after 8 to 13 stimuli, which is followed by a decline. At CAVB, curve is significantly shifted upward. Botom left. no EBS at AAVB induced. whereas there is a considerable induction of EBS at CAVB. Their occurrence shows a distribution similar to that of PSP. Response to ouabain at CAVB (right) has been divided (top right) into a curve (1) describing all stimulation-trains and (2) visualizing only PSP response of trains that were not followed by EBs. Note (1) sawtooth appearance in overall data. (2) fact that curve of nonarrhythmic trains is smooth and shifted upward, and (3) the widening in number of trains that showed EBs postpacing after ouabain (bottom right). 
Table 3: Hemodynamic and arrhythmic effects of ouabain (20 $\mathrm{mg} / \mathrm{kg})$ and fixed rate pacing.

\begin{tabular}{|c|c|c|c|c|c|c|c|c|}
\hline & \multicolumn{4}{|c|}{ AAVB } & \multicolumn{4}{|c|}{ CAVB } \\
\hline & Control & Ouabain & IVR & FRP & Control & Ouabain & IVR & FRP \\
\hline LVESP & $83 \pm 12$ & $88 \pm 13^{\circ}$ & $95 \pm 12$ & $98 \pm 14$ & $102 \pm 10$ & $108 \pm 10^{\circ}$ & $98 \pm 14$ & $99 \pm 17$ \\
\hline $\mathrm{LV}+\mathrm{dP} / \mathrm{dt}$ pre & $825 \pm 230$ & $1005 \pm 345^{\circ}$ & $915 \pm 220$ & $1095 \pm 385$ & $1685 \pm 285$ & $2075 \pm 535^{\circ}$ & $1680 \pm 430$ & $1345 \pm 325^{\circ}$ \\
\hline $\begin{array}{l}P P L V+d P / d t \\
\text { 1st beat }\end{array}$ & $1675 \pm 250$ & $1795 \pm 310^{\circ}$ & $1715 \pm 345$ & $1900 \pm 515 \%$ & $2340 \pm 225 \%$ & $2555 \pm 145 \%$ & $2370 \pm 500$ & $2170 \pm 500$ \\
\hline Arrhythmias & & & & & & & & \\
\hline Inducible dogs & $0 / 6$ & $0 / 6$ & $0 / 5$ & $0 / 5$ & $3 / 6$ & $4 / 6$ & $4 / 5$ & $0 / 5$ \\
\hline DAD & $0 / 6$ & $0 / 6$ & $0 / 5$ & $0 / 5$ & $4 / 6$ & $5 / 6$ & $4 / 5$ & $0 / 5$ \\
\hline VT & $0 / 6$ & $0 / 6$ & $0 / 5$ & $0 / 5$ & $0 / 6$ & $1 / 6$ & $0 / 5$ & $0 / 5$ \\
\hline No. EBs & 0 & 0 & 0 & 0 & $3 \pm 1$ & $9 \pm 10$ & $3 \pm 1$ & 0 \\
\hline
\end{tabular}

* $p<0.05$ vs control or IVR, $\div p<0.05$ vs $L V+d P / d t$ pre.

\section{Discussion}

At 6 weeks of CAVB, steady-state LV and RV systolic contractile function is increased to such an extent that $\mathrm{CO}$ can be maintained. This successful adaptation remains present under positive inotropic interventions but is then accompanied by the occurrence of DADs and DAD-dependent TAs.

\section{The CAVB dog: biventricular compensated contractile function}

Cardiac hypertrophy is an adaptation to mechanical overload of any cause. Whether this adaptation is able to maintain its contractile performance in time or whether there will be degeneration to congestive heart failure is still not clear. To quantify heart failure, numerous parameters have been developed at the integrative, (multi)cellular and molecular level. In the nonfailing myocardium, FF and PESP are well known phenomena, which are decreased in early stages of heart failure. ${ }^{10.1 \%}$ In the CAVB dog, both ventricles perform adequately under baseline as well as more demanding conditions (figures 1 and 3 ). The FF response in the CAVB dog is altered however (figure 1): increasing the rate is no longer associated with an

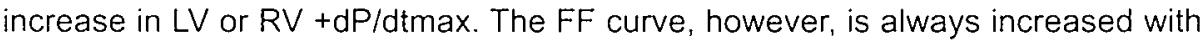
regard to AAVB and never reaches the data obtained in canine heart failure. ${ }^{1215: 6}$ 
Figure 6: Effect of ouabain on inducibility of EBs at CAVB in a dog.

\section{CHRONIC COMPLETE AV-BLOCK}

control
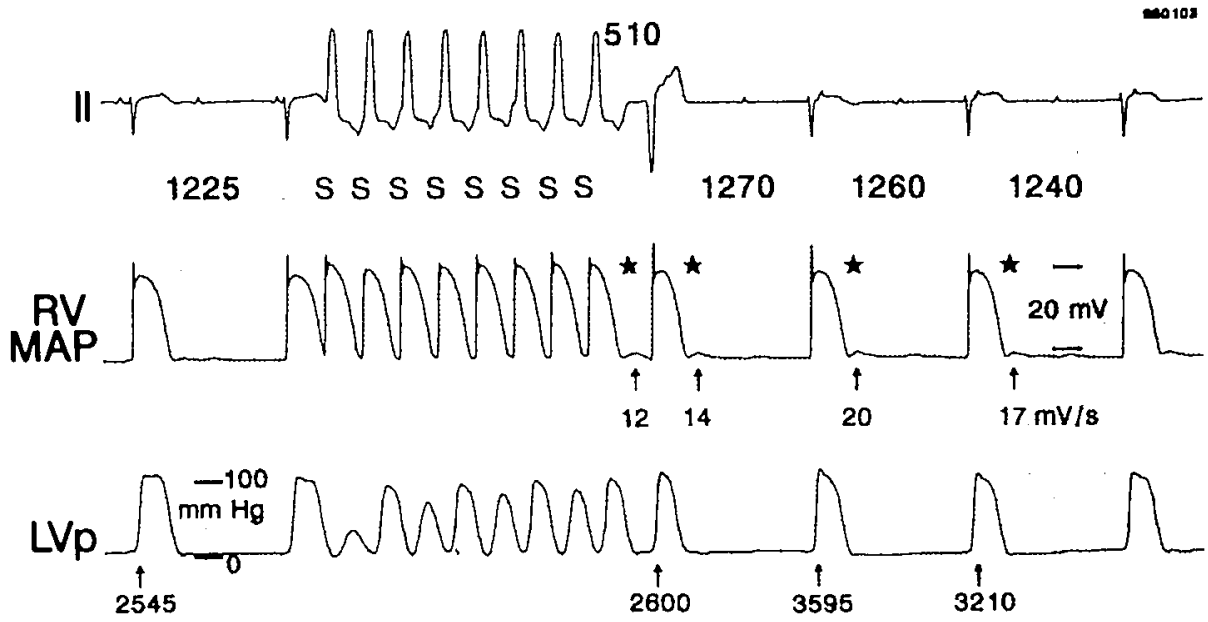

2

ouabain
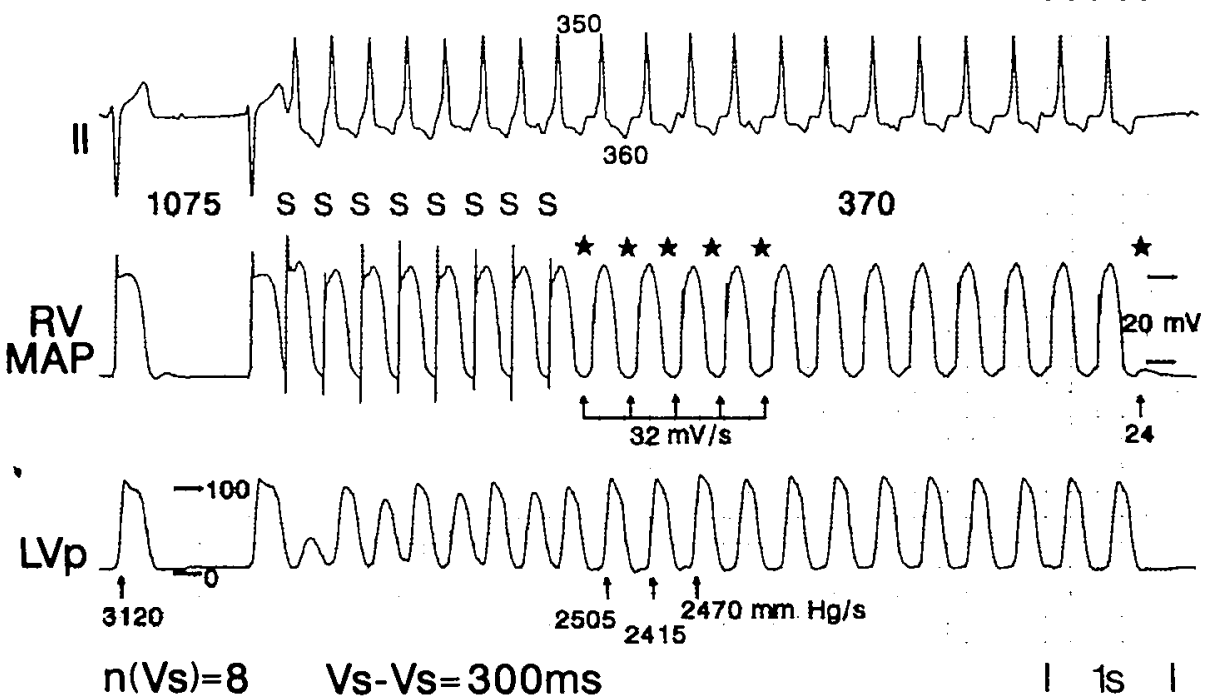

Configuration similar to figures 2 and 4. (1). Pacing with 8 stimuli (S) results in an increase in $D A D$ slope (arrow) and $1 D A D$-related triggered beat (asterisk) under baseline. (2), After ouabain prepacing. +LV dPldt is higher, and pacing now results in occurrence of VT (12 beats). In MAP, $D A D$ s are visible during $V T$ and directly after tachycardia terminates. 
Chapter 2

Figure 7: Relationship between inotropic parameters and EBs.
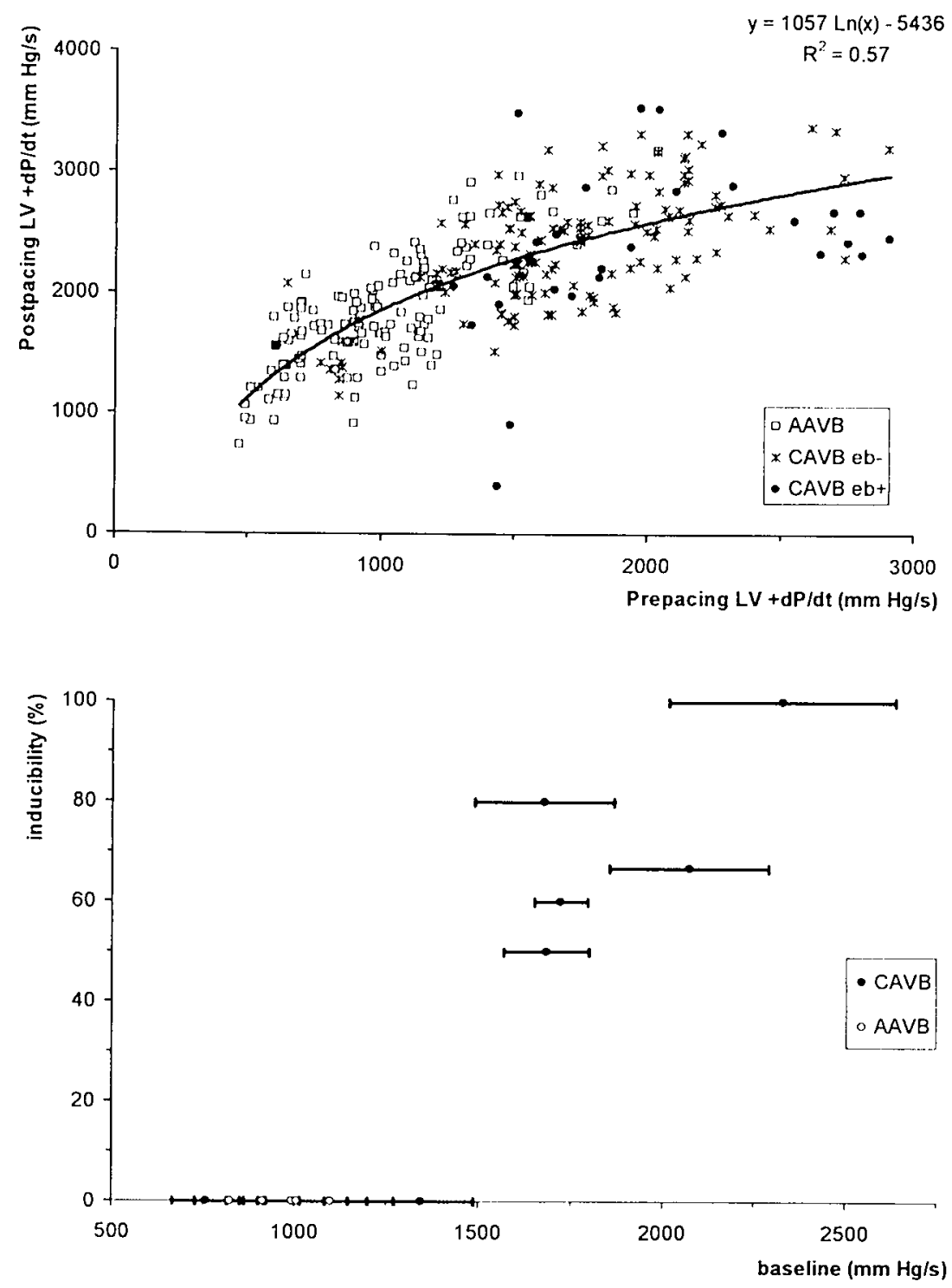

Top, all pacing trains performed as part of this study during AAVB and CAVB with or without inotropic interventions are depicted. PSP achieved is positively related to prepacing inotropic $d P / d t m a x$ and best described logarithmically $(r=0.57, p<0.05)$. It is not possible, however. to discriminate between trains that result $(e b+)$ and those that do not result (eb-) in EBs at CAVB. Bottom. relative group incidence of EBs was related to prepacing $L V d P / d t$. It is clear that a threshold in dPldt has to be reached before EBs occur. 
Interpretation of this finding is complex, but rate-dependent measurements of cell shortening and calcium transients in isolated myocytes confirm that this is an intrinsic property of the cells. 'The possible role of an increased $\mathrm{Na} \cdot \mathrm{Ca}^{\prime \prime}$-exchange current for improved contractile performance at slow rates is discussed in the accompanying article.

PESP is also maintained during CAVB (figure 1). PSP was seen during SR, AAVB, and CAVB (figure 3 ) and its magnitude was dependent on the number of stimuli (figures 3 and 5) and on the prepacing inotropic state (figure 7). The highest PSP values were obtained at CAVB after short pacing trains consisting of 5 to 13 stimuli. To the best of our knowledge, we are the first to describe PSP in vivo. Because this curve remained present under all conditions tested, including FRP, we can exlude alterations in ventricular filling secondary to variations in the interval as the underlying mechanism. It appears that this PSP curve is intrinsic to the myocardium. All these findings are indicative of compensated contractile function in the CAVB dogs at 6 weeks.

\section{Triggered arrhythmias and potentiation of contractile function}

Electrical remodeling in the CAVB dog ${ }^{5 \prime \prime}$ consists of an increase in repolarization times that exceed the expected lengthening on the basis of rate and that is not uniform, leading to an increase in interventricular dispersion (table 2). This dissimilar MAPD lengthening is caused by specific alterations in ionic channel function. ${ }^{7}$ Potential stimuli may include bradycardia, hypertrophy, and/or the alterations in calcium homeostasis. Synergistic effects could explain why our MAPD increase exceeds those reported so far in canine left ventricular hypertrophy. ${ }^{1}$

The PESP protocols never proved to be arrhythmic. Shortlasting, fast pacing trains, however, resulted in EBs in the majority of CAVB dogs but not in those with AAVB (tables 2 and 3 ). The occurrence of EBs coincided with DAD registration on the MAP (figures 2, 4, and 6), thereby indicating triggered activity as the underiying mechanism. Curves of potentiation and of incidence of EBs were similar, suggesting a common origin. The dynamic changes in calcium handling may temporarily create an arrhythmogenic window of calcium overload in the CAVB dog, during which the DADs and EBs occur. This hypothesis was studied further by use of different interventions that modulate the inotropic state. At AAVB, 2 positive inotropic interventions (ouabain and FRP) did not lead to induction of any arrhythmia. The highest PSP obtained, however, was far less than the baseline CAVB value (table 3 ). The same therapeutic dosage of ouabain in CAVB increased the number of pacing trains that responded with EBs, and VT even occurred (figures 5 and 6 ). The negative inotropic interventions at CAVB (FRP and ryanodine) caused prevention of the induction of all DADs and EBs. The block of the sarcoplasmic reticulum calcium release channel by ryanodine has been described to abolish DAD-related EBs. "Thus, the CAVB heart is more susceptible to DAD-dependent arrhythmias 
under circumstances that demand higher contractile performance, in which the increased $\mathrm{Na}{ }^{*} \mathrm{Ca}^{2}$-exchange current can be of great importance. 'It is unclear whether this arrhythmogenic potential is related to the remodeling processes or whether it is purely due to the (maximal attained) inotropism. In the latter, individual parameters such as the basal inotropic state, maximal amount of potentiation, contractile reserve, and threshold at which the sarcoplasmic reticulum spontaneously releases calcium have to be included. Whereas the prepacing inotropic state has a relation with maximal PSP and the occurrence of EBs, single train analysis (figure 7) did not allow prediction of the occurrence of EBs, suggesting that the inotropic state is not the single determinant.

In vitro, an increased propensity of hypertrophied myocardium to DAD-dependent TAs has been described. ${ }^{20.21}$ In these studies, stimulation alone resulted rather infrequently in DADs whereas combining pacing with adrenergic stimulation frequently induced TAs. Because we studied intact animals, local activity of the autonomic nervous system might be related to the observed occurrence of DADs and related EBs.

\section{Clinical implications}

Extrapolation from animal data to humans must be done with great caution. Both hypertrophy ${ }^{22}$ and heart failure ${ }^{23}$ are known to predispose the human heart to ventricular arrhythmias and sudden cardiac death. The exact mechanisms involved are not elucidated, although prolongation of the APD has been described consistently and changes in calcium handling have been implicated, ${ }^{23}$ suggesting TA as a contributing mechanism. Whether DADs occur with maximal inotropism (hypertrophy) or when the function is severely depressed (heart failure) can only be answered when combined, detailed information about the contractile performance and the arrhythmias is available and possible confounding factors, like ischemia, are excluded. This is most easily obtained in animal models. However, arrhythmogenic information has been limited to only a few studies, performed predominantly in heart failure. ${ }^{16.18 .2 \div 25}$

\section{Limitations}

Because we measured at only 2 time points, we cannot exclude a time-specific arrhythmogenic response. Moreover, AAVB and CAVB resemble 2 different neurohumoral situations that can influence the results. In AAVB, compensation mechanisms have been activated, whereas at 6 weeks CAVB, all plasma neurohumoral parameters have returned to baseline. ${ }^{5}$ Second, we do not know to what extent the observed phenomena actually relate to the different remodeling processes. Other factors can aiso play a role in the alterations in contractile function, including the sensitivity of the cardiac contractile proteins and the interstitial tissue of the myocardium. Third, we have concentrated on the initiation of the arrhythmia by DADs, thereby excluding other mechanisms. 
In conclusion, the alterations accompanying the improvement in contractile function in the CAVB dog predispose the heart to DAD-dependent TA.

\section{Acknowledgements}

This study was supported by grants from the Netherlands Organization for Scientific Research (902-16-24) and the Netherlands Heart Foundation (98.042). 


\section{References}

1. Berlin JR, Cannell MB. Lederer WJ. Cellutar origins of the transient inward current in cardiac myocytes: role of fluctuations and waves of elevated intracellular calcium. Circ Res. $1989 ; 65: 115-26$

2. De Ferrari GM, Viola MC. D'Amato $E$, Antolini R, Forti S. Distinct patterns of calcium transients during early and delayed afterdepolarizations induced by iso-proterenol in ventricular myocytes. Circulation. 1995;91:2510-2515.

3. De Groot SHM, Vos MA, Gorgels APM, Leunissen JDM, Van der Steld BJ, Wellens HJJ. Combining monophasic action potential recordings with pacing to demonstrate delayed afterdepolarizations and triggered arrhythmias in the intact heart. Circulation 1995:92:2697-2704.

4. Vos MA. Gorgels APM, Leunissen HDM, van Deursen RTAM. Wellens HJJ. Significance of the number of stimuli to induce triggered arrhythmias in the intact heart. Circ Res. 1991;68:38-44.

5. Vos MA, de Groot SHM, Verduyn SC, van der Zande J, Leunissen HDM, Cleutjens J, van Bilsen M, Daemen M, Schreuder J, Allessie MA, Wellens HJJ. Enhanced susceptibility for acquired torsade de pointes arrhythmias in the dog with chronic, complete AV-block is related to cardiac hypertrophy and electrical remodeling. Circulation. 1998;98:1125-1135.

6. Volders PGA, Sipido KR, Vos MA, Kulscar A, Verduyn SC, Wellens HJJ. Cellular basis of biventricular hypertrophy and arrhythmogenesis in dogs with chronic, complete AV-block and acquired torsade de pointes. Circulation. 1998:98:1136-1147.

7. Sipido KR. Volders PGA, de Groot SHM, Verdonck F, van der Werf F. Wellens HJJ, Vos MA Enhanced $\mathrm{Ca} 2+$ release and $\mathrm{Na} / \mathrm{Ca}$ exchange activity in hypertro-phied canine ventricular myocytes. Circulation. 2000;102:2137-2144

8. Aubert AE. In vivo comparison between two tip pressure transducer systems. Int $J$ Clin Monit Comput. 1995;12:77-83

9. Conway J, Lund-Johansen P. Thermodilution method for measuring cardiac output. Eur Heart J. 1990;11:117-120.

10. Liu CP, Ting CT, Lawrence W, Maughan L, Chang M, Kass DA. Diminished contractile response to increased heart rate in intact human left ventricular hyper-trophy. Circulation. 1993;88:1893-1906

11. Hasenfuss G. Holubarsch C. Hermann HP. Astheimer K. Pieske B, Just H. Influence of the force frequency relationship on haemodynamics and left ventricular function in patients with non-failing hearts and in patients with dilated cardiomy-opathy. Eur Heart J. 1994:15:164-170.

12. Vatner DE, Sato N, Kiuchi K, Shannon RP, Vatner SF. Decrease in myocardial ryanodine receptors and altered excitation-contraction coupling early in the devel-opment of heart failure. Circulation. 1994;90:1423-1430.

13. Burkhoff D. Yue DT. Franz MR. Hunter WC. Sunagawa K. Maughan WL, Sagawa K. Quantitative comparison of the force-interval relationships of the ca-nines right and left ventricles. Circ Res. 1984:54:468-473.

14. ter Keurs HEDJ, Schouten VJA, Bucx JJ, Mulder BM, de Tombe PP. Excitation-contraction coupling in myocardium: implications of calcium release and $\mathrm{Na}+\mathrm{Ca} 2+$ exchange. Can J Physiol. 1987:65:619-626. 
15. Hittinger $L$, Patrick $T$, Ihara $T$, Hasebe N, Shen $Y T$, Kalthof $B$, Shannon RP. Exercise induces cardiac dysfunction in both moderate, compensated and severe hypertrophy. Circulation. 1994:89:2219-2231.

16. Sabbah HN, Goldberg AD, Schoels W. Kono T, Webb C. Brachmann J, Goldstein S. Spontaneous and inducible ventricular arrhythmias in a canine model of chronic heart failure: relation to hemodynamics and sympathoadrenergic activa-tion. Eur Heart J. 1992;13:15621572.

17. Volders PGA, Sipido KR, Vos MA, Spätjens RL, Leunissen HDM, Carmeliet E, Wellens HJJ. Downregulation of delayed rectifier $\mathrm{K}+$ current in dogs with chronic complete atrioventricular block and acquired torsade de pointes. Circulation. 1999:100:2455-2461.

18. Ben-David J, Zipes DP. Ayers GM, Pride HP. Canine left ventricular hypertro-phy predisposes to ventricular tachycardia induction by phase 2 early afterdepo-larizations after administration of BAY K 8644. J Am Coll Cardiol. 1992;20:1576-1584.

19. Hadju S, Leonard E. Action of ryanodine on mammalian cardiac muscle: effects on contractility, and reversal of digitalis induced ventricular arrhythmias. Circ Res. 1961;9:1291-1298.

20. Aronson RS. Ming Z. Cellular mechanisms of arrhythmias in the hypertrophied and failing myocardium. Circulation. 1993; 87 (suppl VII): VII76-VII83.

21. Charpentier F. Baudet S, Le Marec $H$. Triggered activity as a possible mecha-nism for arrhythmias in ventricular hypertrophy. Pacing Clin Electrophysiol. 1991:14:1735-1741.

22. Levy D. Echocardiograpically detected left ventricular hypertrophy: prevalence and risk factors. Ann Intern Med. 1988:108:7-13.

23. Tomaselli GF, Marban E. Electrophysiological remodeling in hypertrophy and heart failure. Cardiovasc Res. 1999:42:270-283.

24. Pak PH, Nuss HB, Tunin RS, Kaab S, Tomaselli GF, Marban E, Kass DA. Repolarization abnormalities, arrhythmia and sudden cardiac death in canine tachy-cardia-induced cardiomyopathy. J Am Coll Cardiol. 1997;30:576-584.

25. Pogwizd SM. Non-reentrant mechanisms underlying spontaneous ventricular arrhythmias in a model of nonischemic heart failure in rabbits. Circulation. 1995:92:1034-1048. 



\section{Chapter 3}

\section{Asynchronous development of electrical remodeling and cardiac hypertrophy in the complete AV block dog}

Marieke Schoenmakers, Christian Ramakers, Jurren M. van Opstal, Jet D.M. Leunissen, Camila Londoño, Marc A. Vos

Department of Cardiology, Cardiovascular Research Institute Maastricht, the Netherlands

Published in: Cardiovascular Research 2003;59:351-359

Robles de Medina ECG award 2002 


\begin{abstract}
Objective: Left ventricular hypertrophy has been associated with the prolongation of QT-time, and an increased risk of ventricular arrhythmias. The renin angiotensin system has been implicated in the development of ventricular hypertrophy. At 5 weeks complete AV block (CAVB) in the dog, there is: 1) biventricular hypertrophy associated with a transient activation of components of the renin angiotensin system, and 2) increased APD, more pronounced in the left than in the right ventricle leading to spatial dispersion of repolarization, and 3) enhanced susceptibility to drug-induced torsade de pointes-arrhythmias. To investigate whether these remodeling processes develop in parallel, time dependency was assessed in absence or presence of the AT1 receptorblocker Irbesartan.
\end{abstract}

Methods and Results: Dogs in sinus rhythm, 2 and 5 weeks CAVB were compared to dogs chronically treated with irbesartan (30 mg/kg BID). Endocardial monophasic APD of left and right ventricle was measured and susceptibility to torsade de pointes was tested by infusing dofetilide $\left(0.025 \mathrm{mg} / \mathrm{kg} / 5^{\prime}\right)$. Hypertrophy was determined by relating heart-tobody weight at sacrifice. Left ventricular APD had increased more than right ventricular APD at 2 and 5 weeks CAVB, leading to an increase in spatial dispersion. At that time torsade de pointes were evocable in the majority of the dogs. Hypertrophy had only developed completely at 5 weeks CAVB. Irbesartan had no effect on electrical and structural parameters or on arrhythmogenicity.

Conclusions: In the CAVB dog ventricular hypertrophy is not a prerequisite for electrical remodeling or drug-induced torsade de pointes, and the AT1-receptor has no dominant role in the completion of these remodeling processes. 


\section{Introduction}

Left ventricular hypertrophy is a common finding in the adult population and associated with an increased QT-time and enhanced risk of ventricular arrhythmias and sudden cardiac death. ${ }^{1.2}$ In numerous animal models the relation between ventricular hypertrophy and the occurrence of electrophysiological changes, like the prolongation of ventricular repolarization, has been confirmed. "In the chronic complete $A V$ block (CAVB) dog, electrical remodeling is further characterized by an increase in spatial dispersion and a higher propensity to (drug induced) early afterdepolarizations, ectopic beats and torsade de pointes-arrhythmias (TdP).

Although the association between the presence of ventricular hypertrophy and the related electrical remodeling and arrhythmogenicity seems firm, the synchronicity in their course of development has never been studied. Therefore we determined the temporal behavior of these processes after creation of AV block.

Secondly, we attempted to dissociate these remodeling processes pharmacologically using irbesartan (I), an angiotensin II type-1 receptor (AT1)-blocker. This approach was selected since in the CAVB dog-model: the renin angiotensin system (RAS) is transiently activated ", and AT1 mRNA expression levels relate to the degree of ventricular hypertrophy".

\section{Methods}

\section{General}

Thirty mongrel dogs (body weight $21-33 \mathrm{~kg}, 15$ females) underwent experimental testing. Irbesartan (Sanofi-Synthélabo, Montpellier, France) was administered orally at a dose of $30 \mathrm{mg} / \mathrm{kg} \mathrm{BID}^{7}$ to 10 dogs, starting one week prior to AV block creation. Serial measurements were performed under premedication (ECG) or during complete anesthesia. Surface ECGs were recorded during regular sinus rhythm (SR) before and during irbesartan, and repetitively after creation of AV block until 2 weeks AV block. Invasive measurements were performed at different time points: SR, acute AV block (AAVB), CAVB2, and/or CAVB5. In which 2 and 5 indicates 2 or 5 weeks CAVB respectively. At the moment of sacrifice, dogs belonged to the following groups: SR $(n=5)$, CAVB2 $(n=8)$, CAVB5 $(n=7)$, CAVB2I $(n=5)$, and CAVB5I $(n=5)$. Since dogs were tested serially the numbers depicted in the tables often exceed the group size. Animal handing was in accordance with the Guide for the Care and Use of Laboratory Animals published by the US National Institutes of Health (NIH Publication No. 85-23, revised 1996). The 'Committee for Experiments on Animals (DEC)' of Maastricht University, the Netherlands approved the experiments.

\section{Experimental design of the studies}

After overnight fasting premedication consisted of acepromazine $(0.6 \mathrm{mg} / \mathrm{kg} / \mathrm{M})$ and buprenorfine $(0.009 \mathrm{mg} / \mathrm{kg}(\mathrm{M})$. The anesthesia, ventilation, preoperative, and postoperative care have been described in previous articles. ${ }^{*}$ in 25 dogs comple- 
te AV block was induced by radiofrequency ablation. A 7 French steerable catheter with a $4 \mathrm{~mm}$ tip (RF Marinr":", Medtronic CardioRhythm, San Jose, CA, USA) was positioned across the tricuspid valve to record a large low atrial and a small His bundle potential, guided by fluoroscopic views from the right and left anterior oblique angles. The temperature controlled radiofrequency energy, with a power limit of 35-50 $\mathrm{W}$ and a target temperature of $70^{\circ} \mathrm{C}$ was delivered from a $500 \mathrm{~Hz}$ generator (Atakr ${ }^{\text {i: }}$, Medtronic CardioRhythm, San Jose, CA, USA) for $2 \mathrm{~min}$, between the large tip thermocouple electrode of the ablation catheter and an adhesive pad applied on the back of the dog. For electrophysiological parameters (EP), the regular 6-lead surface ECG was accompanied by 2 monophasic action potentials (MAPs, EP Technologies Inc) placed at the endocardium of the left and right ventricle (LV and RV respectively). The EP measurements at AAVB and CAVB were performed at two basic rates: 1) the idioventricular rate (IVR), and 2) a fixed pacing rate (FRP) with an interstimulus interval of 500 ms. During FRP, which was performed for $2 \mathrm{~min}$ from the RV MAP, the ventricular effective refractory period (VERP) was determined incrementally (steps of $5 \mathrm{~ms}$ ) at twice diastolic threshold. For hemodynamics, pressure (P) signals were recorded with a Sentron catheter (Sentron Europe Inc), which was positioned in the abdominal aorta for a short period (only during SR) and advanced to the LV cavity where it remained thereafter. All hemodynamic data were gathered during IVR. In the CAVB5 group, no hemodynamic data were collected since an extensive data set already existed. ${ }^{9}$ Definitions, amplifications and filter settings were described in previous publications. 4.810

An arrhythmogenic challenge was performed at CAVB by applying $0.025 \mathrm{mg} / \mathrm{kg}$ dofetilide intravenous for $5 \mathrm{~min} .{ }^{8}$ The occurrence of TdP was scored for $20 \mathrm{~min}$. When TdP was seen $\geq 3$ times, the dog was considered susceptible.

At sacrifice, the heart was excised and weighed. The ventricles were isolated from the atria, RV was removed, and the septum was taken as part of the LV.

\section{Data analysis}

The signals of EP and hemodynamics were sampled at $1 \mathrm{kHz}$ and stored on hard disk. With a custom made computer program (ECG View) with a resolution of $2 \mathrm{~ms}$ and adjustable gain and time scale, the following parameters were measured offline: PP-time, RR-time, QRS-duration, QT-time, duration of the MAP (MAPD) at $100 \%$ repolarization, aortic pressure, LV end diastolic pressure (EDP), LV systolic pressure (SP), and LV peak rate of pressure rise (+dP/dtmax). Corrected (c) QT time "was calculated, and spatial dispersion ( $\triangle M A P D)$ was defined as the difference between LV MAPD and RV MAPD. All data presented are the mean of 5 consecutive beats. An independent observer (CL) checked all measurements.

\section{Analysis of ACE and chymase mRNA}

At sacrifice LV and RV tissue of untreated SR and CAVB dogs was immediately fro- 
zen in liquid nitrogen and stored at $-80^{\circ} \mathrm{C}$ until mRNA analysis. ACE and chymase mRNA levels were assessed at SR, CAVB2, and CAVB5 using quantitative realtime PCR (LightCycler, Roche Diagnostics, Almere, the Netherlands). Total RNA was isolated using the Qiagen RNeasy kit according to the manufacturers protocol. Contamination of genomic DNA was further eliminated by digestion with DNAsel (Promega Benelux, Leiden, the Netherlands). First strand cDNA was synthesized using an optimized reverse transcription protocol. "Real time PCR was performed using the FastStart DNA Master Sybr Green 1 kit (Roche Diagnostics Nederland, Almere, the Netherlands) and dog specific ACE, chymase ${ }^{: 3}$ and GAPDH primers. Data of both ventricles were combined to increase sample size.

\section{Angiotensin II dose-response study}

During SR the pharmacologic activity of irbesartan was characterized in preliminary experiments. The response of the aortic systolic pressure to intravenous incremental boluses of angiotensin II was measured in 3 dogs before and one week after the administration of irbesartan.

\section{Statistics}

Pooled data are expressed as mean \pm SD. Serial comparisons were performed by paired Student's $t$ test and single parameters between independent groups by a 2 way ANOVA with a post-hoc Bonferroni $t$ test. Temporal measurements were tested using ANOVA for repeated measures. Values of $p \leq 0.05$ were considered significant.

\section{Results}

\section{Ventricular remodeling in the CAVB dog (control)}

\section{Time course of electrical remodeling}

In this study, focus was on the electrophysiological changes taking place in the first 2 weeks after creation of AV block. In the left panel of figure 1 changes in PP, RR, and QT-time are depicted at different time points under sedation. Acute AV block resulted in a significant atrial cycle length decrease, while RR and $Q T$ did not significantly increase (left panels). Initially, this lack of severe ventricular bradycardia came as a surprise. From personal observations we learned that this was only the case during the first 24 hours after creation of AV block, thereafter the RR-time increased significantly. This lack of bradycardia could well be related to the severe decrease in PP-time (increased adrenergic state). In time ( 1 week complete AV block: CAVB1) the evolving ventricular bradycardia led to a further lengthening of QT-time, while the PP-time was returning to normal. At CAVB2 there was a further increase in QT-time while the $R R$ remained stable (electrical remodeling). The presence of electrical remodeling was confirmed at CAVB2 when the heart rate was controlied at $500 \mathrm{~ms}$ fixed rate pacing (FRP) under complete anesthesia (right panel figure 1). The QT-time, LV MAPD, RV MAPD, and VERP were significantly 
Chapter 3

Table 1: Electrophysiology in control groups

\begin{tabular}{lll}
\hline IVR & $\begin{array}{l}\text { CAVB2 } \\
(n=8)\end{array}$ & $\begin{array}{l}\text { CAVB5 } \\
(n=7)\end{array}$ \\
\hline RR-time, ms & $1144 \pm 419$ & $1271 \pm 275$ \\
QT-time, ms & $384 \pm 44$ & $413 \pm 75$ \\
QTC-time, ms & $372 \pm 26$ & $389 \pm 66$ \\
LV MAPD, ms & $336 \pm 50$ & $368 \pm 71$ \\
RV MAPD, ms & $296 \pm 40$ & $307 \pm 52$ \\
AMAPD, ms & $40 \pm 22$ & $61 \pm 28$ \\
\hline
\end{tabular}

Figure 1: Time course of electrical remodeling.
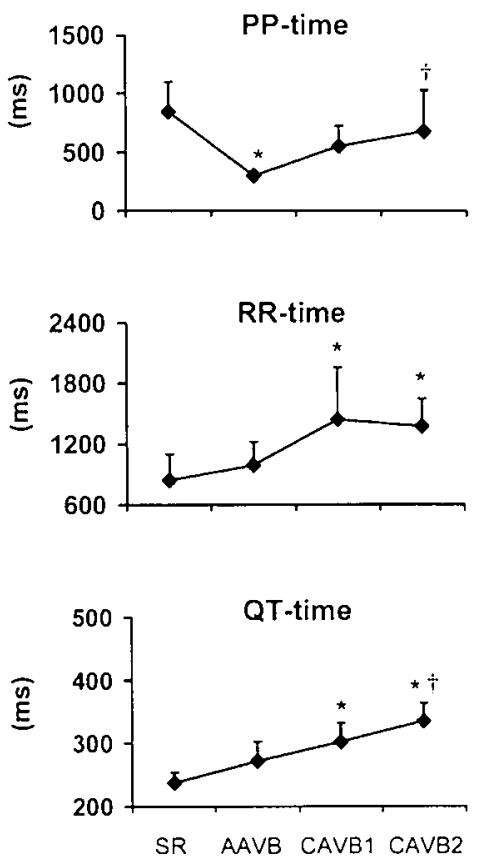

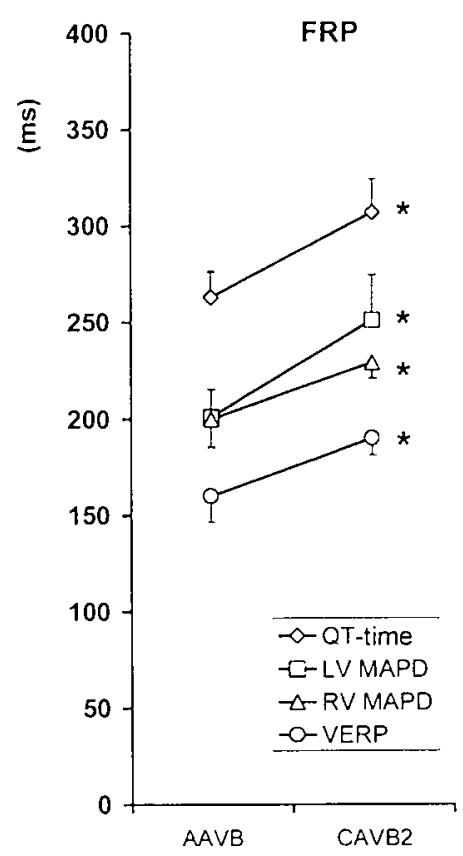

Temporal (x-axis) behavior of PP-time (top). RR-time (middle), and QT-time (bottom) in 8 control dogs (left panel). In the right panel QT-time. LV MAPD. RV MAPD, and VERP during fixed rate pacing with an interstimulus interval of $500 \mathrm{~ms}$ at $A A V B$ and CAVB2 in 6 serially tested dogs are shown. (" $p<0.05$ versus $S R:: p<0.05$ versus AAVB). PP-time initially decreases and returned to $S R$ values at 2 weeks AV-block. After AV-block $R R$-time and ventricular repolarization significantly increase. This increase in electrophysiological parameters was independent of rate (electrical remodeling). 
increased at CAVB2. Moreover, the increase of MAPD was more pronounced in LV than in RV, leading to an increase in spatial dispersion of repolarization ( $\triangle M A P D$ : $14 \pm 10 \mathrm{~ms}$ at $A A V B$ and $26 \pm 23 \mathrm{~ms}$ at CAVB2).

From 2 to 5 weeks CAVB, all electrophysiological parameters remained stable (table 1). Dofetilide administration resulted in the induction of reproducible TdP in the majority of the dogs at both times: 5 out of 6 dogs at CAVB2 and 5 out of 7 at CAVB5.

\section{Development of cardiac hypertrophy}

The presence of cardiac hypertrophy at CAVB5 was demonstrated by a significant increase in heart weight-to-body weight ratio $(H / B w)$ as compared to $S R, 11.6 \pm 1.1$ $\mathrm{g} / \mathrm{kg}$ vs $7.9 \pm 0.7 \mathrm{~g} / \mathrm{kg}$ (figure 2). In contrast, the CAVB2 group did not show cardiac hypertrophy ( $\mathrm{H} / \mathrm{Bw}: 8.8 \pm 0.9 \mathrm{~g} / \mathrm{kg}$ ). When comparing the individual $\mathrm{H} / \mathrm{BW}$ ratios, one appreciates that the H/Bw ratios of 3 dogs in the CAVB2 group is outwith the range observed in the SR group but within the range of the CAVB5 group. This indicates the presence of cardiac hypertrophy in these dogs.

Figure 2: Time course of cardiac hypertrophy.

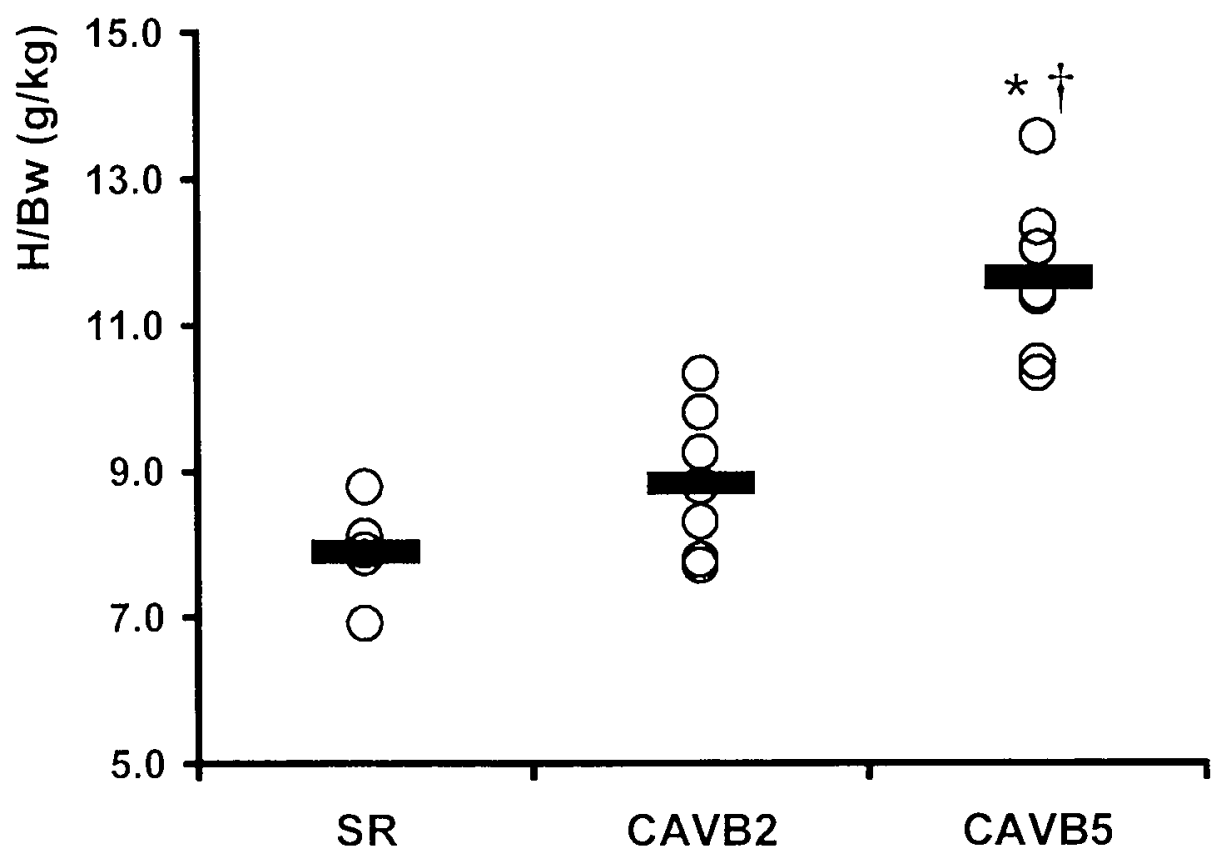

Heart weight related to body weight (HIBw) for SR. CAVB2. and CAVB5 groups. The dots represent individual dogs and a horizontal bar represents the mean value of a specific group. $(" p<0.05$ versus SR: : $p<0.05$ versus CAVB2). At CAVB5 cardiac hypertrophy was present as seen by a significant HIBW as compared to SR and CAVB2. 


\section{Hemodynamic parameters}

The LVSP and LVEDP showed comparable values at SR and CAVB2: LVSP $110 \pm 23$ $\mathrm{mmHg}$ and $103 \pm 20 \mathrm{mmHg}$ respectively, and LVEDP $8 \pm 5 \mathrm{mmHg}$ and $8 \pm 1 \mathrm{mmHg}$ respectively. Contractility of the LV however was significantly higher at CAVB2 as seen by an increased $+d \mathrm{P} / \mathrm{dtmax}$ as compared to $\mathrm{SR}(2543 \pm 1054 \mathrm{mmHg} / \mathrm{s}$ versus $1447 \pm 396 \mathrm{mmHg} / \mathrm{s}$ respectively). None of the dogs showed physical signs of congestive heart failure either during the experimental period or at autopsy.

Figure 3: Changes in ACE and chymase mRNA expression at CAVB.
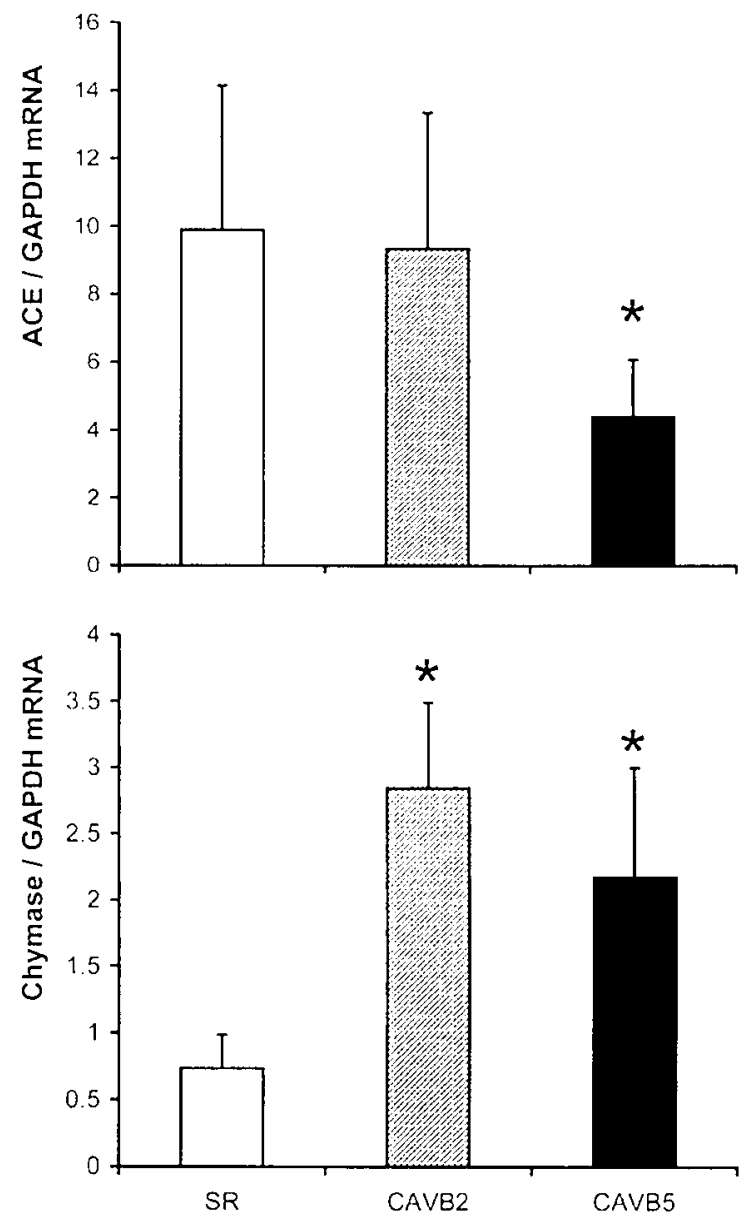

ACE MRNA (upper panel), and chymase MRNA (lower panel) ( $y$-axis) at SR. CAVB2. and CAVB5. related to GAPDH mRNA. (" $p<0.05$ versuS SR). ACE-expression was unaltered at CAVB2. while decreased at CAVB5. Ventricular chymase-expression was increased both at CAVB2 and CAVB5. 


\section{Time dependent changes in mRNA expression levels of ACE and chymase}

The two components of the cardiac tissue RAS showed a change in mRNA expression after creation of AV block. Ventricular ACE mRNA expression was unchanged at CAVB2 as compared to SR, and decreased at CAVB5. The mRNA expression of chymase however was increased at both CAVB2 and CAVB5 (figure 3).

\section{Effect of Irbesartan on ventricular remodeling Effectiveness of ATI-blockade}

During SR the pharmacologic activity of irbesartan was characterized in preliminary experiments. Daily administration of irbesartan resulted in 1) a similar mean aortic $P(96 \pm 9$ before versus $92 \pm 13 \mathrm{mmHg}$ during irbesartan), and 2 ) a downward shift of the dose-response curve of angiotensin II (figure 4). At a subdepressor dosage regimen, effective blockade of angiotensin II was reached.

\section{Effect of irbesartan on electrophysiological parameters during $S R$}

Daily chronic adminstration of irbesartan during SR did not alter EP. Serially $(n=10)$, the heart rhythm (PP-time: $726 \pm 198 \mathrm{~ms}$ before and $722 \pm 213 \mathrm{~ms}$ during irbesartan), conduction (QRS-width: $59 \pm 9 \mathrm{~ms}$ versus $64 \pm 12 \mathrm{~ms}$ ) and ventricular repolarization (QT-time: $234 \pm 16 \mathrm{~ms}$ versus $227 \pm 28 \mathrm{~ms}$ ) were not influenced after one week of treatment. In the EP group comparison, where control $(n=12)$ and irbesartan $(n=10)$ were compared, this lack of effect was confirmed by determination of LV MAPD ( $213 \pm 16 \mathrm{~ms}$ versus $204 \pm 22 \mathrm{~ms}$ respectively), RV MAPD (203 $\pm 14 \mathrm{~ms}$ versus $196 \pm 19 \mathrm{~ms})$, and $\triangle$ MAPD ( $12 \pm 9 \mathrm{~ms}$ versus $11 \pm 8 \mathrm{~ms})$.

\section{AT1-blockade and ventricular remodeling}

Within 2 weeks after creation of AV block, electrical remodeling occurred in the irbesartan treated animals. The changes were similar to those seen in the control groups. In table 2, QT, LV MAPD, RV MAPD, $\triangle M A P D$, and VERP during fixed rate pacing (FRP), serially conducted at AAVB and CAVB2 are depicted. All electrophysiological parameters increased significantly at CAVB2. From 2 to 5 weeks AV block all parameters remained stable, e.g. QTC is shown in figure 5. Thus, irbesartan did not prevent the occurence of electrical remodeling. Dofetilide administration resulted in the reproducible induction of $T \mathrm{dP}$ in the majority of the dogs: 2 out of 4 at CAVB2l, and 3 out of 5 at CAVB5I. Both the induction and duration of the TdPs were comparable in the irbesartan groups, and comparable to the arrhythmias in the control groups. A representative example is shown in figure 6.

LVSP and LVEDP were unaltered at CAVB2I and CAVB5I when compared to the SR group. The LVSP was $103 \pm 4 \mathrm{mmHg}$ at CAVB2I, $98 \pm 20 \mathrm{mmHg}$ at CAVB5I and $95 \pm 13 \mathrm{mmHg}$ at SR, and the LVEDP was $9 \pm 3 \mathrm{mmHg}, 5 \pm 2 \mathrm{mmHg}$ and $8 \pm 3 \mathrm{mmHg}$ respectively. Contractility of the LV had significantly increased at CAVB2I 
Chapter 3

Figure 4: Angiotensin II dose response test.

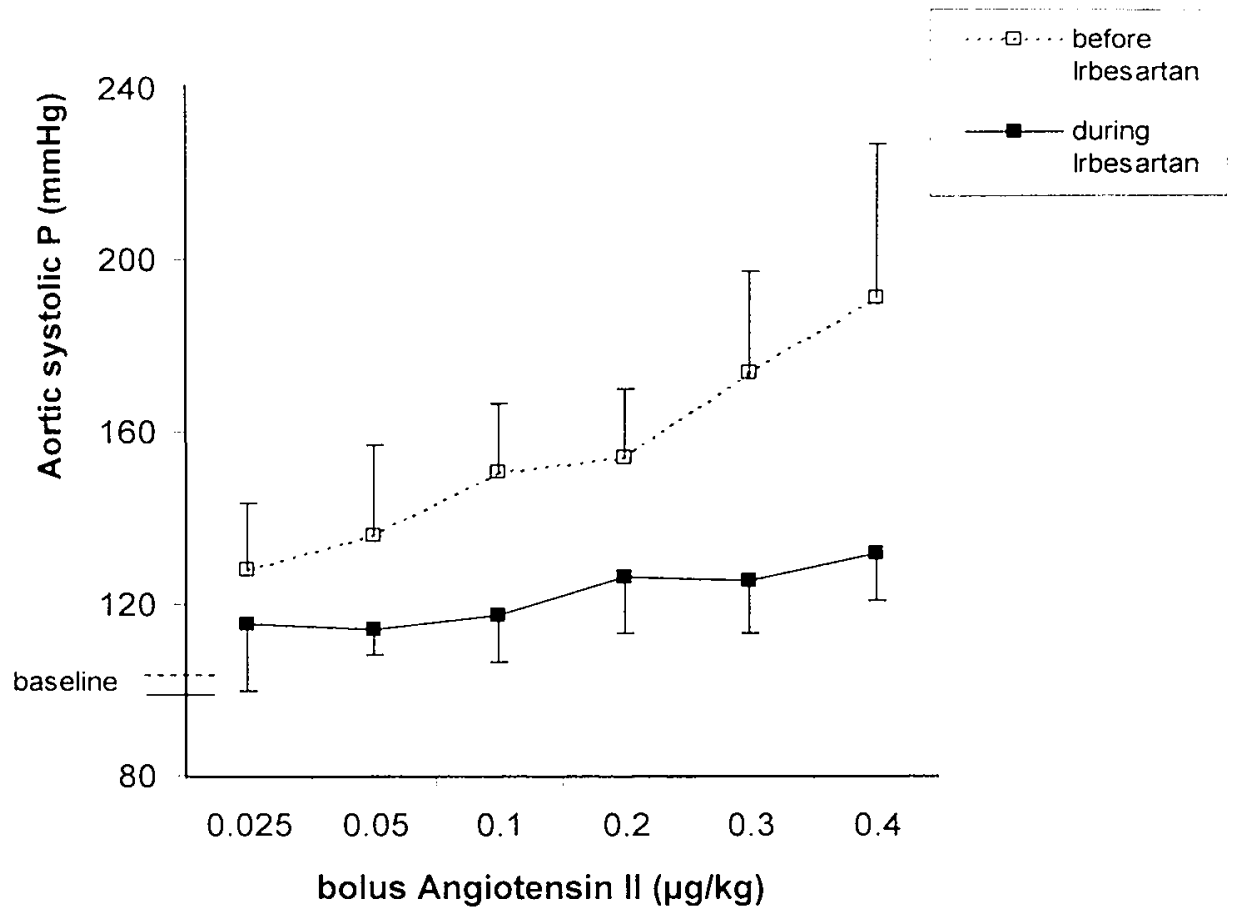

The response of aortic systolic pressure $(P)$ ( $y$-axis) to infusion of different boluses of angiotensin II ( $x$-axis) is shown. Boluses were infused within $30 \mathrm{~s}$, with intervals of $\geq 5$ min in order to allow the aortic systolic $P$ to return to its baseline value. Before irbesartan a higher bolus led to a higher rise in pressure, and after one week oral administration of irbesartan this response was decreased.

Table 2: Electrical remodeling in irbesartan group

\begin{tabular}{lll}
\hline FRP (cycle length $500 \mathrm{~ms})$ & $\begin{array}{l}\text { AAVBI } \\
(n=6)\end{array}$ & $\begin{array}{l}\text { CAVB21 } \\
(n=6)\end{array}$ \\
\hline QT-time, ms & $263 \pm 18$ & $313 \pm 13^{*}$ \\
LV MAPD, ms & $202 \pm 18$ & $256 \pm 19^{*}$ \\
RV MAPD, ms & $208 \pm 22$ & $224 \pm 20^{*}$ \\
AMAPD, ms & $11 \pm 12$ & $32 \pm 17^{*}$ \\
VERP & $164 \pm 9$ & $190 \pm 11^{*}$ \\
\hline
\end{tabular}

$(" p<0.05$ vs AAVB1) 
Figure 5: Asynchronous development of electrical remodeling and hypertrophy.

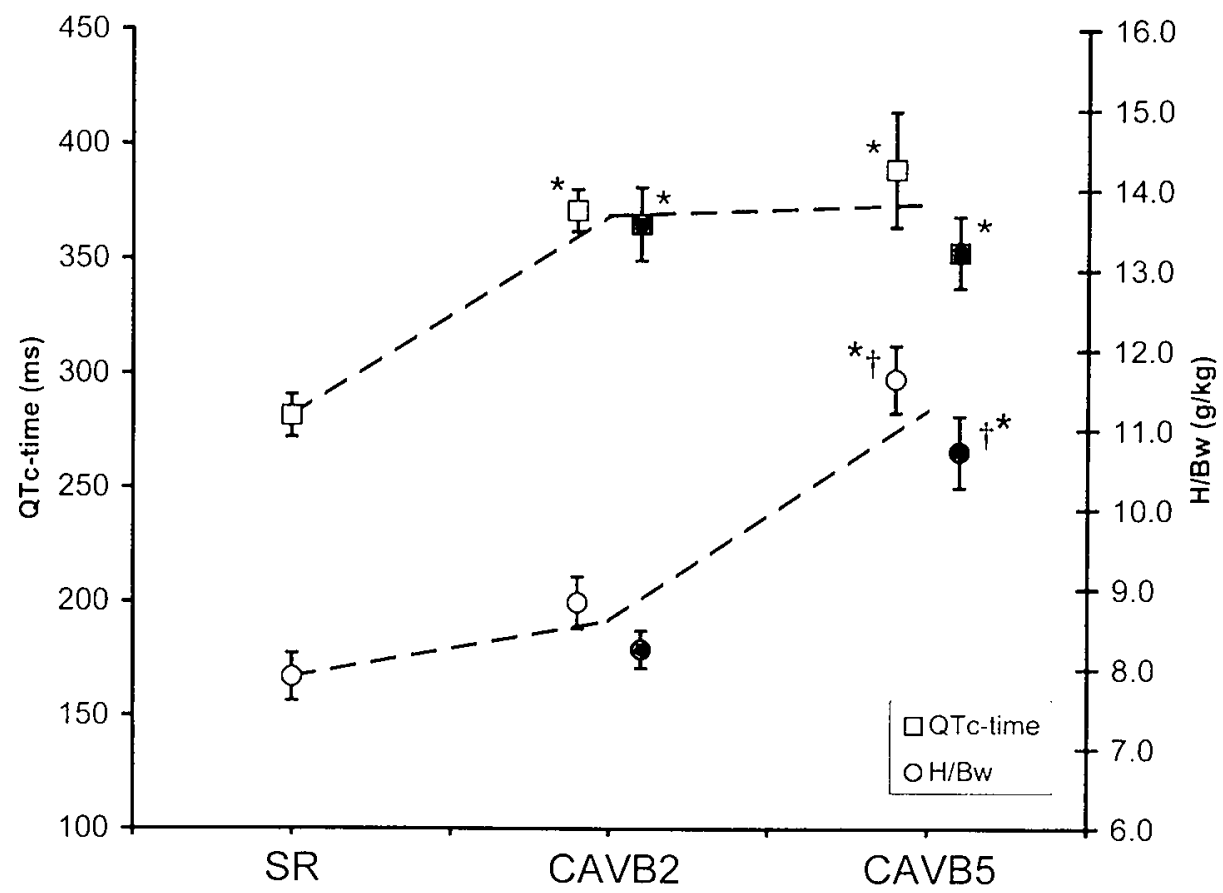

QTC-time (squares) and HIBW (circles) are plotted against time: SR, CAVB2, and CAVB5. Control groups (white) and irbesartan groups (black) are shown in the same picture. The dotted line connects the mean of irbesartan and control groups taken together at similar time points merely to emphasize the different time course of changes seen. $\left({ }^{*} p<0.05\right.$ versus $S R: \therefore p<0.05$ versus CAVB2). Electrical remodeling, represented by QTC-time. develops fast and seems complete at CAVB2 for both control and Irbesartan. Hypertrophy develops more slowly as seen by a significant increase at CAVB5 for both control and Irbesartan groups.

(LV $+d P / d t m a x: ~ 2463 \pm 512 \mathrm{mmHg} / \mathrm{s})$, and CAVB5I $(2338 \pm 564 \mathrm{mmHg} / \mathrm{s})$ as compared to $\mathrm{SR}(1570 \pm 188 \mathrm{mmHg} / \mathrm{s})$. The hemodynamic parameters were comparable to control. None of the irbesartan treated animals showed signs of congestive heart failure.

Observations concerning the development of cardiac hypertrophy were similar in the irbesartan groups as compared to control (figure 5). Hypertrophy was present at CAVB5I $(10.7 \pm 1.0 \mathrm{~g} / \mathrm{kg})$ but not at CAVB2I $(8.3 \pm 0.5 \mathrm{~g} / \mathrm{kg})$. A subanalysis revealed that the LV weight-to-body weight ratio at CAVB21 $(4.7 \pm 0.3 \mathrm{~g} / \mathrm{kg})$ was significantly less than at CAVB5I $(6.1 \pm 0.6 \mathrm{~g} / \mathrm{kg})$. The same was true for the RV weight-to-body weight ratio: $1.8 \pm 0.2 \mathrm{~g} / \mathrm{kg}$ at CAVB2I versus $2.3 \pm 0.4 \mathrm{~g} / \mathrm{kg}$ at CAVB5I. 
Figure 6: Dofetilide-induced TdP in irbesartan treated CAVB dog.

\section{CAVB2 I}

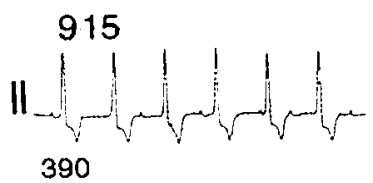

AVR
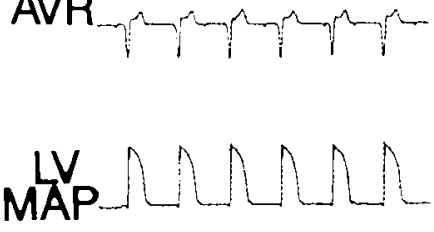

370

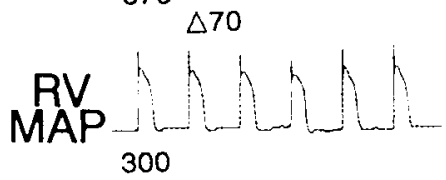

\section{Dofetilide $\left(0.025 \mathrm{mg} / \mathrm{kg} / 5^{\prime}\right)$}
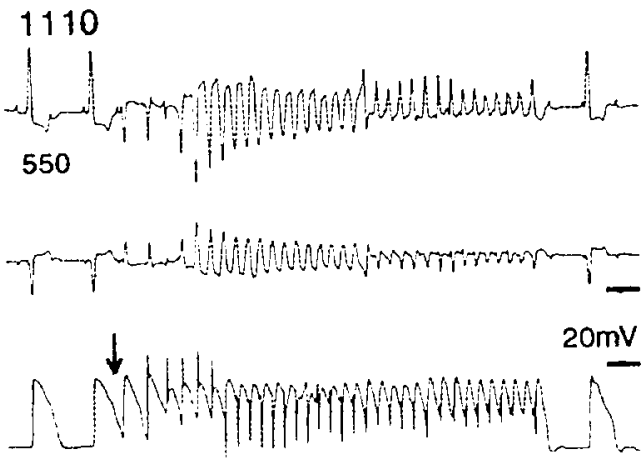

510

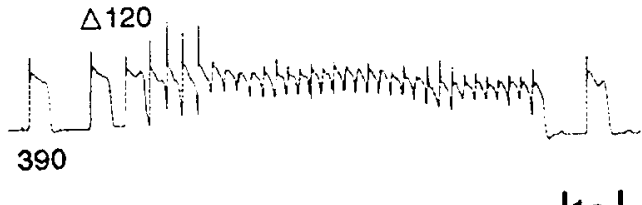

000533

Two surface ECG-leads and LV and RV MAP recordings at a paper speed of $10 \mathrm{~mm} / \mathrm{s}$. When dofetilide was administered at CAVB2 in an irbesartan treated dog, the QT-time, LV MAPD, RV $M A P D$ and $\triangle M A P D$ clearly increased before a self-terminating TdP occurred.

\section{Different time course of electrical remodeling and cardiac hypertrophy}

When plotting the values of the control and Irbesartan groups at similar time points (figure 5), the distinction in temporal behavior of the two remodeling processes can be appreciated. Electrical remodeling is complete at CAVB2, while cardiac hypertrophy has only developed at CAVB5.

\section{Discussion}

In the CAVB dog, ventricular electrical remodeling and the arrhythmia-prone condition, i.e. dofetilide-induced TdP, are already present at CAVB2, while the development of cardiac hypertrophy seems to follow a slower time course. Irbesartan, the AT1-blocker, does not prevent ventricular remodeling in this model, regardless of the fact that components of the renin angiotensin system have been implicated in hypertrophy. 


\section{Temporal dissociation of electrical remodeling from cardiac hypertrophy}

The long-term ( $>5$ weeks) adaptations of the CAVB dog have been the subject of many publications. Electrical remodeling can be characterized by a nonhomogeneous lengthening of MAPD (LV>RV) leading to spatial dispersion of repolarization. The incidence of class 111 antiarrhythmic-induced $T d P$ is high, and the incidence of sudden cardiac death is $10-15 \%$. There is eccentric biventricular hypertrophy, not accompanied by excessive collagen depositions or changes in capillary-fiber ratio. At 5-6 weeks CAVB, mechanical adaptations have led to a hemodynamically compensated state: LV and RV +dP/dtmax have increased, cardiac output is maintained, and ventricular EDP is unchanged in comparison to SR. This study is the first one to describe the temporal dissociation of electrical remodeling and related proarrhythmia from cardiac hypertrophy in an in vivo dog model. An increased QT, ventricular MAPD prolongation, spatial dispersion of repolarization, and susceptibility to drug-induced TdP were uniformly present at CAVB2. Cardiac hypertrophy on the other hand developed more slowly: at CAVB2 hypertrophy was absent in the majority of the dogs, while at CAVB5 it was fully present. LV and RV weights showed comparable results. Lack of synchrony has been indicated in the first days after myocardial infarction in the rat, where downregulation of $\mathrm{K}+$-channel genes and currents was present while no hypertrophy was detectable yet. "In two papers pharmacological separation of these processes during their developmental phase was reported. In a murine model of pressure overload, cyclosporin A was able to prevent myocyte hypertrophy, while the prolongation of the action potential was only attenuated. "In aortic-banded rats changes in gene products of $\mathrm{I}_{\mathrm{f}}, \mathrm{I}_{\mathrm{TO}}$ and $\mathrm{I}_{\mathrm{CI}}$ were prevented by treatment with a $\mathrm{Ca}$ "-antagonist, while LV hypertrophy developed. "However none of these pharmacological studies described the arrhythmogenic consequences of the dissociation. These studies and the present one, where electrical remodeling and hypertrophy develop asynchronously, indicate the presence of different signalling routes. More recently, it was suggested that the reduction of ion channel gene products might even be the starting point of hypertrophic signalling.

\section{No sign of heart failure in the CAVB dog}

Another important finding is that during short-term volume overload, when hypertrophy is not yet present (CAVB2), there are no signs of congestive heart failure: LVEDP is not elevated, $\mathrm{LV}+\mathrm{dP} / \mathrm{dt}$ max is significantly increased, and there are no physical signs of pump failure. This suggests that during the early time course of mechanical overload mechanisms other than hypertrophy come into play to compensate for the increased workload of the heart. Mouse models of pressure overload, either transgenic or treated with cyclosporin A, confirm that a preserved cardiac function is not necessarily accompanied by cardiac hypertrophy. ${ }^{2 * 2 *}$ Whether contractile improvements can be maintained in the long run without the involvement 
of cardiac hypertrophy is unclear. In this study, where mechanical adaptations and cardiac hypertrophy are both present at CAVB5, hypertrophy may be necessary for the long-term compensation.

\section{Lack of effect of irbesartan}

For several reasons we selected AT1-inhibition: 1) tissue and plasma components of the RAS are (transiently) elevated in the CAVB dog, ${ }^{\circ} 2$ ) chymase mRNA was elevated at CAVB while ACE-expression was unchanged or even decreased, possibly suggesting a predominance of chymase in tissue angiotensin II production after AV block, 3) other pathways, like bradykinin, influenced by ACE-inhibitors are left untouched by AT1-blockade, and 4) irbesartan can be applied effectively at a dosage not influencing blood pressure thereby preserving hemodynamics. Though the activation of AT1 in the mammalian heart mainly results in the development of myocyte hypertrophy in vitro ", conflicting data have been published concerning the effect of blockade in vivo. Most prevention studies have focused on the effect of AT1-blockade during pressure overload. For example, in some studies concerning aorta banding in rats, hypertrophy was attenuated, while in others no effect was seen. "s:3: AT1-blockers failed to prevent cardiac hypertrophy in constrictive pulmonary artery-banded rabbits, cats, and fetal sheep. ${ }^{25 \% 2}$ Prevention studies in volume overload models are scarce. In rat models of volume overload AT1-blockade attenuated hypertrophy. "Perry et al. described the presence of myocyte hypertrophy after mitral valve regurgitation despite AT1-blockade in the dog. ${ }^{3.5}$ In the CAVB dog no prevention of hypertrophy by irbesartan was seen at CAVB5I as compared to CAVB5. However, a blunted response cannot be ruled out. This all, leads us to believe that AT1 may not be the dominant factor in the development of mechanical overload-induced hypertrophy, but that other signaling pathways are of importance. Moreover, irbesartan was not able to prevent electrical remodeling in this model. Furthermore, the relation between the presence of electrical remodeling and the susceptibility to dofetilide-induced $\mathrm{TdP}$ remained present.

\section{Clinical implications}

In clinical studies an increased QT-time and the presence of ventricular arrhythmias has been documented in patients with left ventricular hypertrophy. "A positive correlation between the increase in LV mass and the QT duration has been implicated. "This experimental study suggests that electrical remodeling and proarrhythmia are likely to precede the presence of hypertrophy.

So far, no clinical study has addressed temporal aspects of electrical remodeling, proarrhythmia and hypertrophy. We realize that conducting such a study will merely be impossible due to ethical and practical constraints. Therefore the CAVB dog is a very suitable model to study these aspects in detail. 


\section{Limitations}

We do not know whether Irbesartan actually reached the AT1 on the membrane of the cardiomyocyte, though we assume this was the case because its vascular counterpart was blocked as checked by angiotensin 11 dose-response studies. Since we did not measure angiotensin II levels in the cardiac tissue, we have to be careful in relating the changed levels of ACE and chymase mRNA after AV block to the RAS in general. We are aware of the fact that groups are too small in order to compare the incidence of dofetilide-induced TdP between controls and Irbesartan treated dogs, however we want to emphasize that irbesartan did not influence electrical remodeling. We realize that since $L V$ hemodynamics were only measured during IVR contractility of the LV was as such not fully characterized.

\section{Conclusions}

In the complete AV block dog, ventricular hypertrophy is not a prerequisite for electrical remodeling or drug-induced torsade de pointes. In the model, the AT1 receptor has no dominant role in the completion of these ventricular remodeling processes.

\section{Acknowledgements}

Financial support by the Netherlands Heart Foundation (98.042) is gratefully acknowledged. We thank Dr. Ben Jansen for helpful advice, Roel Spätjens for technical assistance, and Dr. Dino Nisato for kindly providing Irbesartan. 


\section{References}

1. Bikkina $M$. Larson MG. Levy $D$. Asymptomatic ventricular arrhythmias and mortality risk in subjects with left ventricular hypertrophy. J Am Coll Cardiol. 1993;22:1111-6.

2. Oikarinen L, Nieminen MS, Viitasalo M. Toivonen L, Wachtell K, Papademetriou V, Jern S, Dahlof B. Devereux RB. Okin PM. Relation of QT interval and QT dispersion to echocardiographic left ventricular hypertrophy and geometric pattern in hypertensive patients. The LIFE sludy. The Losartan Intervention For Endpoint Reduction. J Hypertens. 2001:19:1883-91

3. Tomaselli GF. Marban E. Electrophysiological remodeling in hypertrophy and heart failure. Cardiovasc Res. 1999;42:270-83.

4. Vos MA, de Groot SH, Verduyn SC, van der Zande J, Leunissen HD. Cleutjens JP, van Bilsen M. Daemen MJ, Schreuder JJ, Allessie MA, Wellens HJ. Enhanced susceptibility for acquired torsade de pointes arrhythmias in the dog with chronic, complete AV block is related to cardiac hypertrophy and electrical remodeling. Circulation. 1998;98:1125-35.

5. Volders PG, Sipido KR, Vos MA, Kulcsar A, Verduyn SC, Wellens HJ. Cellular basis of biventricular hypertrophy and arrhythmogenesis in dogs with chronic complete atrioventricular block and acquired torsade de pointes. Circulation. 1998:98:1136-47.

6. Verduyn SC, Ramakers C, Snoep G, Leunissen JD, Wellens HJ, Vos MA. Time course of structural adaptations in chronic AV block dogs: evidence for differential ventricular remodeling. Am J Physiol Heart Circ Physiol. 2001;280:H2882-90.

7. Spinale FG, Holzgrefe HH, Walker JD, Mukherjee R, Kribbs SB, Powell JR. Antonaccio M. Angiotensin II subtype-1 receptor blockade during the development of left ventricular hypertrophy in dogs: effects on ventricular and myocyte function. I Cardiovasc Pharmacol. 1997;30:623-31.

8. Van Opstal JM, Leunissen JD. Wellens HJ, Vos MA. Azimilide and dofetilide produce similar electrophysiological and proarrhythmic effects in a canine model of Torsade de Pointes arrhythmias. Eur J Pharmacol. 2001;412:67-76.

9. De Groot SH, Schoenmakers M, Molenschot MM, Leunissen JD, Wellens HJ, Vos MA. Contractile adaptations preserving cardiac output predispose the hypertrophied canine heart to delayed afterdepolarization-dependent ventricular arrhythmias. Circulation. 2000;102:2145-2151.

10. Vos MA, Verduyn SC. Wellens HJ. Early afterdepolarizations in the in situ canine heart: mechanistic insights into acquired torsade de pointes arrhythmias. In: Franz MR, editor, Monophasic Action Potentials: Bridging Cell and Bedside, Armonk, NY: Futura Publishing. 2000:553-569.

11. Van de Water A, Verheyen J, Xhonneux R, Reneman RS. An improved method to correct the QT interval of the electrocardiogram for changes in heart rate. J Pharmacol Methods. 1989:22:207-17

12. Lekanne Deprez RH. Fijnvandraat AC, Ruijter JM. Moorman AF. Sensitivity and accuracy of quantitative real-time polymerase chain reaction using SYBR green I depends on CDNA synthesis conditions. Anal Biochem. 2002;307:63-9.

13. Lee YA, Liang CS. Lee MA. Lindpaintner K. Local stress, not systemic factors, regulate gene expression of the cardiac renin-angiotensin system in vivo: a comprehensive study of all its components in the dog. Proc Natl Acad Sci USA. 1996;93:11035-40. 
14. Volders PG, Sipido KR. Vos MA, Spatjens RL, Leunissen JD, Carmeliet E, Wellens HJ. Downregulation of delayed rectifier $K(+)$ currents in dogs with chronic complete atrioventricular block and acquired torsades de pointes. Circulation. 1999;100:2455-61.

15. Van Opstal JM, Verduyn SC, Leunissen HD, de Groot SH, Wellens HJ, Vos MA. Electrophysiological parameters indicative of sudden cardiac death in the dog with chronic complete AV-block. Cardiovasc Res. 2001;50:354-61.

16. Huang $B$, Qin D, El-Sherif N. Early down-regulation of $K+$ channel genes and currents in the postinfarction heart. J Cardiovasc Electrophysiol. 2000;11:1252-61.

17. Wang Z, Kutschke W. Richardson KE, Karimi M. Hill JA. Electrical remodeling in pressure-overload cardiac hypertrophy: role of calcineurin. Circulation. 2001:104:1657-63.

18. Hiramatsu M. Furukawa T. Sawanobori T. Hiraoka M. Ion channel remodeling in cardiac hypertrophy is prevented by blood pressure reduction without affecting heart weight increase in rats with abdominal aortic banding. J Cardiovasc Pharmacol. 2002:39:866-74.

19. Kassiri Z, Zobel C, Nguyen TT, Molkentin JD, Backx PH. Reduction of 1(10) causes hypertrophy in neonatal rat ventricular myocytes. Circ Res. 2002;90:578-85.

20. Hill JA, Karimi M, Kutschke W, Davisson RL, Zimmerman K, Wang Z, Kerber RE. Weiss RM. Cardiac hypertrophy is not a required compensatory response to short- term pressure overload. Circulation. 2000;101:2863-9.

21. Esposito G, Rapacciuolo A, Naga Prasad SV, Takaoka H, Thomas SA, Koch WJ, Rockman HA. Genetic alterations that inhibit in vivo pressure-overload hypertrophy prevent cardiac dysfunction despite increased wall stress. Circulation. 2002;105:85-92.

22. Paradis P, Dali-Youcef N, Paradis FW. Thibault G, Nemer M. Overexpression of angiotensin II type I receptor in cardiomyocytes induces cardiac hypertrophy and remodeling Proc Natl Acad Sci U S A. 2000;97:931-6.

23. Obayashi M, Yano M, Kohno M. Kobayashi S, Tanigawa T, Hironaka K, Ryouke T, Matsuzaki M. Dose-dependent effect of ANG II-receptor antagonist on myocyte remodeling in rat cardiac hypertrophy, Am J Physiol. 1997;273:H1824-31.

24. Baba HA, Iwai T, Bauer M. Irlbeck M. Schmid KW, Zimmer HG. Differential effects of angiotensin 11 receptor blockade on pressure- induced left ventricular hypertrophy and fibrosis in rats. J Mol Cell Cardiol. 1999:31:445-55

25. Rouleau JL, Kapuku G, Pelletier S, Gosselin H, Adam A, Gagnon C, Lambert C, Meloche S. Cardioprotective effects of ramipril and losartan in right ventricular pressure overload in the rabbit: importance of kinins and influence on angiotensin II type 1 receptor signaling pathway. Circulation. 2001:104:939-44.

26. Koide M. Carabello BA, Conrad CC. Buckley JM, DeFreyte G, Barnes M, Tomanek RJ, Wei CC. Dell'Italia LJ, Cooper Gt, Zile MR. Hypertrophic response to hemodynamic overload: role of load vs. renin- angiotensin system activation. Am J Physiol. 1999:276:H350-8.

27. Segar JL, Scholz TD, Bedell KA, Smith OM. Huss DJ, Guillery EN. Angiotensin AT1 receptor blockade fails to attenuate pressure-overload cardiac hypertrophy in fetal sheep. Am J Physiol. 1997:273:R1501-8. 


\section{Chapter 3}

28. Ruzicka M, Yuan B, Harmsen E. Leenen FH. The renin-angiotensin system andi volume overload-induced cardiac hypertrophy in rats. Effects of angiotensin converting enzyme inhibitor versus angiotensin II receptor blocker. Circulation. 1993;87:921-30

29. Ishiye M, Umemura K, Uematsu T, Nakashima M. Angiotensin AT1 receptor-mediated attenuation of cardiac hypertrophy due to volume overload: involvement of endothelin. Eur J Pharmacol. 1995;280:11-7.

30. Perry GJ, Wei CC, Hankes GH, Dillon SR, Rynders P, Mukherjee R, Spinale FG, Dell'Italia LJ. Angiotensin 11 receptor blockade does not improve left ventricular function and remodeling in subacute mitral regurgitation in the dog. J Am Coll Cardiol. 2002:39:1374-9. 
Chapter 4

\section{In the CAVB dog, maximally attained inotropy is negatively associated with susceptibility to drug-induced torsade de pointes: Inverse relation of electrical remodeling and poststimulus potentiation}

Marieke Schoenmakers ", Jurren M. van Opstal ", Jet D. M. Beekman "., S. H. Marieke de Groot ", Marc A. Vos a.b

"Department of Cardiology, Cardiovascular Research Institute Maastricht, the Netherlands; "Department of Medical Physiology, University Medical Center Utrecht, the Netherlands 


\begin{abstract}
Introduction: In the CAVB dog, ventricular remodeling predisposes the animals to drug-induced torsade de pointes (TdP). In this study, the evolution of contractile remodeling and its relevance for susceptibility to dofetilide-induced TdP were addressed.
\end{abstract}

Methods: In anesthetized dogs, left ventricular (LV) parameters (+dP/dtmax, ECG and endocardial monophasic APD) were recorded at acute $A V$ block (AAVB), and after 2 and 6 weeks chronic complete AV block (CAVB). LV +dP/dtmax was measured before and after a number of pacing protocols, including poststimulus potentiation (PSP) using 1-33 stimuli (300 ms interval). A dofetilide challenge $\left(0.025 \mathrm{mg} / \mathrm{kg} / 5^{\prime} \mathrm{IV}\right.$ ) was performed to classify dogs as TdP susceptible or resistant.

Results: Contractile remodeling was already present at 2 and similar to 6 weeks CAVB. Arrhythmogeneity followed the same time course: dofetilide induced TdP in $0 / 9$ at AAVB, 11/14 at 2, and 11/18 at 6 weeks CAVB ( $p<0.05$ versus AAVB). At CAVB baseline, contractile (and electrical) parameters were not different between susceptible and resistant dogs. However, when contractility was challenged (PSP), maximal PSP was significantly higher in the resistant than in the suscepible dogs $(6000 \pm 957 \mathrm{mmHg} / \mathrm{s}$ versus $4501 \pm 1002 \mathrm{mmHg} / \mathrm{s} ; p<0.05)$. Individual LV APD after dofetilide correlated inversely to LV PSP $(r=-0.76 ; p<0.007)$, resulting in a clustering of the 2 groups, in which the susceptible dogs had besides lower maximal PSP also longer APDs after dofetilide than the resistant ones $(420 \pm 82 \mathrm{~ms}$ versus $326 \pm 68 \mathrm{~ms} ; p<0.05)$.

Conclusions: Contractile remodeling develops within 2 weeks after creation of complete AV block. In the CAVB dog, maximal PSP is negatively associated with electrical remodeling and susceptibility to dofetilideinduced TdP. CAVB dogs susceptible to TdP have longer repolarization times and attain a lower maximal inotropy. 


\section{Introduction}

Inducing bradycardia by creation of complete AV block in the dog leads to a reduction in cardiac output. 'Neurohumoral pathways become activated to overcome this acute phase of decompensation. Subsequently, these and other signals provide the stimuli for ventricular remodeling ", which can be characterized by (cellular) alterations in structural, electrophysiological, and contractile parameters. "Some of these remodeling processes are believed to provide the basis for the compensated cardiac function seen at 6 weeks chronic complete AV block (CAVB). This beneficial effect, however, is also associated with a higher susceptibility to ventricular arrhythmias as indicated by an increased incidence of (drug-induced) early and delayed afterdepolarizations, torsade de pointes (TdP), and sudden cardiac death in (large) subpopulations of CAVB dogs.

When comparing the time course of these remodeling processes, it becomes evident that electrical remodeling and dofetilide-induced TdP are already present at 2 weeks CAVB, while hypertrophy follows a slower time path." In this study, the first objective was to determine the temporal behavior of contractile remodeling. Next, we were interested in the relevance of the contractile alterations for susceptibility to TdP. At CAVB, the majority of the anesthetized dogs show reproducible $T d P$ when challenged by a class 11 I-antiarrhythmic drug, like dofetilide or ibutilide. Animals susceptible or resistant to drug-induced TdP cannot easily be distinguished on the basis of electrophysiological parameters at baseline. It requires either a considerable number of dogs and/or specific methodologies to discriminate between the groups." After an arrhythmogenic challenge with a class III-antiarhythmic drug, however, electrophysiological parameters become quite different: susceptible CAVB dogs have significantly longer repolarization times as compared to resistant ones. "So far, no information has been provided for differences in contractile parameters. In this study, contractile values at baseline and during a contractile challenge were determined. Moreover, the mutual relationship between electrical and contractile remodeling with respect to arrhythmogenesis was established.

\section{Methods}

Under aseptic conditions and during complete anesthesia 58 dogs (body weight $27 \pm 4 \mathrm{~kg}, 23$ females) were subjected to a total of 92 experiments. Studies were conducted at acute complete AV block (AAVB, $n=38$ ), 2 (CAVB2, $n=14$ ), and 6 weeks CAVB (CAVB6, $n=40$ ). Left ventricular (LV) contractility was determined during idioventricular rate (IVR) and as a response to force-frequency (FF), post-extrasystolic potentiation (PESP), and post-stimulus potentiation (PSP) protocols. Electrophysiological parameters consisted of the standard surface ECG lead recordings and endocardial monophasic action potential (MAP, EP Technologies Inc.) registrations of the LV and right ventricle (RV). Animal hand- 
ling was in accordance with the European Directive for the Protection of Vertebrate Animals used for Experimental and other Scientific Purposes (European Community Directive \#86/609/CEE)'. The 'Committee for Experiments on Animals (DEC)' of Maastricht University, the Netherlands approved the experiments.

\section{Invasive measurements and arrhythmogenic challenge}

Perioperative care, anesthesia, ventilation, and the creation of complete AV block have been described previously." Pressure (Sentron Europe Inc.) and MAP catheters were positioned under fluoroscopic guidance and recorded simultaneously. MAP phases were defined according to the definitions used for transmembrane potentials ${ }^{13}$ and the amplifications and filter settings used were described elsewhere. ${ }^{10}$ Susceptibility to TdP was determined during a dofetilide challenge $\left(0.025 \mathrm{mg} / \mathrm{kg} / 5^{\prime}\right.$ I.V.). "The occurrence of TdP "was scored for 20 minutes and dogs were considered susceptible when $T d P$ was seen $\geq 3$ times. When TdP reproducibly occurred after dofetilide, verapamil $\left(0.2-0.4 \mathrm{mg} / \mathrm{kg} / 3^{\prime}\right.$, $\mathrm{n}=4$ ), mibefradil (1.00 $\mathrm{mg} / \mathrm{kg} / 2^{\prime}, \mathrm{n}=7$ ), or levcromakalim $\left(0.01 \mathrm{mg} / \mathrm{kg} / 3^{\prime}, \mathrm{n}=6\right)$ were administerd as antidotes.

\section{Data analysis and definitions}

LV pressure and electrophysiological signals were sampled at $1 \mathrm{kHz}$ and stored on hard disk. LV peak rate of pressure rise (+dP/dtmax), RR-time and QT-time in lead II, duration of the MAP (MAPD) at $100 \%$ repolarization were measured offline by use of a software program (ECG View). Data presented are the mean of 5 consecutive beats, with the exception of PSP and PESP (for protocols see '). Maximal values represent the highest $L V+d P / d t m a x$ values obtained for FF (during steady state of 50 or 80 paced beats/min), PESP (potentiation after extrastimulus of $250 \mathrm{~ms}$ ) or PSP (potentiation after $5,8,10$, or 13 stimuli). Interventricular dispersion of repolarization ( $\triangle M A P D)$ was defined as the difference between LV and RV MAPD. For the correlation studies, data from CAVB2 and $6(n=11)$ in which electrical, contractile and arrhythmogenic parameters were determined during the same experiment were combined.

\section{Statistics}

Pooled data are expressed as mean \pm SD unless otherwise stated. Statistical tests included ordinary ANOVA followed by Bonferroni $t$ test, 2-tailed Student's $t$ test for unpaired events, $\%$-test, and linear regression analysis. Values of $\mathrm{P} \leq 0.05$ were considered significant. 


\section{Results}

\section{Time course of contractile remodeling and arrhythmogeneity}

Contractile remodeling is present at CAVB2 and comparable to CAVB6 as shown in figure 1 , where the increase in $\mathrm{LV} \mathrm{dP} / \mathrm{dt}$ max is significant at both time points (upper left panel), and most pronounced during the slow heart rates resulting in a negative force-frequency relationship (upper right panel). In addition, LV PESP (lower left) and LV PSP (lower right panel) are also similarly enhanced at CAVB2 and 6.

Figure 1: Contractile remodeling is present at CAVB2
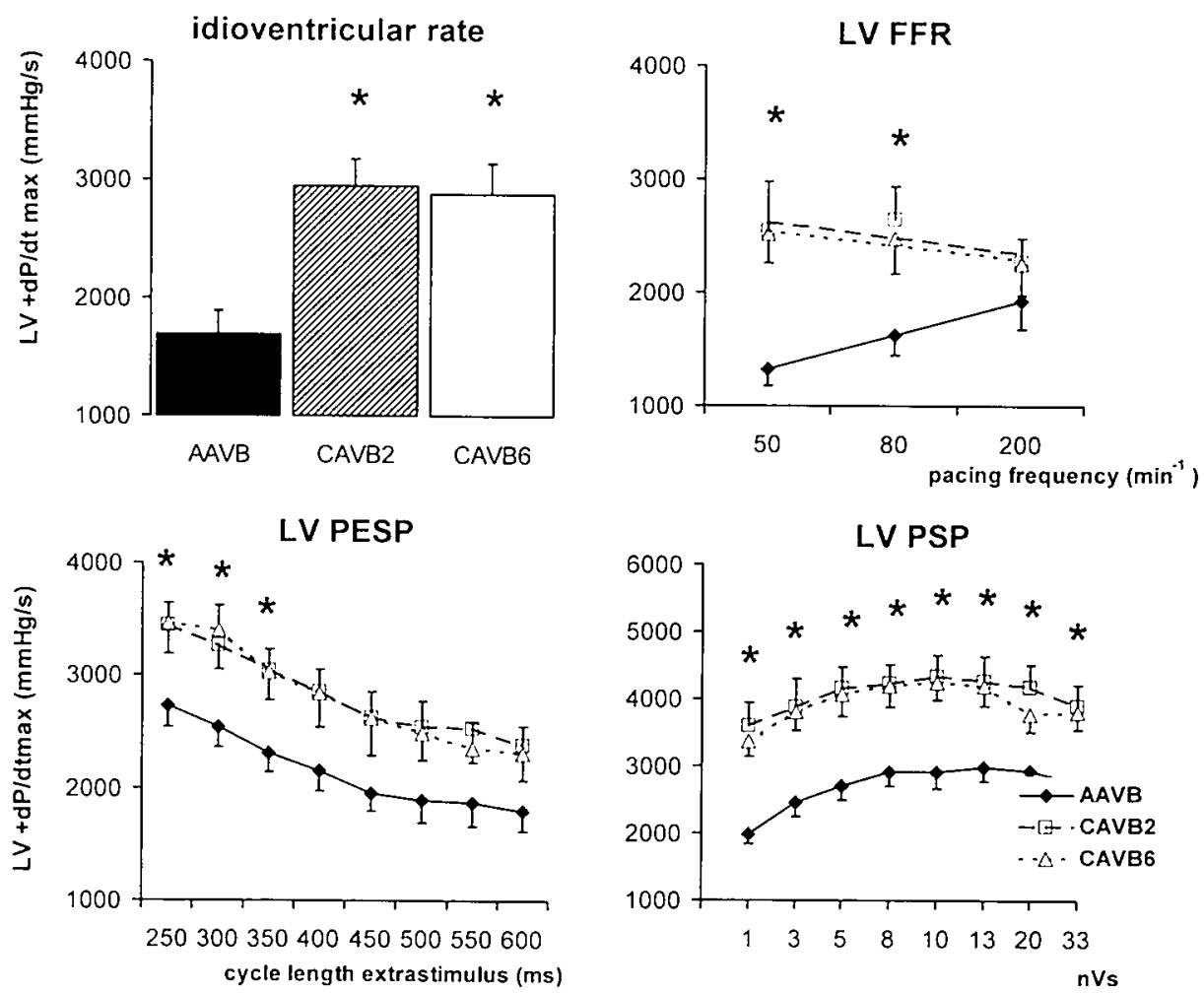

$L V+d P / d t \max$ (y-axis) is quantified during IVR (upper left). using FF relation (FFR, upper right), PESP (lower left). and PSP protocols (lower right) at AAVB, CAVB2, and CAVB6, respectively. Data are expressed as mean \pm sem. ( $p<0.05$ versus AAVB)

Contractile remodeling is present at CAVB2 and comparable to CAVB6 as shown by an increased $L V+d P l d t m a x$. This increase in contractility is most pronounced during the slow heart rates resulting in a negative LV FFR. In addition. LV PESP and LV PSP are similarly enhanced at CAVB2 and 6. 
We confirm that electrical remodeling is present at CAVB2 and comparable to CAVB6 as indicated by a prolongation of QT-time, LV MAPD, RV MAPD, and $\triangle M A P D$ at comparable idioventricular rates, e.g. QT-time is $293 \pm 26 \mathrm{~ms}$ at AAVB, $358 \pm 40 \mathrm{~ms}$ at CAVB2, and $374 \pm 49 \mathrm{~ms}$ at CAVB6 $(p<0.05)$.

Moreover, the majority of CAVB dogs are susceptible to dofetilide-induced TdP, since 11 out of $14(79 \%)$ are inducible at CAVB2 and 11 out of 18 at CAVB6 $(61 \%)$. This incidence is significantly higher than at AAVB $(p<0.05)$, where none of the animals ( 0 out of 9 ) are inducible.

\section{Contractile remodeling and susceptibility to dofetilide-induced $T d P$}

At CAVB, dogs can be can subdivided in 2 populations based on the arhythmogenic response to dofetilide: TdP susceptible and TdP resistant. During baseline circumstances LV +dP/dtmax is not different for the 2 groups (table 1), as is the IVR (RR-time is $1095 \pm 346 \mathrm{~ms}$ for susceptible and $975 \pm 212 \mathrm{~ms}$ for resistant dogs: not significant). When contractility is challenged, maximal values of the 2 groups seem to be different for LV FF and LV PESP. Only maximal LV PSP, however, shows significant differences, where resistant dogs attain the highest LV PSP values. In this, there is no effect of the postpacing cycle length, since the RR-time for susceptible and resistant dogs is comparable $(1198 \pm 210 \mathrm{~ms}$ and $1087 \pm 37 \mathrm{~ms}$ respectively: not significant)

Electrophysiologically, we can confirm that susceptible CAVB dogs have longer repolarization times after dofetilide infusion when compared to resistant ones, e.g. LV MAPD $420 \pm 82 \mathrm{~ms}$ and $326 \pm 68 \mathrm{~ms}$ respectively $(p<0.05)$. This in contrast to the baseline values, which are not different: LV MAPD for susceptibles is $325 \pm 33 \mathrm{~ms}$ and $290 \pm 58 \mathrm{~ms}$ for resistant animals (not significant).

Table 1: Contractile parameters for CAVB dogs susceptible and resistant to dofetilide-induced TdP

\begin{tabular}{lll}
\hline & Susceptible & Resistant \\
\hline LV +dP/dtmax at IVR, mmHg/s & $2903 \pm 944$ & $3817 \pm 960$ \\
Maximal FF, mmHg/s & $2612 \pm 714$ & $3358 \pm 763$ \\
Maximal PESP, mmHg/s & $3492 \pm 793$ & $4024 \pm 772$ \\
Maximal PSP, mmHg/s & $4501 \pm 1002$ & $6000 \pm 957^{*}$ \\
\hline
\end{tabular}

* $p<0.05$ vs Susceptible 


\section{Inverse relation between maximal PSP and electrical remodeling}

Under baseline circumstances, there is no relation between electrophysiological parameters (QT-time, LV MAPD, RV MAPD or $\triangle M A P D$ ) and LV +dP/dtmax (figure 2; upper panel). Furthermore, challenging contractility by FF, PESP or PSP does not show a relation for maximal LV FFR, maximal LV PESP or maximal PSP in relation to any of the baseline electrophysiological parameters either. There is, however, a significant correlation when maximal LV PSP is related to challenged repolarization (dofetilide) (lower panel). Correlations are seen for maximal LV PSP and QT-time ( $r=-0.76 ; p=0.011)$, maximal LV PSP and LV MAPD ( $r=-0.76$; $p=0.007$; figure 2, lower panel), and maximal LV PSP and $\triangle M A P D(r=-0.68$; $p=0.022$ ). No significant relations are found for maximal LV PSP and RV MAPD, maximal LV FF or LV PESP and any of the electrophysiological parameters after dofetilide infusion.

Thus, CAVB dogs susceptible to dofetilide-induced TdP are characterized by lower maximal LV PSP and longer MAPD values after dofetilide, resulting in a clustering to the lower right in the challenged LV MAPD-maximal LV PSP graph (lower panel).

\section{Elimination of dofetilide-induced TdP by antidotes}

The infusion of dofetilide leads to an increase of LV +dP/dtmax during the IVR. The administration of verapamil, mibefradil or levcromakalim 10 minutes after the infusion of dofetilide in CAVB dogs susceptible to TdP, completely abolishes (verapamil and levcromakalim) or reduces (mibefradil: from $100 \%$ to $67 \%$ ) the incidence of TdP. This anti-arrhythmic effect is accompanied by a decrease in MAPD, homogenization of repolarization (decreased $\triangle M A P D$ ), and a reduction of $L V+d P / d t m a x$. After the administration of verapamil the cycle length was kept similar to dofetilide values by pacing, while the RR-time did not change after levcromakalim or mibefradil infusion.

\section{Discussion}

Contractile remodeling develops within 2 weeks after creation of complete AV block. In the CAVB dog, maximal LV PSP is negatively associated with electrical remodeling and susceptibility to dofetilide-induced TdP. Susceptible CAVB dogs, attain lower maximal inotropy and have longer repolarization times.

\section{Evolution of left ventricular contractile remodeling}

The CAVB dog model has been characterized extensively, especially $\sim 6$ weeks after creation of AV block when different aspects of ventricular remodeling have developed. ${ }^{13,810}$ At this time, there is compensation of bradycardia-induced volume overload as indicated by normalization of cardiac output at the slow IVR, which is associated with an increased LV and RV +dP/dtmax. During faster heart rates the $+\mathrm{dP} / \mathrm{dtmax}$ is lower, causing a negative FF relation. Still, when challenged by single extrastimuli upon a fast 
Figure 2: Inverse relation of maximal PSP and LV MAPD after dofetilide
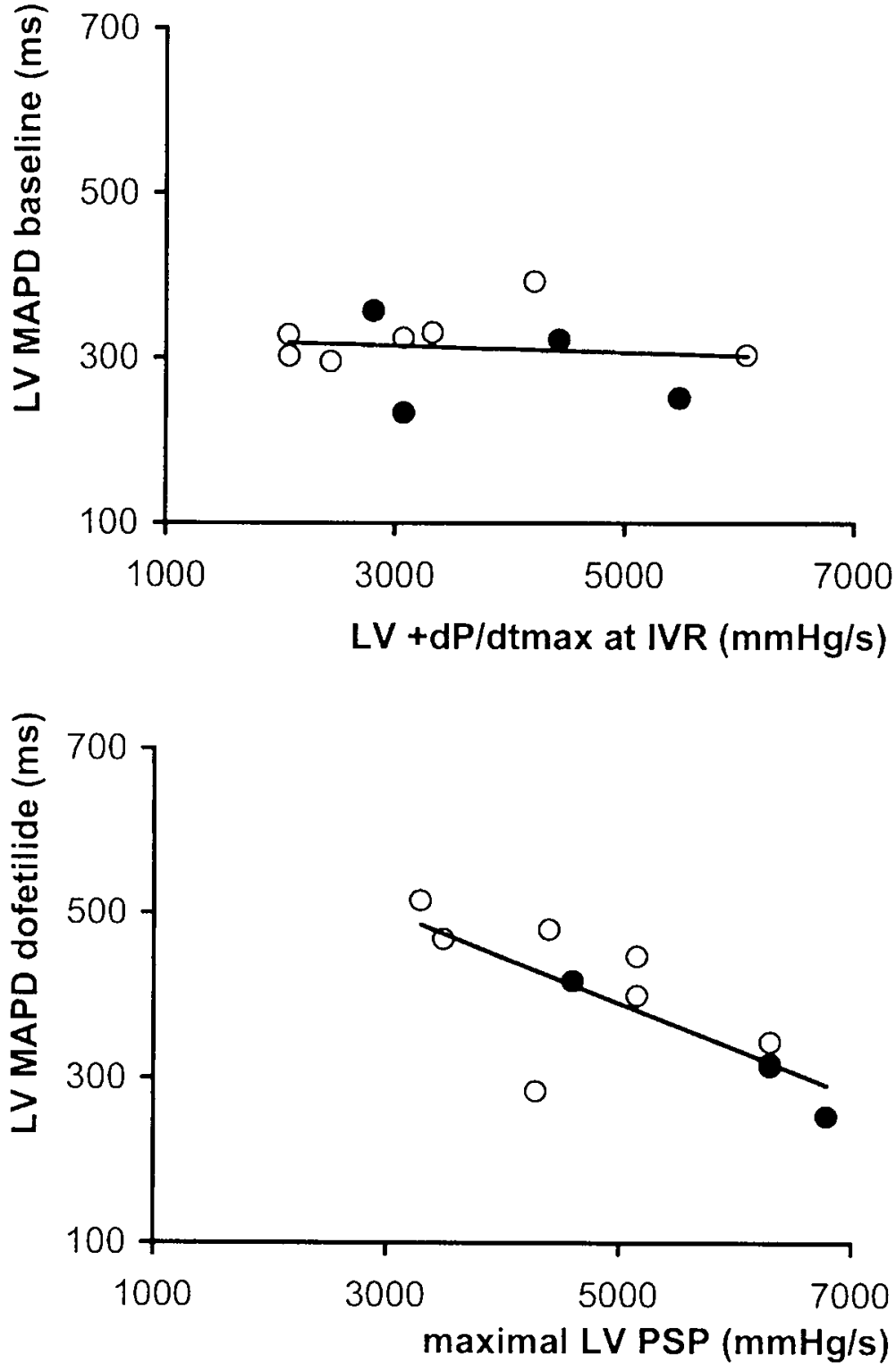

Correlation of LV MAPD ( $y$-axis) with $L V+d P / d t m a x$ during baseline (upper panel. $r=-0.13$ ) is absent in 11 dogs tested. When challenged LV MAPD (dofetilide) is expressed against maximal LV PSP (lower panel) a significant inverse correlation is seen ( $r=-0.76: p=0.007$ ). Characteristically. TdP resistant dogs (black dots: clustering on the lower right side) seem to have preserved PSP and shorter LV MAPD when compared to susceptibles (white dots). 
pacing rate (PESP) or fast short pacing trains during IVR (PSP) the inotropic response is (more than) adequate and reaches new absolute heights in $+\mathrm{dP} / \mathrm{dtmax}$.

In this study, we show that contractile remodeling, as quantified by $L V+d P / d t m a x$ at the IVR, FF, PESP, and PSP, was already present after 2 weeks CAVB. This temporal behavior parallels the evolution of electrical remodeling (heterogeneous prolongation of ventricular MAPD) and seems to be different from the structural adaptations resulting in biventricular hypertrophy, which follow a slower time path." Susceptibility to drug-induced TdP was also present at 2 weeks CAVB, which suggests that the arrhythmogenic predisposition might be dependent on ventricular electrophysiological and contractile changes.

\section{Linking left ventricular potentiation of contraction to susceptibility to torsade de pointes}

When CAVB dogs were subdivided in susceptible and resistant to dofetilide-induced $\mathrm{TdP}$, their individual response provided further insight into the relevance of contractile remodeling for arrhythmogenesis. For this purpose, the results of CAVB2 and 6 were combined. It was evident that the resistant dogs attained the higher maximal inotropic values when challenged by the PSP protocol (table 1). Neither during the IVR (baseline LV $+d P / d t m a x$ ), at steady state pacing (FF), nor PESP could these differences between the groups be shown.

\section{Inverse relation of left ventricular potentiation of contraction and left ventri- cular electrical remodeling}

Relating individual contractile and electrophysiological parameters showed no relation during baseline circumstances. The same was true for FF or PESP when related to the (maximally) challenged repolarization by dofetilide, an $I_{K r}$-blocker. However, a significant correlation was only present when LV contractility was pushed towards a maximum by PSP and related to QT-time, LV MAPD or $\triangle M A P D$ after dofetilide, linking a lower maximal PSP to longer LV repolarization times (and vice versa).

The restriction of this response to the LV suggests that this ventricle might well undergo the more dramatic changes, although this has to be said with caution since RV contractile performance was not measured in this study. However, when comparing the electrophysiological differences of the LV and RV at CAVB, a similar picture emerges for the repolarization reserve, which seems to have diminished more in the LV than in the RV.

\section{Contractile remodeling cause or bystander of susceptibility to torsade de pointes}

When determining the relevance of contractile remodeling for arrhythmogeneity, it is not clear how its contribution should be viewed. From the inverse relation bet- 
ween maximally attained inotropy and challenged left ventricular repolarization, one would expect that positive inotropic interventions should be anti-arrhythmic and negative inotropic interventions would favor arrhythmias. The opposite, however, seems to be true. First, in this study we have shown that dofetilide administration not only leads to lengthening of MAPD, but also to an increase in baseline inotropy $(L V+d P / d t \max )$. Secondly, in the present study elimination of dofetilide-induced $T d P$ by different antidotes provided evidence that the anti-arrhythmic effect was based upon MAPD shortening and negative inotropy (decreased LV +dP/dtmax during the IVR). Finally, we have previously shown that positive inotropic interventions are related to induction of (delayed) afterdepolarizations and triggered activity.' Therefore, it is tempting to speculate that the severity of electrical remodeling is the only determinant of the ability of dofetilide to cause TdP. On its turn, the severity of electrical remodeling could be based upon the magnitude of the LV contractile adaptations necessary to compensate for (sub)acute hemodynamic overload. The more contractile adjustments are necessary to survive following AV block, the more the lengthening of the LV action potential is required, resulting in a decrease of LV repolarization reserve, which predisposes the heart to arrhythmias when challenged by repolarization-prolonging drugs.

The enhancement of contractility, taking place in the first days to weeks after CAVB, likely involves increased intracellular (diastolic) calcium levels, which will activate molecular signalling resulting in transcriptional reprogramming. ${ }^{2}$ Interestingly, $\mathrm{Ca}^{2 \cdot}$ dependent transcription has been associated with the development of electrical remodeling and susceptibility to polymorphic ventricular tachyarrhythmias. ${ }^{17.18}$

\section{Limitations}

Since we did not measure intracellular $\left[\mathrm{Ca}^{2 *}\right]$, molecular parameters involved in intracellular $\left[\mathrm{Ca}^{2 *}\right]$ regulation, or $\mathrm{Ca}^{2 \cdot}$-dependent transduction pathways, we are unable to draw definite conclusions about the role of calcium and contractility in the development of electrical remodeling and susceptibility to (drug-induced) TdP.

\section{Conclusions}

In the CAVB dog, contractile remodeling, electrical remodeling, and susceptibility to dofetilde-induced TdP develop in parallel. In the CAVB dog, maximally attained inotropy is inversely related to left ventricular electrical remodeling and susceptibility to drug-induced torsade de pointes, showing that susceptible dogs have lower maximal contractile performance and longer repolarization times.

\section{Acknowledgements}

We greatly appreciate the assistance of $\mathrm{M}$. Thomsen during the experiments. Financial support by the Netherlands Heart Foundation (98.042) is gratefully acknowledged. 


\section{References}

1. De Groot SH, Schoenmakers M, Molenschot MM, Leunissen JD, Wellens HJ, Vos MA. Contractile adaptations preserving cardiac output predispose the hypertrophied canine heart to delayed afterdepolarization-dependent ventricular arrhythmias. Circulation. 2000;102:2145-2151.

2. Sussman MA, McCulloch A, Borg TK. Dance band on the Titanic: biomechanical signaling in cardiac hypertrophy. Circ Res. 2002;91:888-98.

3. Vos MA, de Groot SH, Verduyn SC, van der Zande J, Leunissen HD, Cleutjens JP, van Bilsen M, Daemen MJ, Schreuder JJ, Allessie MA, Wellens HJ. Enhanced susceptibility for acquired torsade de pointes arrhythmias in the dog with chronic, complete AV block is related to cardiac hypertrophy and electrical remodeling. Circulation. 1998;98:1125-35.

4. Schoenmakers M, Ramakers C, Van Opstal JM, Leunissen HD, Londono C, Vos MA. Asynchronous development of electrical remodeling and cardiac hypertrophy in the complete AV block dog. Cardiovasc Res. 2003;59:351-359.

5. Volders PG, Sipido KR, Vos MA, Kulcsar A, Verduyn SC, Wellens HJ. Cellular basis of biventricular hypertrophy and arrhythmogenesis in dogs with chronic complete atrioventricular block and acquired torsade de pointes. Circulation. 1998;98:1136-47.

6. Sipido KR, Volders PG, de Groot SH, Verdonck F, Van De Werf F, Wellens HJ, Vos MA. Enhanced $\mathrm{Ca}(2+)$ release and $\mathrm{Na} / \mathrm{Ca}$ exchange activity in hypertrophied canine ventricular myocytes : potential link between contractile adaptation and arrhythmogenesis. Circulation. 2000;102:2137-2144.

7. Vos MA, Verduyn SC, Gorgels AP, Lipcsei GC, Wellens HJ. Reproducible induction of early afterdepolarizations and torsade de pointes arrhythmias by d-sotalol and pacing in dogs with chronic atrioventricular block. Circulation. 1995;91:864-72.

8. Van Opstal JM, Verduyn SC, Leunissen HD, de Groot SH, Wellens HJ, Vos MA. Electrophysiological parameters indicative of sudden cardiac death in the dog with chronic complete AV-block. Cardiovasc Res. 2001;50:354-61.

9. Verduyn SC, Vos MA, van der Zande J, Kulcsar A, Wellens HJ. Further observations to elucidate the role of interventricular dispersion of repolarization and early afterdepolarizations in the genesis of acquired torsade de pointes arrhythmias: a comparison between almokalant and dsotalol using the dog as its own control. J Am Coll Cardiol. 1997;30:1575-84.

10. Van Opstal JM, Leunissen JD. Wellens HJ, Vos MA. Azimilide and dofetilide produce similar electrophysiological and proarrhythmic effects in a canine model of Torsade de Pointes arrhythmias. Eur J Pharmacol. 2001:412:67-76.

11. Thomsen MB, Verduyn SC, Stengl M, Van Opstal JM, Leunissen HD, De Pater G, Volders PG. Vos MA. Beat-to-beat variability is an independent and early indicator for d-Sotalol induced arrhythmias in vivo. (abstract) J Am Coll Cardiol. 2003;41:91A.

12. Van Opstal JM. Drug-induced Torsade de Pointes arrhythmias and sudden cardiac death in the remodeled canine heart. Thesis, Maastricht University, the Netherlands; 2003.

13. Vos MA, Verduyn SC, Wellens HJ. Early afterdepolarizations in the in situ canine heart: mechanistic insights into acquired torsade de pointes arrhythmias. Monophasic Action Potentials: Bridging Cell and Bedside. 2000:553-569. 


\section{Chapter 4}

14. Eckardi L, Haverkamp W, Borggrefe M, Breithardt G. Experimental models of torsade de pointes. Cardiovasc Res. 1998;39:178-93.

15. Volders PG, Sipido KR, Carmeliet E, Spatjens RL, Wellens HJ, Vos MA. Repolarizing K+ currents ITO1 and IKs are larger in right than left canine ventricular midmyocardium. Circulation. 1999:99:206-10.

16. Volders PG, Sipido KR, Vos MA. Spatjens RL, Leunissen JD, Carmeliet E. Wellens HJ. Downregulation of delayed rectifier $\mathrm{K}(+)$ currents in dogs with chronic complete atrioventricular block and acquired torsades de pointes. Circulation. 1999;100:2455-61.

17. Anderson ME. Connections Count : Excitation-Contraction Meets Excitation-Transcription Coupling. Circ Res. 2000:86:717-719

18. Wu Y, Temple J, Zhang R, Dzhura I, Zhang W, Trimble R, Roden DM, Passier R, Olson EN. Colbran RJ. Anderson ME. Calmodulin kinase II and arrhythmias in a mouse model of cardiac hypertrophy. Circulation. 2002;106:1288-93. 


\section{Chapter 5}

\section{Dose-dependent reduction of electrical remodeling and acquired torsade de pointes by carvedilol in the complete AV block dog}

Marieke Schoenmakers ", Jet D.M. Beekman "', Roel L.H.M.G. Spätjens ", Marc A. Vos "1"

"Department of Cardiology, Cardiovascular Research Institute Maastricht, Maastricht University, Maastricht, the Netherlands; "Department of Medical Physiology, University Medical Center Utrecht, Utrecht, the Netherlands

Manuscript submitted

Poster prize NVVC Autumn Congress 2003 


\begin{abstract}
Objective: The adrenergic system has been implicated in the regulation of repolarization and in arrhythmogenesis. The complete AV block (AVB) dog has a transitory elevated adrenergic state, enhanced susceptibility to (class III-induced) torsade de pointes (TdP), and sudden cardiac death. We hypothesized that chronic administration of the adrenoceptor blocker carvedilol (Carv) would prevent electrical remodeling (heterogeneous prolongation of ventricular APD) and TdP.
\end{abstract}

Methods and Results: At acute and 2 weeks chronic (C) AVB, 10 control dogs were compared to dogs receiving low dose $(1 \mathrm{mg} / \mathrm{kg} / \mathrm{BID})$ $(\mathrm{N}=4)$ or high dose $(10 \mathrm{mg} / \mathrm{kg} / \mathrm{BID})(\mathrm{N}=9)$ Carv orally starting 1 week prior to acute AVB. Under anesthesia, endocardial monophasic APD of both ventricles, and left ventricular hemodynamics were serially measured. Susceptibility to acquired $T d P$ was determined by dofetilide $\left(0.025 \mathrm{mg} / \mathrm{kg} / 5^{\prime}\right.$ I.V.) at CAVB. At CAVB, high dose Carv significantly attenuates prolongation of left ventricular APD, while it does not affect right ventricular APD, leading to complete prevention of the increase in spatial dispersion. Low dose Carv has no effect on electrical remodeling. Furthermore, high dose Carv reduces the susceptibility to dofetilide-induced TdP by approximately $50 \%$ as compared to low dose and control. At this time, contractile remodeling, as defined by the increase in left ventricular $+\mathrm{dP} / \mathrm{dtmax}$ during baseline and dynamic circumstances, is present in all groups.

Conclusions: In the CAVB dog, high dose carvedilol attenuates electrical remodeling and reduces susceptibility to drug-induced $T d P$, while contractile remodeling is unaffected. In this model, the adrenergic system contributes significantly to development of electrical remodeling and arrhythmogenesis. 


\section{Introduction}

Beta-blockers are known to prevent sudden cardiac death in patients suffering from cardiac diseases associated with prolongation of repolarization, such as congestive heart failure and the congenital long QT-syndrome. ${ }^{1 \cdot 3}$ In specific forms of the long QT-syndrome there is a direct link between the increased sympathetic state of the patient and the occurrence of torsade de pointes-arrhythmias (TdP). ${ }^{2}$ In several experimental models the role of the sympathetic nervous system in the genesis of (lethal) ventricular arrhythmias has been well established.: ${ }^{: 6}$ Moreover, $\beta$-adrenergic stimulation has been implicated in the modulation of cardiac ion currents and, hence, the regulation of action potential duration and excitation-contraction coupling. ${ }^{7.10}$

An animal model in which the increased adrenergic state may well be at the basis of electrical remodeling is the chronic complete AV block (CAVB) dog. Norepinephrine plasma levels and atrial rate are increased from the creation of $A V$ block up to several weeks thereafter. ${ }^{112}$ After 2 weeks of CAVB, ventricular repolarization is prolonged and spatial dispersion of repolarization has increased (electrical remodeling), which is associated with an increased susceptibility to drug-induced TdP. ${ }^{12}$ We hypothesized that chronic administration of carvedilol, a non-selective $\beta$-adrenergic blocker and 10 -fold weaker $\alpha 1$-antagonist ${ }^{13, * *}$, would prevent electrical remodeling and subsequently decrease susceptibility to dofetilide-induced $T d P$ in the CAVB dog.

\section{Methods \\ General}

Twenty-three mongrel dogs (body weight $26 \pm 3 \mathrm{~kg}, 14$ females) were included in the study. Carvedilol (Carv) (Roche Diagnostics, Germany) administration was started during normally conducted sinus rhythm 1 week before creation of complete $A V$ block in a high dose $(\mathrm{H})(10 \mathrm{mg} / \mathrm{kg} / \mathrm{BID})$ to 9 dogs and in a low dose $(\mathrm{L})$ ( $1 \mathrm{mg} / \mathrm{kg} / \mathrm{BID}$ ) to 4 dogs. Oral administration of Carv lasted until sacrifice at 2 weeks chronic complete AV block (CAVB), which amounted to a total of 3 weeks. Serial measurements were performed during premedication (ECG recordings at sinus rhythm before and 1 week after Carv administration) and under complete anesthesia at sinus rhythm, acute AV-block (AAVB) and 2 weeks CAVB. Animal handling was in accordance with the 'European Directive for the Protection of Vertebrate Animals used for Experimental and other Scientific Purposes (European Community Directive \#86/609/CEE)'. The 'Committee for Experiments on Animals (DEC)' of Maastricht University, the Netherlands approved the experiments.

\section{Rate control in high dose carvedilol group}

Severe bradycardia and syncopes were observed in the week following creation of 
AV block in the first 3 dogs belonging to the Carv $\mathrm{H}$ group. One dog died due to congestive heart failure. Therefore, we decided to control heart rate in the other 6 . During complete anesthesia at sinus rhythm an endocardial lead (StimTine, Vitatron Netherlands) was positioned via the external jugular vein in the apex of the right ventricle (RV), and was guided subcutaneously towards the neck where a pacemaker was implanted. The pacemaker was programmed at VVI $50(1200 \mathrm{~ms}$ interval), which was based on the mean RR-time at CAVB in a recent publication. "' The pacemaker was activated 1 week later, just after measurements at AAVB. We lost 1 dog due to ventricular fibrillation during an attempt to reposition the pacing lead after 1 week complete AV block, and another due to acute pump failure following creation of AV block. In the remaining 4 dogs that had a pacemaker, $95 \%$ of the ventricular activations in the first week following AV block originated from the pacemaker, while in the second week the majority was the result of intrinsic ventricular pacemaker activity (idioventricular rate), with the exception of 1 dog in which the paced rhythm remained dominant.

\section{Experimental design}

After overnight fasting, administration of premedication " was followed by induction of complete anesthesia by sodium pentobarbital ( $20 \mathrm{mg} / \mathrm{kg}$ IV). The dogs were artificially ventilated (Dräger, Pulmonat, Lubeck, Germany) through a cuffed endotracheal tube at a respiratory rate of $12-14 / \mathrm{min}$ using a mixture of oxygen, nitrous oxide $(40 / 60 \%)$ and halothane (vapor concentration $0.5 \%-1 \%$ ). Tidal volume was adjusted $(10-25 \mathrm{ml} / \mathrm{kg})$ to maintain end-expired carbon dioxide concentration between $3.5-4 \%$. A thermal mattress was used to maintain adequate body temperature. During the experiments, dogs received $0.5-1 \mathrm{~L}$ $0.9 \% \mathrm{NaCl}$ through a peripheral vein to prevent volume depletion. Experiments were carried out under aseptic conditions, and antibiotics (1000 mg ampicillin) were administered before and after the experiments. Complete AV block was induced through radiofrequency ablation as described previously. ${ }^{2}$ Electrophysiological signals consisted of 6 surface ECG lead recordings and 2 monophasic action potential registrations (MAP, EP Technologies Inc.) during the idioventricular rate (IVR). Under fluoroscopic guidance MAPS were placed at the endocardium in the apex of the left ventricle (LV) and RV. Electrophysiological signals were amplified with a customized isolated DC-coupled differential amplifier at a frequency range of $0-500 \mathrm{~Hz}$ with a $20 \mathrm{mV}$ calibration pulse. The offset of the amplifier was variable and could be adjusted to the recorded signal. MAP phases were defined according to the definitions used for transmembrane potentials, where amplitude was defined as the voltage difference between phase 2 and 4 of the MAP signal. ${ }^{.5}$ Apart from a minimal amplitude of $15 \mathrm{mV}$, the MAP had to have a stable configuration and a smooth shape to be acceptable for measurements. Pressures of the LV were recorded 
by a single micromanometer transducer catheter (Sentron Europe inc) during IVR and postextrasystolic potentiation (PESP). The PESP protocol consisted of a steady state paced rhythm with cycle length of $600 \mathrm{~ms}$, which was interrupted every $20^{\text {"1' }}$ beat by an extrastimulus with decreasing coupling intervals from 550 to $250 \mathrm{~ms}$." Prior to insertion pressure sensors were emerged in a $37{ }^{\circ} \mathrm{C} 0.9 \%$ $\mathrm{NaCl}$ solution to minimize temperature drift. The Sentron interface was used to calibrate the pressure transducer. Electrophysiological and LV pressure signals were recorded simultaneously, stored on hard disk and sampled at a rate of 1 $\mathrm{kHz}$. Susceptibility to TdP was determined before and after the administration of dofetilide $\left(0.025 \mathrm{mg} / \mathrm{kg} / 5^{\prime}\right.$ ' I.V.). ${ }^{\text {i: }}$

\section{Data analysis and definitions}

By use of a software program (ECG View), the following data were measured offline: PP-time, RR-time, QRS-duration, and JT-time in lead II, duration of the MAP (MAPD) at $100 \%$ repolarization, LV peak systolic pressure (SP), LV enddiastolic pressure (EDP), and LV peak rate of pressure rise (+dP/dtmax). Spatial dispersion ( $\triangle M A P D$ ) was defined as the difference between LV MAPD and RV MAPD. Data presented are the mean of 5 consecutive beats, with the exception of PESP. "id TdP was defined as a polymorphic ventricular tachycardia with a cycle length of $\leq 300 \mathrm{~ms}$ and consisting of at least 5 beats characterized by an onset with abnormal QT prolongation and/or abnormal TU complexes, a progressively changing ventricular axis, and spontaneous termination with the exception of rare degeneration into ventricular fibrillation. "When TdP degenerated into ventricular fibrillation cardioversion was applied through patches on the thorax, which had been placed in advance. TdP were scored during baseline circumstances, and for 15 minutes from the start of dofetilide infusion. If TdP were seen $\geq 3$ times, the dog was considered susceptible. Duration of each TdP was measured.

\section{Statistics}

Data are presented as mean $\pm S D$. Statistical tests between groups included 2tailed Student's $t$ test for unpaired events, ordinary ANOVA with a post-hoc Bonferroni $t$ test, Kruskal-Wallis nonparametric ANOVA with Dunn's multiple comparison's test (for duration of $\mathrm{TdP}$, due to absence of Gaussian distribution), and $\chi^{2}$-test. Values of $P \leq 0.05$ were considered significant.

\section{Results}

\section{Blockade of the adrenergic system by carvedilol}

Several observations indicate that carvedilol, independent of dose, inhibits the adrenergic system in this study. One week carvedilol administration during sinus rhythm decreases heart rate from $117 \pm 24 \mathrm{~min}^{-1}$ to $82 \pm 13 \mathrm{~min}^{-1}$ in the Carv $\mathrm{L}$ 
group, and from $120 \pm 43 \mathrm{~min}^{-1}$ to $70 \pm 11 \mathrm{~min}^{-1}$ in the Carv $\mathrm{H}$ group. Acutely after creation of complete AV block, the atrial rate increases with $73 \%$ in the control dogs, while this reaction is attenuated in Carv treated animals: $57 \%$ for Carv $\mathrm{L}$ and $51 \%$ for Carv $\mathrm{H}$. At this time, deceleration of the ventricular rate is normally in the range of $-20 \%$ (figure 1 , left panel). With carvedilol, this reduction is much more pronounced $(-37 \%$ for Carv $L$ and $-34 \%$ for Carv $H$ ), and reaches significance when low and high dose groups are combined. Secondly, the increase in $L V+d P / d$ tmax seen in the control group (45\%: figure 1, right panel) is absent in the Carv groups: $-12 \%$ for Carv $L$ and $-2 \%$ for Carv $H(p<0.05)$.

Figure 1: Blockade of the adrenergic system at acute AV block by carvedilol independent of dose

\section{Ventricular rate}

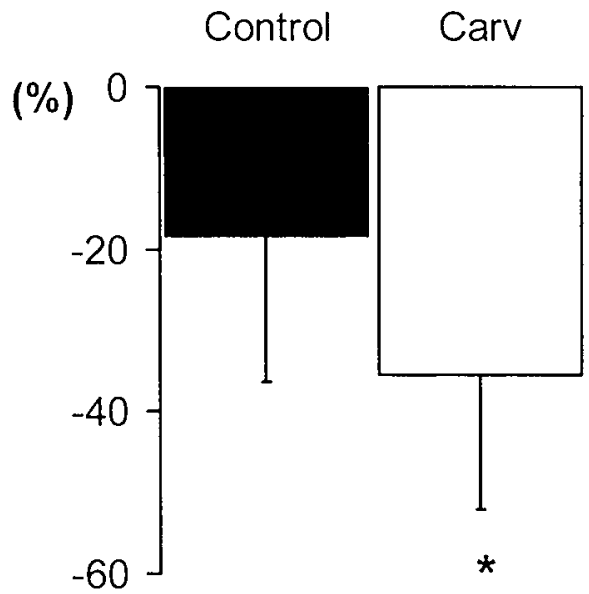

\section{$\mathrm{LV}+\mathrm{dP} / \mathrm{dtmax}$}

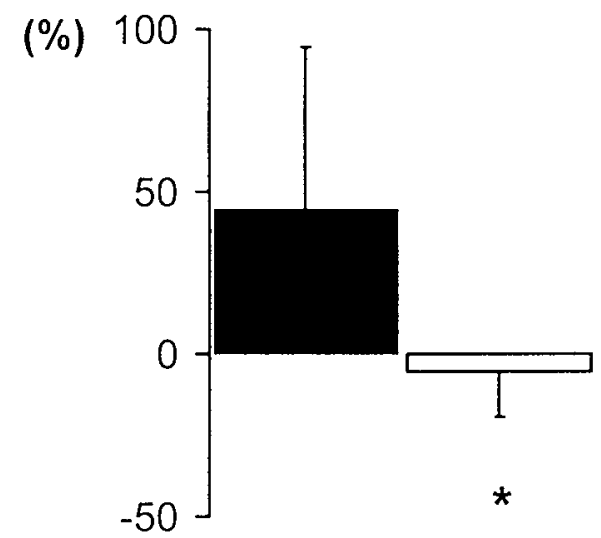

Relative change ( $y$-axis) of ventricular rate (left panel) and LV +dP/dtmax (right panel) from sinus rhythm to acute AV block for control, and Carv $L$ and $H$ combined ( $x$-axis). (" $p<0.05$ versus control)

Creation of AV block results in a ventricular rate decrease, which is most pronounced for the carvedilol treated animals. The increase in LV +dPldtmax is absent in the carvedilol groups. suggesting less compensation to bradycardia-induced volume overload.

\section{Dose-dependent attenuation of electrical remodeling by carvedilol}

All measurements are performed during the idioventricular rate, which is comparable between between the groups: RR-time is $815 \pm 134 \mathrm{~ms}$ for control AAVB, $1089 \pm 383 \mathrm{~ms}$ for control CAVB, $1067 \pm 174 \mathrm{~ms}$ for Carv L CAVB, and $1052 \pm 105 \mathrm{~ms}$ 
for Carv H CAVB. Moreover, the QRS-duration is not significantly different: $75 \pm 23$ $\mathrm{ms}$ for control AAVB, $95 \pm 22 \mathrm{~ms}$ for control CAVB, $120 \pm 52$ for Carv L CAVB, and $94 \pm 17 \mathrm{~ms}$ for Carv H CAVB. High dose carvedilol (Carv H) attenuates ventricular electrical remodeling at CAVB as shown in figure 2. The increase in JT-time (upper left panel) is significantly attenuated by Carv $\mathrm{H}$. Also the increase in LV MAPD (upper right) is significantly attenuated, while the increase in RV MAPD (lower left) seems to be reduced but not significantly. The pronounced increase in spatial disersion ( $\triangle M A P D$; lower right) after creation of AV block is completely prevented by Carv $H$. Carv $L$, however, has no effect on electrical remodeling.

Figure 2: Attenuation of electrical remodeling by high dose carvedilol
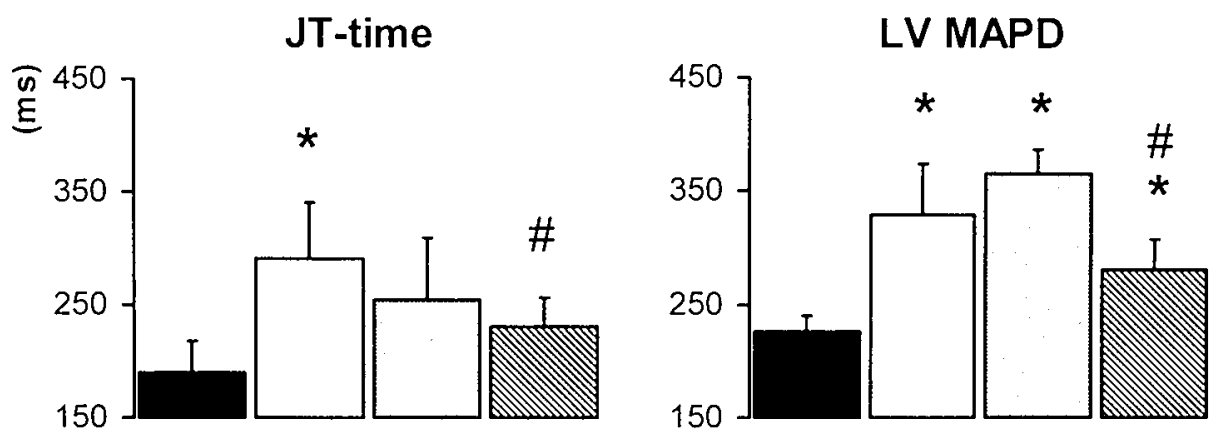

RV MAPD
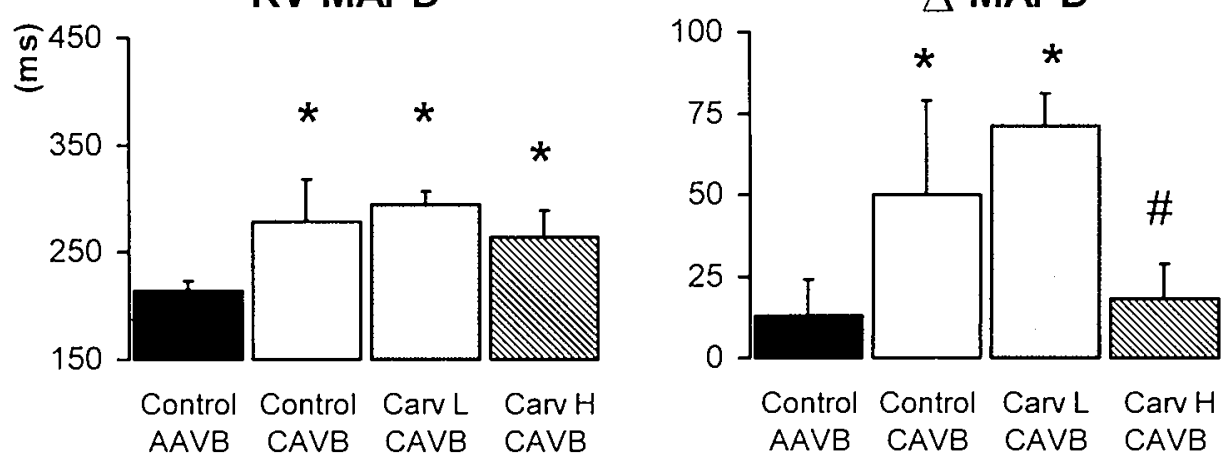

JT-time (upper left panel), LV MAPD (upper right), RV MAPD (lower left), and $\triangle M A P D$ (lower right) ( $y$-axis) of unremodeled (control AAVB), remodeled (control CAVB), Carv L, and Carv $H$ treated groups ( $x$-axis). (" $p<0.05$ versus control AAVB; $\#<0.05$ versus control CAVB and CarV L CAVB)

Carv H significantly attenuated JT-time and LVMAPD, while RV MAPD on the other hand is not significantly affected. Furthermore, the increase in spatial dispersion is completely prevented by Carv H. Carv L. however, does not have any effect on electrical remodeling. 


\section{Reduction of susceptibility to torsade de pointes by high dose carvedilol}

High dose carvedilol reduces the susceptibility to TdP. Under baseline circumstances at CAVB, spontaneous reproducible TdP are seen in 1 out of 10 control dogs and 1 out of 4 Carv L dogs, while absent in the Carv $\mathrm{H}$ group. Furthermore, Carv $\mathrm{H}$ reduces the susceptibility to dofetilide-induced $\mathrm{TdP}$ by approximately $50 \%$ as compared to control and Carv L dogs (figure 3). Also, the severity of TdP is affected by Carv $H$, since there are less long $T d P$ as compared to control or Carv L groups. In the Carv $\mathrm{H}$ group the minimum duration of $T d P$ is $1.4 \mathrm{~s}$, the maximum duration is $11.5 \mathrm{~s}$ with a median of $2.6 \mathrm{~s}$, which is significantly different from the control (minimum: $1.4 \mathrm{~s}$; maximum: $19.6 \mathrm{~s}$ with a median of $3.5 \mathrm{~s}$ ) and Carv L groups (minimum: $1.7 \mathrm{~s}$; maximum: $14.9 \mathrm{~s}$ with a median of $3.4 \mathrm{~s})(\mathrm{p}<0.05)$.

Figure 3: Reduction of susceptibility to acquired TdP by high dose carvedilol

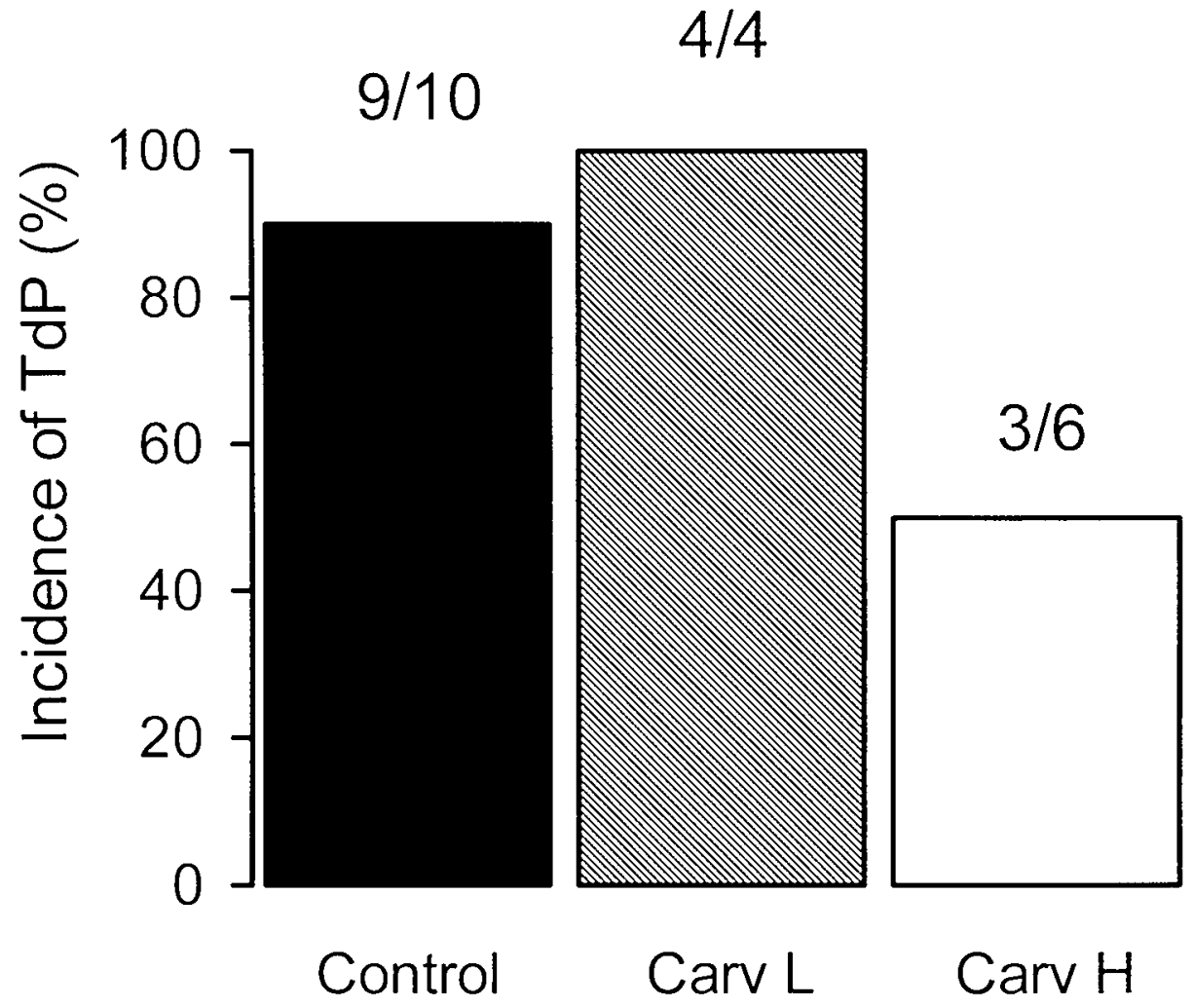

Incidence of TdP ( $y$-axis) of CAVB control. Carv L, and Carv H groups.

Susceptibility of Carv H (50\%) is reduced as compared to control $(90 \%)$ and Carv L $(100 \%)$. ( $p=0.082)$ 


\section{No prevention of contractile remodeling by carvedilol}

To our surprise, contractile remodeling at CAVB is not affected by carvedilol (table 1). The increase in baseline contractility ( $L V+d P / d t m a x)$ from AAVB to CAVB is comparable between the groups: control $51 \pm 66 \%$, Carv $L 66 \pm 23 \%$, and Carv $H$ $51 \pm 26 \%$. This is associated with a decrease in LV EDP: $-11 \pm 25 \%$ for control, $-13 \pm 32 \%$ for Carv $L$, and $-5 \pm 46 \%$ for Carv $H$, which suggests a compensatory response. LV SP remains stable in all groups. Furthermore, PESP has increased at CAVB and is similar in all groups, as illustrated for control and Carv $\mathrm{H}$ in figure 4.

Figure 4: No effect of high dose carvedilol on contractile remodeling
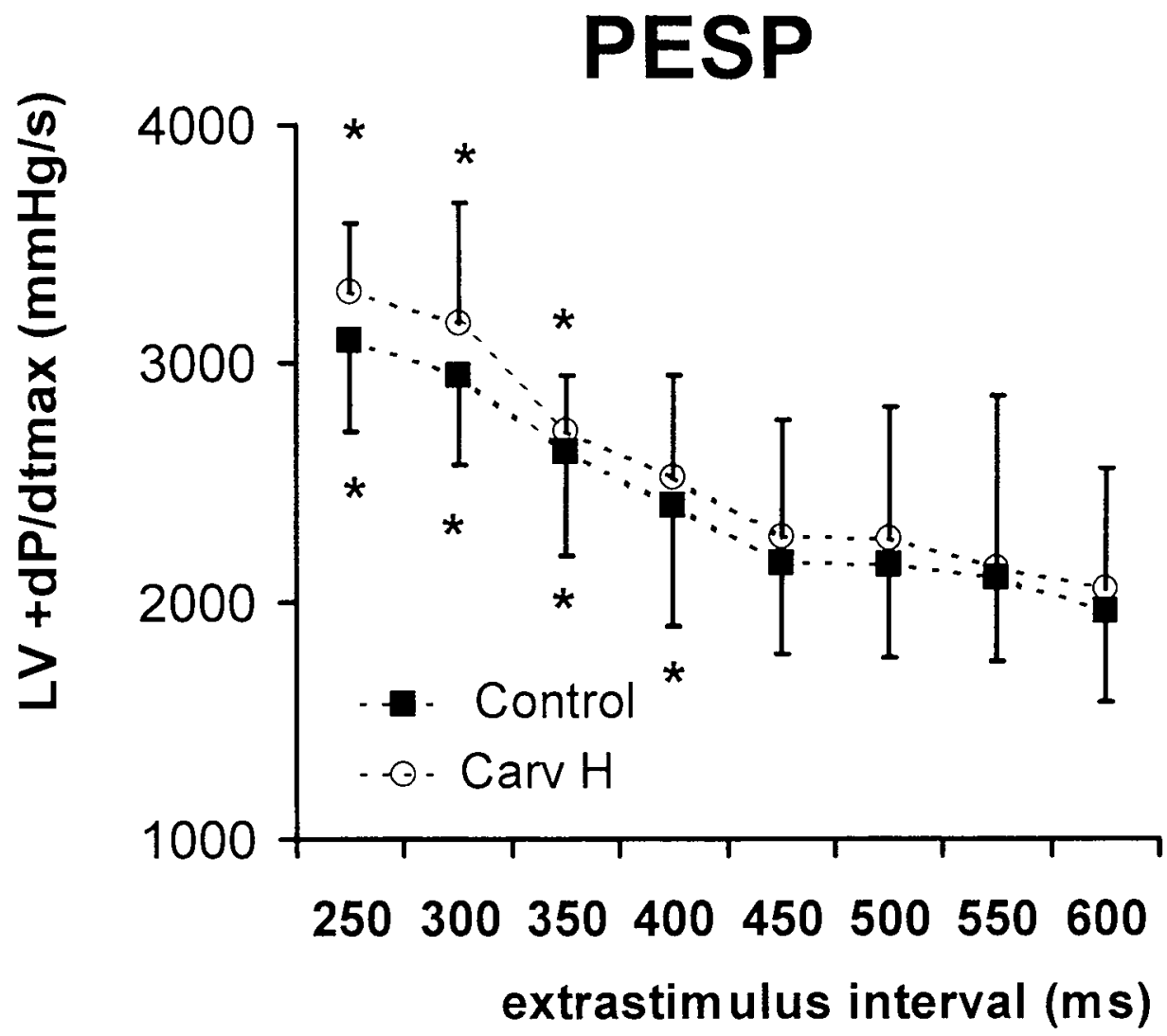

Postextrastimulus potentiation (PESP) at CAVB for control (black squares) and Carv $H$ (white circles). The left ventricular PESP response ( $L V+d P l d t m a x ; y$-axis) is shown when the coupling interval of the extrastimulus is decreased from 600 (steady state) to $250 \mathrm{~ms}$ ( $x$-axis). (* $p<0.05$ versus $600 \mathrm{~ms}$ )

PESP for control and Carv $H$ are similar. 


\begin{tabular}{llll} 
Idioventricular rate & Control & Carv L & Carv H \\
\hline LV $+\mathrm{dP} / \mathrm{dtmax}, \mathrm{mmHg} / \mathrm{s}$ & $2717 \pm 792$ & $2699 \pm 437$ & $2584 \pm 303$ \\
LV EDP, $\mathrm{mmHg}$ & $9 \pm 2$ & $13 \pm 3$ & $11 \pm 3$ \\
LV SP, $\mathrm{mmHg}$ & $107 \pm 14$ & $108 \pm 15$ & $107 \pm 10$ \\
\hline
\end{tabular}

\section{Discussion}

The non-selective adrenergic blocker carvedilol effectively inhibits the adrenergic system in the CAVB dog, independent of dose. High dose carvedilol attenuates the increase in repolarization times (JT-time and LV MAPD) and prevents the increase in spatial dispersion of repolarization, which is associated with a reduced susceptibility to dofetilide-induced TdP. Contractile remodeling, however, is not affected by carvedilol.

\section{Relevance of the b-adrenergic system for compensation of acute hemodyna- mic overload}

Creation of complete AV block in the dog leads to activation of the sympathetic nervous system, as indicated by a rise of norepinephrine in the blood plasma and an increased atrial rate. ${ }^{112}$ In this study, adrenergic blockade resulted in a more pronounced bradycardia after creation of AV block, and the inhibition of the acute inotropic response to volume overload. Moreover, in the first week following acute AV block chronic administration of high dose carvedilol led to severe signs of pump failure, for which rate control was necessary. Therefore, we confirm that the adrenergic system is activated at acute AV block. Furthermore, we demonstrate that carvedilol was able to inhibit the adrenergic system, independent of dose.

Carvedilol is a potent $\beta_{1}$ and $\beta_{2}$-adrenoceptor antagonist, and a 10 -fold weaker $\alpha_{1}$ adrenoceptor inhibitor. ${ }^{13.14}$ If $\beta$-blockade in the low dose Carv group is sufficient, the additional adrenergic effects only emerge in the high dose group. This emphasizes the specific role of the $\beta$-adrenergic system in compensation of hemodynamic overload in the CAVB dog.

\section{Differential response of electrical and contractile remodeling after carvedilol administration}

Contractile remodeling is characterized by an increased left and right ventricular contractile function as measured in vivo and in vitro, which is most pronounced at the slow heart rates. ${ }^{16.18}$ These contractile alterations are associated with functional compensation as indicated by the normalization of cardiac output. ${ }^{16}$ 
Contractile remodeling is already present 2 weeks after creation of AV block, which parallels the temporal behavior of electrical remodeling. ${ }^{12}$ Electrical remodeling has been defined as the heterogeneous prolongation of ventricular (M)APD, which results in spatial dispersion of repolarization. 11.199 These changes are associated with the occurrence of afterdepolarizations, (epinephrine-induced) triggered ectopic beats, and increased susceptibility to (drug-induced) torsade de pointes-arrhyth mias. "1.12.2\% Sudden cardiac death, which has an incidence of $10-15 \%$ in the model, is related to the appearance of polymorphic ventricular tachycardias and tends to occur during excitement. " Contractile remodeling, electrical remodeling, and susceptibility to $\mathrm{TdP}$ are not dependent on the presence of biventricular hypertrophy since this has only developed fully after 5 weeks of CAVB. "

In the present study, there was a significant attenuation of electrical remodeling in the left ventricle and normalization of spatial dispersion of repolarization after 2 weeks CAVB in the Carv $\mathrm{H}$ group. Moreover, the susceptibility to dofetilide-induced $\mathrm{TdP}$ was reduced by approximately $50 \%$. This dose-dependency of carvedilol suggested, besides a role for the $\beta$-adrenergic system, also an important role for the $\iota$-adrenergic system in the transduction pathway(s) leading to electrical remodeling and ventricular arrhythmogenesis.

To our surprise, there was no effect of Carv $\mathrm{H}$ on contractile remodeling, since the increase of baseline LV $+\mathrm{dP} / \mathrm{dtmax}$ and PESP and the associated decrease in LV EDP were similar to CAVB control. This differential response of electrical and contractile remodeling to chronic administration of carvedilol suggests different signailing pathway(s).

\section{Role of the adrenergic system in ventricular electrical remodeling and arrhythmogenesis}

To the best of our knowledge, this is the first study to describe the attenuation of electrical remodeling by chronic oral administration of an adrenoceptor blocker in an in vivo dog model. There are, however, more models in which the occurrence of electrical remodeling, ventricular tachycardias, and even sudden death is attributed to the sympathetic nervous system. In a colony of german shepherd dogs with inherited spontaneous arrhythmic death, and in a dog model of sudden cardiac death after healed myocardial infarction, ventricular tachycardias could be evoked by $\alpha$-adrenergic or $\beta$-adrenergic stimulation. ${ }^{622.24}$ Acute administration of adrenoceptor blockers resulted in the prevention of electrophysiological changes in both models. Furthermore, susceptibility to ventricular arrhythmias has been associated with alterations in ventricular sympathetic innervation. ${ }^{6.25}$

The prolongation of ventricular APD in the CAVB dog has been related to a decrease in $I_{k_{r}}$ and $I_{k_{s}}$, and an increased forward and reverse mode of the $\mathrm{Na}^{\circ} \mathrm{Ca}^{2 *}$ exchanger. $^{18.26}$ Furthermore, the decrease in $I_{k s}$ has been associated with downregulation of KVLQT1 and MinK expression. ${ }^{27}$ In functional and structural 
alterations of ion currents the adrenergic system has been implicated, although focus has mostly been on (3-adrenergic effects. Both acute modulation and chronic downregulation of $I_{\mathrm{KS}}$ have been associated with $\beta$-adrenergic stimulation. ${ }^{8.9}$ In this, a mechanistic link between $\beta$-adrenergic signalling and regulation of KVLQT 1 has been demonstrated.' Moreover, (i-adrenergic activation has been associated with enhanced forward and reverse mode of the $\mathrm{Na}^{\circ} \mathrm{Ca}^{2 *}$-exchanger. "In this respect, the reduction of electrical remodeling by high dose carvedilol in the CAVB dog, might well have been executed through attenuation of ionic remodeling of specific currents.

\section{Clinical relevance}

Adrenoceptor blockers have proven beneficial in reducing total mortality, including sudden cardiac death, in patients. ${ }^{1.3}$ In a recent trial, carvedilol was reported to extend survival of congestive heart failure patients even further than the selective $\beta_{1}$-adrenoceptor inhibitor metoprolol, which might be attributed to additional effects. ${ }^{13.28}$ In heart failure, ventricular arrhythmias have mostly been related to reentry, while the role of triggered activity seems to be more modest. In this experimental study only high dose carvedilol reduced electrical remodeling and arrhythmogeneity in a model of afterdepolarization-related ventricular tachyarrhythmias, while contractile remodeling was unaffected by either dose. The high dose of carvedilol used in this study corresponds with a $>10$ times higher dose than the human dose. This stresses the importance of more comprehensive adrenergic blockade in specific patients by e.g. an increase of the dose of carvedilol.

\section{Limitations}

We cannot rule out that pacing had an effect in the Carv $\mathrm{H}$ group. Not only will VVI pacing protect the dog for slow heart rates, electrical stimulation also changes the activation pattern. It is known, however, that especialiy in the first weeks after CAVB the idioventricular focus will frequently shift. Secondly, in this study there were no differences in repolarization times or in susceptibility to torsade de pointes between paced and non-paced Carv $\mathrm{H}$ dogs.

\section{Conclusions}

In the CAVB dog, high dose carvedilol attenuates electrical remodeling and reduces susceptibility to drug-induced $\mathrm{TdP}$, while contractile remodeling is unaffected. This suggests that in the canine model of CAVB, the adrenergic system contributes significantly to development of electrical remodeling and arrhythmogenesis.

\section{Acknowledgements}

We thank Prof.Dr. G. Sponer (Roche Diagnostics, Germany) for technical advice and kindly providing carvedilol. For the availability of the pacemakers we express 
our gratitude to L. Kretzers (Medtronic Bakken Research Center, Maastricht, the Netherlands). We wish to thank our colleagues Dr. J. van Opstal, D. Donker, M. Thomsen, J. Jungschleger, and M. Truin for technical assistance, and Dr. M. Stengl for helpful comments on the manuscript. Financial support by the Netherlands Heart Foundation (98.042) is gratefully acknowledged. 


\section{References}

1. Effect of metoprolol $\mathrm{CR} / \mathrm{XL}$ in chronic heart failure: Metoprolol CR/XL Randomised Intervention Trial in Congestive Heart Failure (MERIT-HF). Lancet. 1999;353:2001-7.

2. Schwartz PJ, Priori SG, Spazzolini C, Moss AJ, Vincent GM, Napolitano C, Denjoy I, Guicheney P. Breithardt G, Keating MT, Towbin JA, Beggs AH, Brink P, Wilde AA, Toivonen L, Zareba $W$, Robinson JL. Timothy $\mathrm{KW}$, Corfield $\mathrm{V}$, Wattanasirichaigoon D, Corbett $\mathrm{C}$, Haverkamp W. Schulze-Bahr E, Lehmann MH, Schwartz K, Coumel P, Bloise R. GenotypePhenotype Correlation in the Long-QT Syndrome: Gene-Specific Triggers for Life-Threatening Arrhythmias. Circulation. 2001:103:89-95.

3. Packer M. Bristow MR, Cohn JN, Colucci WS, Fowler MB, Gilbert EM. Shusterman NH. The effect of carvedilol on morbidity and mortality in patients with chronic heart failure. U.S. Carvedilol Heart Failure Study Group. N Engl J Med. 1996;334:1349-55.

4. Chen P, Chen LS, Cao J, Sharifi B, Karagueuzian HS. Fishbein MC. Sympathetic nerve sprouting, electrical remodeling and the mechanisms of sudden cardiac death. Cardiovasc Res. 2001:50:409-16.

5. Schwartz PJ, Billman GE, Stone HL. Autonomic mechanisms in ventricular fibrillation induced by myocardial ischemia during exercise in dogs with healed myocardial infarction. An experimental preparation for sudden cardiac death. Circulation. 1984:69:790-800.

6. Moise NS, Gilmour RF, Jr., Riccio ML. An animal model of spontaneous arrhythmic death. J Cardiovasc Electrophysiol. 1997;8:98-103.

7. Marx SO, Kurokawa J, Reiken S, Motoike H, D'Armiento J, Marks AR, Kass RS. Requirement of a macromolecular signaling complex for beta adrenergic receptor modulation of the KCNQ1KCNE1 potassium channel. Science. 2002;295:496-9.

8. Zhang LM, Wang $Z$, Nattel S. Effects of sustained beta-adrenergic stimulation on ionic currents of cultured adult guinea pig cardiomyocytes. Am J Physiol Heart Circ Physiol. 2002;282:H880-9.

9. Volders PG, Stengl M, Van Opstal JM, Gerlach U, Spatjens RL, Beekman JDM, Sipido KR, Vos MA. Probing the contribution of $\mathrm{I}(\mathrm{KS})$ to canine ventricular repolarization; Key role for betaardrenergic receptor stimulation. Circulation. 2003;107:2753-2760.

10. Wei S, Ruknudin A, Hanlon SU, McCurley JM, Schulze DH, Haigney MCP. Protein kinase A hyperphosphorylation increases basal current but decreases bela-adrenergic responsiveness of the sarcolemmal $\mathrm{Na}(+)-\mathrm{Ca}(2+)$ exchanger in failing pig myocytes. Circ Res. 2003:92:897-903.

11. Vos MA, de Groot SH, Verduyn SC, van der Zande J, Leunissen HD, Cleutjens JP, van Bilsen M, Daemen MJ, Schreuder JJ, Allessie MA, Wellens HJ. Enhanced susceptibility for acquired torsade de pointes arrhythmias in the dog with chronic, complete AV block is related to cardiac hypertrophy and electrical remodeling. Circulation. 1998;98:1125-35.

12. Schoenmakers M, Ramakers C, Van Opstal JM, Leunissen HD, Londono C, Vos MA. Asynchronous development of electrical remodeling and cardiac hypertrophy in the complete AV block dog. Cardiovasc Res. 2003;59:351-359.

13. Ruffolo RR, Jr., Gellai M. Hieble JP, Willette RN, Nichols AJ. The pharmacology of carvedilol. Eur J Clin Pharmacol. 1990;38:S82-8. 
14. Qvigstad E, Osnes J-B, Sandnes D. Schiander I, Bøkenes J, Sjaastad I, Skomedal T. Carvedilol blockade of rat myocardial alpha1-adrenoceptors. Eur J Pharmacol. 2003:481:83-89.

15. Vos MA, Verduyn SC, Wellens HJ. Early afterdepolarizations in the in situ canine heart: mechanistic insights into acquired torsade de pointes arrhythmias. Monophasic Action Potentials: Bridging Cell and Bedside. 2000:553-569.

16. De Groot SH, Schoenmakers M, Molenschot MM, Leunissen JD, Wellens HJ, Vos MA. Contractile adaptations preserving cardiac output predispose the hypertrophied canine heart to delayed afterdepolarization-dependent ventricular arrhythmias. Circulation. 2000;102:2145-2151.

17. Eckardt L, Haverkamp W, Borggrefe M, Breithardt G. Experimental models of torsade de pointes. Cardiovasc Res. 1998;39:178-93.

18. Sipido KR, Volders PG, de Groot SH, Verdonck F, Van De Werf F, Wellens HJ, Vos MA. Enhanced $\mathrm{Ca}(2+)$ release and $\mathrm{Na} / \mathrm{Ca}$ exchange activity in hypertrophied canine ventricular myocytes : potential link between contractile adaptation and arrhythmogenesis. Circulation. 2000;102:2137-2144.

19. Volders PG, Sipido KR, Vos MA, Kulcsar A, Verduyn SC, Wellens HJ. Cellular basis of biventricular hypertrophy and arrhythmogenesis in dogs with chronic complete atrioventricular block and acquired torsade de pointes. Circulation. 1998:98:1136-47.

20. Van Opstal JM, Schoenmakers M, Verduyn SC, de Groot SH, Leunissen JD, van Der Hulst FF, Molenschot MM, Wellens HJ, Vos MA. Chronic amiodarone evokes no torsade de pointes arrhythmias despite QT lengthening in an animal model of acquired long-QT syndrome. Circulation. 2001;104:2722-7.

21. Van Opstal JM, Verduyn SC, Leunissen HD, de Groot SH, Wellens HJ, Vos MA. Electrophysiological parameters indicative of sudden cardiac death in the dog with chronic complete AV-block. Cardiovasc Res. 2001;50:354-61.

22. Sosunov EA, Gainullin RZ, Moise NS, Steinberg SF, Danilo P, Rosen MR. beta(1) and beta(2)adrenergic receptor subtype effects in german shepherd dogs with inherited lethal ventricular arrhythmias. Cardiovasc Res. 2000;48:211-9.

23. Billman GE. Effect of alpha 1-adrenergic receptor antagonists on susceptibility to malignant arrhythmias: protection from ventricular fibrillation. J Cardiovasc Pharmacol. 1994;24:394-402.

24. Biliman GE, Castillo LC, Hensley J, Hohl CM, Altschuld RA. Beta2-adrenergic receptor antagonists protect against ventricular fibrillation: in vivo and in vitro evidence for enhanced sensitivity to beta2-adrenergic stimulation in animals susceptible to sudden death. Circulation. 1997:96:1914-1922.

25. Cao JM, Chen LS, KenKnight BH, Ohara T, Lee MH, Tsai J, Lai WW, Karagueuzian HS, Wolf PL, Fishbein MC, Chen PS. Nerve sprouting and sudden cardiac death. Circ Res. 2000;86:816-21.

26. Volders PG, Sipido KR, Vos MA, Spatjens RL, Leunissen JD, Carmeliet E, Wellens HJ. Downregulation of delayed rectifier $\mathrm{K}(+)$ currents in dogs with chronic complete atrioventricular block and acquired torsades de pointes. Circulation. 1999;100:2455-61.

27. Ramakers C, Vos MA, Doevendans PA, Schoenmakers M, Wu YS, Scicchitano S, lodice A, Thomas GP, Antzelevitch C, Dumaine R. Coordinated down-regulation of KCNQ1 and KCNE1 expression contributes to reduction of $1(K s)$ in canine hypertrophied hearts. Cardiovasc Res. 2003:57:486-96. 
Chapter 5

28. Poole-Wilson PA, Swedberg K, Cleland JG, Di Lenarda A, Hanrath P, Komajda M, Lubsen J, Lutiger B, Metra M. Remme WJ. Torp-Pedersen C, Scherhag A, Skene A. Comparison of carvedilol and metoprolol on clinical outcomes in patients with chronic heart failure in the Carvedilol Or Metoprolol European Trial (COMET): randomised controlled trial. Lancet. 2003;362:7-13. 
Chapter 6

\section{General discussion}




\section{Relevance of hypertrophy for electrical remodeling and ventricular arrhythmias}

In humans, left ventricular hypertrophy has been associated with several cardiovascular disease states. Furthermore, ventricular hypertrophy has been related to electrical remodeling, like prolongation of QT-time, and has been associated with enhanced propensity to ventricular arrhythmias and sudden cardiac death. ${ }^{12}$ Therefore, regression of left ventricular hypertrophy was hypothesized to be beneficial for reduction of electrical remodeling, e.g. decrease of QT-time. This hypothesis was tested in patients suffering from congestive heart failure, aortic stenosis, and hypertension (table 1). ${ }^{310}$ Placement of a left ventricular assist device in endstage heart failure patients led to a decrease of hypertrophy and reduction of QTtime, which was associated with shorter ventricular action potentials. Some patients, however, did not show any change in electrophysiological parameters, suggesting interindividual differences. Resynchronization therapy in heart failure patients also significantly reduced hypertrophy, while the effects on changes in repolarization time remain unclear." Aortic valve replacement in patients with aortic stenosis, and administration of an ACE inhibitor or angiotensin II type-1 receptor blocker in hypertensive patients reduced both hypertrophy and QT-time.

\section{Table 1: Regression of ventricular hypertrophy in patients}

\begin{tabular}{lll}
\hline Intervention & LVH & QT(C)-time \\
\hline LVAD in CHF & $\downarrow$ & $\downarrow$ \\
BiV-PES in CHF & $!$ & $?$ \\
Valve replacement in aortic stenosis & $\downarrow$ & $\downarrow$ \\
ACE-inhibition in hypertension & $\downarrow$ & $!$ \\
AT1RB in hypertension & $\downarrow$ & \\
\hline
\end{tabular}

LVH: left ventricular hypertrophy; LVAD: left ventricular assist device;

CHF: congestive heart failure; BiV: biventricular pacing; ACE:

angiotensin converting enzyme; AT1RB: angiotensin II type-1 receptor blocker

References: $3-10$

Unfortunately, changes in incidence of ventricular arrhythmias or sudden cardiac death were not mentioned in these studies. Furthermore, with the presently available techniques it is nearly impossible to find out whether regression of hypertrophy and reduction of QT-time are an expression of normalization. 
To study this specific aspect, animal models of hypertrophy are very suitable, since information concerning baseline circumstances is available, and the moment of intervention can be standardized. In table 2, the effects on electrical remodeling after regression of ventricular hypertrophy in different animal models are presented. Removal of the stressor or pharmacological intervention was associated with either partial or total regression of hypertrophy. Total reversal of hypertrophy was related to normalization of electrical remodeling after administration of an ACEinhibitor in the spontaneously hypertensive rat ${ }^{12}$ and the hypertensive rabbit ${ }^{13}$, and after removal of the band in the aortic banded cat ${ }^{i:}$. Removal of the band in the aortic banded cats, however, did not always lead to regression of left ventricular hypertrophy, which suggested that irreversible structural changes had occurred. i" In the chronic complete AV block (CAVB) dog, normalization of left ventricular mass by pacing at physiological heart rate did not seem to have an effect on QT-time. $^{15,16}$

Table 2: Reversal of ventricular remodeling in animal models of hypertrophy

\begin{tabular}{lllll}
\hline Model & Intervention & $\begin{array}{l}\text { Reversal of } \\
\text { Hypertrophy }\end{array}$ & $\begin{array}{l}\text { Reversal of } \\
\text { Electrical } \\
\text { remodeling }\end{array}$ & $\begin{array}{l}\text { Susceptibility to } \\
\text { Ventricular } \\
\text { Arrhythmias }\end{array}$ \\
\hline SH rat & ACE-inhibitor & Total & Total & $?$ \\
N+B rabbit & ACE-inhibitor & Total & Total & $*$ \\
N+B rabbit & AT1RB & Partial & Total & $*$ \\
Aortic banded cat & Removal band ** Total & Total & Decreased \\
CAVB dog & RVa-PES & Total & No & $?$ \\
CAVB dog & BiV-PES & Total & No & $?$ \\
\hline
\end{tabular}

SH: spontaneously hypertensive; ACE: angiotensin converting enzyme; $N+B$ : unilateral nephrectomy and contralateral renal artery banding; LVH: left ventricular hypertrophy; AT1RB: angiotensin II type-1 receptor blocker; CAVB:chronic complete AV block; RVa-PES: right ventricular apex pacing; BiV-PES: biventricular pacing. * Both untreated and treated $N+B$ rabbits are not inducible to ventricular arrhythmias. "* Removal of the band led to regression of both hypertropyh and electrical remodeling in $50 \%$ of the cats, while there was no effect on hypertrophy or electrophysiology in the other $50 \%$.

References: 12-17 
Administration of an angiotensin II type-1 receptor blocker in the hypertensive rabbit-model only led to partial regression of hypertrophy, while ventricular electrophysiology normalized. ${ }^{17}$ This indicates that in some models the presence of hypertrophy is not a requirement for electrical remodeling. The arrhythmogenic consequence of regression of structural and electrical remodeling has only been studied in the aortic banded cats. In this model, reversal of electrical remodeling was associated with a decrease in susceptibility to pacing-induced polymorphic ventricular tachycardias. ${ }^{1:}$

Although regression studies are clinically relevant, they do not provide possible cause-effect relations since remodeling and re-remodeling may be different processes. In order to gain more insight into how the different remodeling processes are inter-related, temporal aspects from the start of pathology, like e.g. induction of bradycardia-induced volume overload, are of importance. In chapters 3 and 4 , changes in electrophysiology, heart weight, and susceptibility to dofetilide-induced torsade de pointes (TdP) from acute AV block up to 5-6 weeks CAVB were explored. In a recent study these aspects were even studied up to 10 weeks CAVB. ${ }^{8}$ The results of these studies are summarized in figure 1. Electrical remodeling, as defined by a heterogeneous prolongation of ventricular MAPD, develops within 2 weeks after AV block and is stable in time. Ventricular hypertrophy (increased heart or ventricular weight-to-body weight ratio), however, is still absent after 2 , is fully present at 6 weeks AV block, and increases little thereafter. Susceptibility to dofetilide-induced $\mathrm{TdP}$ shows a similar time course as electrical remodeling. The latter has to be said with great caution, since there are not sufficient data on TdP inducibility any later than 6 weeks CAVB. Studies with d-sotalol up to 25 weeks after AV block in a few dogs suggest that susceptibility to drug-induced TdP is probably reproducible in time (H.D.M. Beekman, personal communication). This suggests that in the CAVB dog hypertrophy is not a requirement for electrical remodeling or susceptibility to drug-induced TdP. So far, this is the only model in which development of hypertrophy, electrical remodeling and arrhythmogeneity have been studied simultaneously. Other investigators have also reported asynchronous development of remodeling, albeit ionic and structural remodeling. ${ }^{19}$ In the first days after myocardial infarction in the rat, downregulation of $K^{*}$-channel gene-products and currents is already present, while hypertrophy will develop later in time. Studies in the CAVB dog and the post myocardial infarction rat-model ${ }^{19}$, suggest that ventricular electrical remodeling and hypertrophy may have different signalling routes. The same message is expressed in the following prevention studies, where also information is provided concerning remodeling-specific signaling pathways. Inhibition of ACE in the ageing rat prevented the increase in heart mass, while the prolonged ventricular action potential was unaffected. ${ }^{20}$ In mice with pressure overload, calcineurin blockade was able to prevent myocyte hypertrophy, while there was limited effect on prolongation of the action potential. ${ }^{21}$ in aortic-banded rats, 
changes in $I_{f}, I_{T o}$ and $I_{C l}$ gene products were prevented by treatment with a $\mathrm{Ca}^{2 *}$ antagonist, while ventricular hypertrophy developed as normal. "2? Unfortunately, in these studies the arrhythmogenic consequence of the dissociation of hypertrophy and electrical remodeling has not been addressed.

Figure 1: Remodeling in the CAVB dog in time.

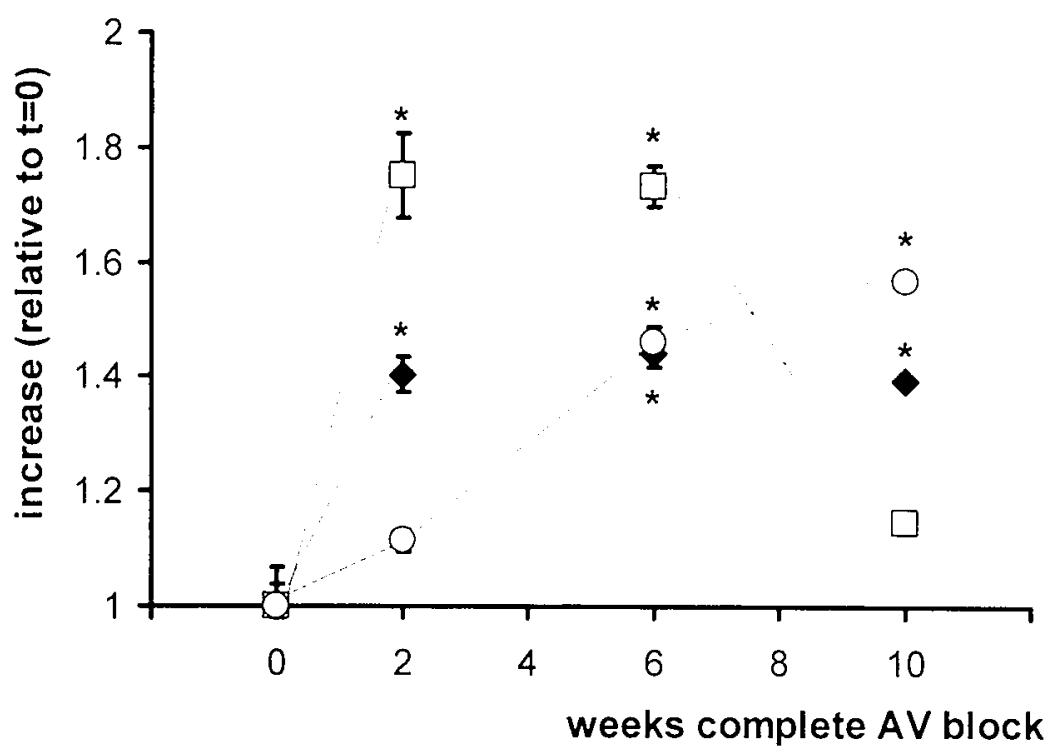

Electrical remodeling ( $L V$ MAPD: black diamonds). contractile remodeling ( $L V+d P d /$ tmax: white squares). and cardiac hypertrophy (heart-to-body weight ratio: white circles) ( $y$-axis) at 0, 2. 6. and 10 weeks of complete AV block ( $x$-axis). Mean \pm sem. (" $p<0.05$ versus 0 weeks AV block)

Electrical remodeling is evident after 2 weeks of complete AV block and stable in time. Contractile remodeling is also present at 2 weeks. remains stable until 6 weeks, but has declined after 10 weeks CAVB. Cardiac hypertrophy is still absent at 2, while present at 6 weeks $C A V B$, and shows a slow increase thereafter.

\section{Role of contractile remodeling for electrical remodeling and arrhythmogeneity}

The contractile adaptations following acute AV block in the dog were described in chapter 2. In short, induction of bradycardia-induced volume overload leads to an initial decrease in cardiac output. After several weeks, however, cardiac output has normalized, which is related to an increased contractile performance of the left and right ventricle (LV and RV respectively) with a maximum during slow heart rates. Ventricular potentiation, defined as the contractile response to a single extrastimulus (postextrasystolic potentiation: PESP) or short fast pacing trains (poststimulus potentiation: 
PSP), has increased, which is related to an enhanced propensity for delayed afterdepolarizations. Positive inotropic interventions (e.g. ouabain administration) are associated with triggered ectopic beats and ventricular tachycardias, while negative inotropic interventions (e.g. ryanodine administration) eliminate all arrhythmic events. At the cellular level, increased $\mathrm{Ca}^{2 *}$-transients (especially at the low frequencies), increased $\mathrm{Ca}^{2 *}$-influx through the $\mathrm{Na}^{*} \mathrm{Ca}^{*}$-exchanger, increased inward and outward current of the $\mathrm{Na}^{\circ} \mathrm{Ca}^{2}$-exchanger, enhanced sarcoplasmic reticulum-calcium content, and enhanced spontaneous sarcoplasmic reticulum-calcium releases have been linked to the preserved contractile function and delayed afterdepolarization-dependent arrhyth-

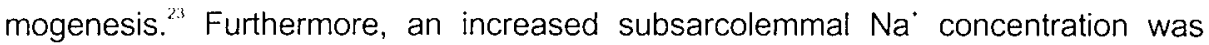
found to contribute to the changed properties of the $\mathrm{NaCa}^{2}{ }^{2 *}$-exchanger. ${ }^{2.3}$ In a rabbit model of heart failure, upregulation of the $\mathrm{Na}^{\circ} \mathrm{Ca}^{2 *}$ exchanger, decreased $\mathrm{Ca}^{2 *}$-transients, decreased sarcoplasmic reticulum-calcium content, and enhanced spontaneous sarcoplasmic reticulum-calcium releases were associated with increased cellular $\mathrm{Na}$ ' concentration. ${ }^{25.26}$ These changes were related to an increased susceptibility to ventricular tachyarrhythmias. Studies in both models indicate that $\mathrm{Na}^{+} \mathrm{Ca}^{2 \cdot}$ exchange upregulation seems to be a critical link between contractile (dys)function and arrhythmogenesis.

In chapter 4 , the time course of contractile remodeling was assessed. As illustrated in figure 1 , contractile remodeling, like electrical remodeling and susceptibility to dofetilide-induced TdP, is already present at 2, and stable up to 6 weeks AV block. Thereafter contractility declines, while electrical remodeling remains stable, which was also suggested by Dr. M. Peschar. ${ }^{16}$ Since susceptibility to drug-induced TdP has not been studied any later than 6 weeks CAVB, its time course can not be compared to contractile remodeling. This suggests that contractile remodeling might be of relevance in the evolution and short-term maintenance of electrophysiological remodeling and arrhythmogenesis, while it might not be important in sustenance of electrical remodeling in the CAVB dog-model.

In order to explore the relevance of the forementioned contractile adaptations for susceptibility to TdP at 2 and 6 weeks CAVB, contractile performance of dogs susceptible and resistant to dofetilide-induced TdP was compared in chapter 4. Baseline contractility, maximal force-frequency, and maximal PESP were not different between the 2 subgroups. However, maximally attained inotropism, as measured by maximal PSP, was significantly lower for the susceptible CAVB dogs. Moreover, maximal PSP showed a significant inverse relation to challenged LV repolarization (prolongation of MAPD during dofetilide administration), while there was no relation present for baseline $L V+d P / d t m a x$ and $L V$ repolarization. Dogs susceptible to dofetilide-induced TdP were characterized as the ones having lower maximally attained inotropism and more (heterogeneously) prolonged repolarization. However, the role of contractility for induction and elimination of TdP seemed to be the opposite, since induction of dofetilide-induced TdP was related to an 
increase in LV $+d P / d t m a x$, and elimination of $T d P$ was associated with a decrease. This led to the hypothesis that the severity of electrical remodeling was the only determinant of the ability of dofetilide to cause $T d P$, while the severity of electrical remodeling could be based upon the magnitude of the LV contractile adaptations necessary to compensate for the (sub)acute bradycardia-induced volume overload. The latter hypothesis was partly confirmed by chronic carvedilol administration in the CAVB dog in chapter 5. Chronic administration of high dose carvedilol, a non-selective adrenoceptor blocker, inhibited the acute compensatory response after creation of $\mathrm{AV}$ block, which was associated with the attenuation of electrical remodeling and reduction of susceptibility to dofetilide-induced TdP at 2 weeks AV block.

Based on all this, there are several hypotheses that describe the possible role of contractile and electrical adaptations for arrhythmogenesis in the CAVB dog, as shown in figure 2 .

Figure 2: Relevance of strucural, electrical and contractile remodeling for susceptibility to drug-induced TdP in the CAVB dog.

Bradycardia-induced volume overload
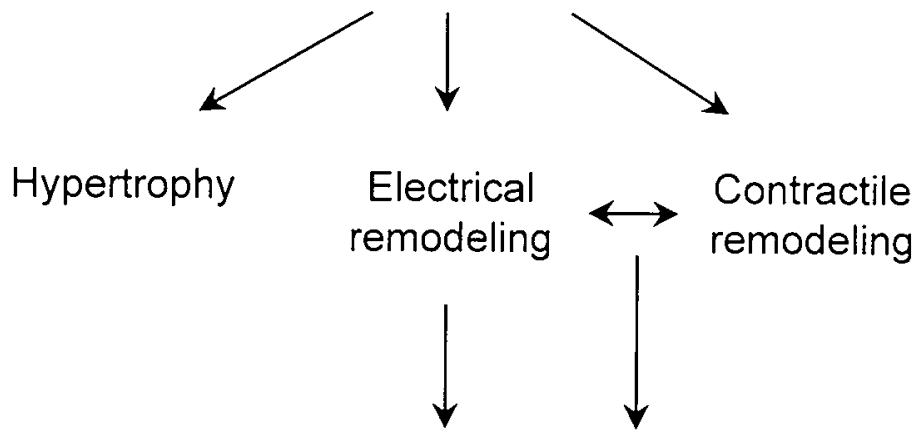

\section{Susceptibility to torsade de pointes}

Hypotheses for development of susceptibility to torsade de pointes-arrhythmias (TdP) in the chronic complete AV block dog.

Bradycardia-induced volume overload leads to hypertrophy, electrical remodeling. and contractile remodeling. Solely electrical remodeling or the synergy between electrical and contractile adaptations will result in increased susceptibility to (drug-induced) TdP. 
Figure 3: No effect of chronic cyclosporin A administration on electrical remodeling.

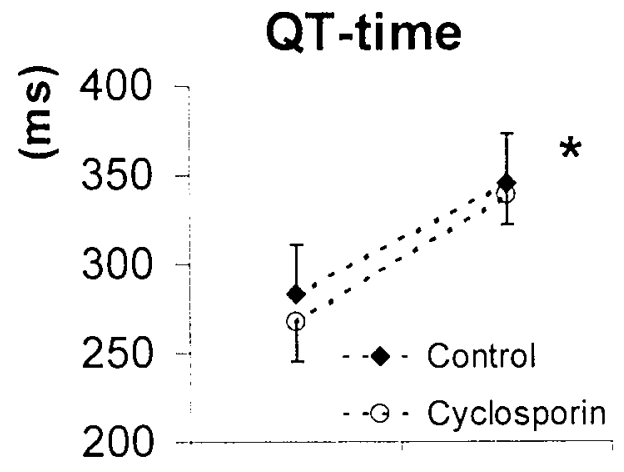

LV MAPD
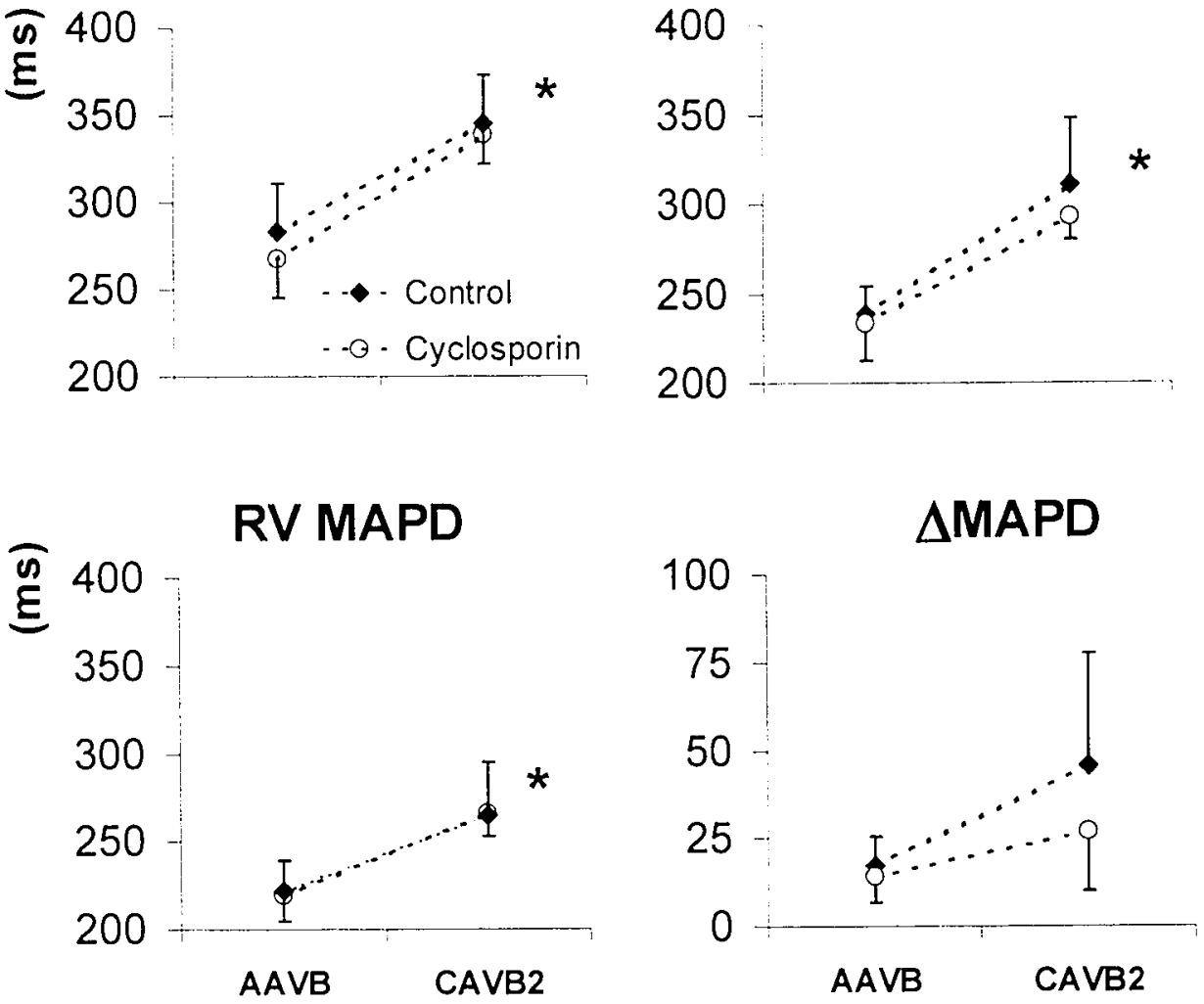

QT-time, left ventricular (LV) monophasic APD (MAPD), right ventricular (RV) MAPD. and interventricular dispersion of repolarization ( $M M A P D)$ ( $y$-axis) serially at acute AV block (AAVB) and 2 weeks complete AV block (CAVB2) for control $(n=8)$ and cyclosporin A (20 mg/kg/BID; for 3 weeks) treated animals ( $n=5)$. Mean $\pm S D$. (" $p<0.05$ versus $A A V B$ for control and cyclosporin $A)$ With comparable RR-times $(958 \pm 295 \mathrm{~ms}$ for control and $958 \pm 82 \mathrm{~ms}$ for cyclosporin $A$ at AAVB. and $1097 \pm 258 \mathrm{~ms}$ and $903 \pm 100 \mathrm{~ms}$ respectively at CAVB2). cyclosporin A did not have any effect on prolongation of QT-time. LV MAPD, RV MAPD, or the increase in $\triangle M A P D$.

Signalling pathways in electrical remodeling and ventricular tachyarrhythmias In the CAVB dog several components of the renin-angiotensin system and the adrenergic system are (transiently) elevated, and have been implicated in transduction pathway(s) leading to electrical remodeling. ${ }^{27 \cdot 24}$ In table 3 , the results of studies on prevention of remodeling by chronic oral administration of different drugs in the CAVB dog are presented. The angiotensin II type-1 receptor did not 
seem to be dominant in electrical remodeling, hypertrophy or susceptibility to druginduced TdP after induction of bradycardia-induced volume overload, as shown in chapter 3. In a spontaneously hypertensive rat-model, however, chronic blockade of the angiotensin II type-1 receptor resulted in the reduction of hypertrophy and a decrease of action potential duration (APD) prolongation." Also calcineurin did not seem to play a role in electrical remodeling or inducibility to $\mathrm{TdP}$ in the CAVB dog, since chronic oral administration of cyclosporin $A$ had no effect on electrical remodeling (figure 3 ) or inducibility to dofetlilide-induced TdP (4 susceptibles out of 5 ). This in contrast to a murine model of pressure overload, where calcineurin seemed dominant in the development of electrical remodeling." The adrenergic system, however, had an important role in development of electrical remodeling and suscepibility to (dofetilide-induced) TdP in the CAVB dog-model, as demonstrated in chapter 5.

Table 3: Results of prevention studies in the CAVB dog

\begin{tabular}{|c|c|c|c|c|c|}
\hline Drug & Blocks & $\begin{array}{l}\text { Electrical } \\
\text { Remodeling }\end{array}$ & Hypertrophy & $\begin{array}{l}\text { Contractile } \\
\text { Remodeling }\end{array}$ & $\begin{array}{l}\text { Susceptibility } \\
\text { to torsade de pointes }\end{array}$ \\
\hline Irbesartan & AT 1 & $=$ & $=$ & $\Leftrightarrow$ & $=$ \\
\hline Carvedilol * & $\beta_{1}, \beta_{2}, u_{1}$ AR & $\downarrow$ & $?$ & $=$ & $\pm !$ \\
\hline Cyclosporin A & calcineurin & $=$ & $?$ & $\hat{\imath}$ & $=$ \\
\hline
\end{tabular}

AT1: angiotensin 11 type-1 receptor; AR: adrenergic receptor.

* Results are from the high dose carvedilol $(10 \mathrm{mg} / \mathrm{kg} / \mathrm{BID}$ ) group.

When comparing the results of this thesis to studies on signalling pathways in other models of heterogeneously prolonged repolarization and (afterdepolarization-related) ventricular tachyarrhythmias, one appreciates the role of specific membrane receptors and downstream factors (table 4). It is important to keep in mind that the signalling factors presented in table 4 only take up a tiny part of the extensive signalling system present in cardiomyocytes. ${ }^{31.3 \%}$

Membrane receptors implicated in electrial remodeling and ventricular tachyarrhythmias in these specific models are: 1) the endothelin A receptor in APD prolongation in cardiomyopathy, and 2$)\left(\iota_{1}\right.$ - and $\beta$-adrenergic receptors in inherited susceptibility to afterdepolarizations and sudden death, and heterogeneous MAPD prolongation in increased susceptibility to TdP (CAVB dog). . $^{33 \cdot 35}$

Downstream factors, which have been related to electrical remodeling and arrhythmias in these models are protein kinase $A(P K A)$, and $\mathrm{Ca}^{2 *} /$ calmodulin-dependent protein kinase (CaMK). These factors are dependent on intracellular calcium (CaMK) and may also play a role in intracellular calcium handling.

As one notices (see table 4), electrical remodeling in early (EAD) and delayed after- 
depolarization (DAD)-related ventricular tachyarrhythmias seems to be associated with CaMK and PKA activity, mostly related to adrenoceptor activation. In the transgenic mouse model of increased CaMK activity, EAD and ventricular arrhythmias were elicited upon (3-adrenergic stimulation. ${ }^{36}$ CaMK activity itself was found to be essential in $\mathrm{Ca}^{2 *}$-handling and the occurrence of an arrhythmogenic transient inward current. ${ }^{37.38}$ Inhibition of CaMK (or PKA) eliminated drug-induced TdP in the rabbit." DAD-induced ventricular tachycardias in the german shepherd dog with inherited sudden arrhythmic death were related to an increased $\beta$-receptor density and defective downstream $\beta$-adrenergic receptor signalling. ${ }^{35.40}$ Moreover, the arrhythmias in this dog-model appeared similar to the catecholaminergic polymorphic ventricular tachycardias seen in affected children and adolescents. ${ }^{34}$ In a mouse model, which mimicks these specific tachycardias, PKA-phosphorylation of the FKBP12.6 depleted ryanodine receptor was found to be at the basis for the repetitive and spontaneous sarcoplasmic reticulum $\mathrm{Ca}^{2 *}$-releases, $\mathrm{DAD}$, and catecholamine-induced polymorphic ventricular tachycardias."

Table 4: Signal transduction in ventricular electrical remodeling and arrhythmogenesis

\begin{tabular}{lll}
\hline Model & Membrane receptor & Downstream factor \\
\hline ER/VA in cardiomyopathic hamster & ETA & \\
ER/TdP in CAVB dog & $\beta_{1}, \beta_{2}$, or $\leftrightarrow$ AR * \\
ER/EAD/DAD/VT in i-SD dog & $\kappa$ and $\beta_{1}$ AR ** & \\
ER/EAD/NT in CaMK IV TG mouse & & CaMK II \\
EAD/TdP in rabbit & & CaMK, PKA *** \\
DAD/CPVT in FKBP12.6 (-l-) mouse & & PKA \\
\hline
\end{tabular}

ER:electrical remodeling, here heterogeneous prolongation of APD; VA: ventricular arrhythmias; ETA:endothelin A receptor; PO:pressure overload; TdP: drug-induced torsade de pointes; AR: adrenergic receptor; EAD: early afterdepolarization; DAD delayed afterdepolarization; VT: ventricular tachycardia; i-SD:inherited sudden death; CaMK: $\mathrm{Ca}^{2} /$ calmodulin-dependent protein kinase; TG:transgenic; PKA: protein kinase A; CPVT: catecholaminergic polymorphic ventricular tachycardia. " Carvedilol inhibited $\beta_{1}, \beta_{2}$, and $\mu_{1} A R$, therefore it was impossible to pinpoint to a specific AR. ${ }^{* *} u_{1}$ AR is associated with EAD-related VT, and $\beta_{1}$ AR with DAD-induced VT. *** In vitro drug-induced EAD were associated with increased CaMK activity, while in vivo both PKA- and CaMK-inhibition led to elimination of drug-induced TdP. References: 33-36,39-42 
This all implicated that CaMK and PKA are very important signalling factors in electrical remodeling and afterdepolarization-related arrhythmogenesis. Furthermore, these factors may be future candidates in studies concerning (prevention of) electrical remodeling and susceptibility to TdP-arrhythmias in the CAVB dog.

\section{Implications for future research}

In the CAVB dog, electrical and contractile remodeling, and susceptibility to TdP arrhythmias develop faster than hypertrophy. In time, the contractile adaptations regress, while electrical remodeling remains stable, and hypertrophy seems to progress. Sudden cardiac death is present at ali stages of CAVB, indicating that different mechanisms might contribute at different times, with electrical remodeling as the most consistent.

In development of electrical remodeling and susceptibility to TdP after creation of AV block, the activation of adrenoceptors played an important role. Knowledge concerning the role of specific membrane receptors and the relevance of increased (diastolic) calcium for the evolution of electrical remodeling and arrhythmogenesis will be the basis for cellular and molecular identification of downstream transduction factors and their effects on gene expression. This will be essential for the development of new treatment strategies, like prevention, for ventricular remodeling and arrhythmogenesis. 


\section{References:}

1. Bikkina M, Larson MG, Levy D. Asymptomatic ventricular arrhythmias and mortality risk in subjects with left ventricular hypertrophy. J Am Coll Cardiol. 1993;22:1111-6.

2. Oikarinen L, Nieminen MS, Viitasalo M, Toivonen L, Wachtell K, Papademetriou V, Jern $S$, Dahlof B. Devereux RB, Okin PM. Relation of QT interval and QT dispersion to echocardiographic left ventricular hypertrophy and geometric pattern in hypertensive patients. The LIFE study. The Losartan Intervention For Endpoint Reduction. J Hypertens. 2001:19:1883-91.

3. Harding JD, Piacentino V, 3rd, Gaughan JP. Houser SR, Margulies KB. Electrophysiological alterations after mechanical circulatory support in patients with advanced cardiac failure. Circulation. 2001;104:1241-7.

4. Zafeiridis A, Jeevanandam V, Houser SR, Margulies KB. Regression of cellular hypertrophy after left ventricular assist device support. Circulation. 1998:98:656-62.

5. St John Sutton MG, Plappert T, Abraham WT, Smith AL, DeLurgio DB, Leon AR, Loh E, Kocovic $D Z$, Fisher WG, Ellestad M, Messenger J, Kruger K. Hilpisch KE, Hill MR. Effect of cardiac resynchronization therapy on left ventricular size and function in chronic heart failure. Circulation. 2003;107:1985-90.

6. Darbar D, Cherry $C J$, Kerins DM. QT dispersion is reduced after valve replacement in patients with aortic stenosis. Heart. 1999;82:15-8.

7. Gonzalez-Juanatey JR, Garcia-Acuna JM, Pose A, Varela A, Calvo C, Cabezas-Cerrato J, de la Pena MG. Reduction of QT and QTC dispersion during long-term treatment of systemic hypertension with enalapril. Am J Cardiol. 1998;81:170-4.

8. Malmqvist K, Kahan T, Edner M, Held C. Hagg A, Lind L, Muller-Brunotte R, Nystrom F, Ohman KP, Osbakken MD, Ostergern J. Regression of left ventricular hypertrophy in human hypertension with irbesartan. J Hypertens. 2001;19:1167-76.

9. Lim PO, Nys M, Naas AA, Struthers AD, Osbakken M, MacDonald TM. Irbesartan reduces QT dispersion in hypertensive individuals. Hypertension. 1999:33:713-8.

10. Gosse P, Roudaut R, Herrero G, Dallocchio M. Beta-blockers vs. angiotensin-converting enzyme inhibitors in hypertension: effects on left ventricular hypertrophy. I Cardiovasc Pharmacol. 1990;16 Suppl 5:S145-50.

11. Medina-Ravell VA, Lankipalli RS, Yan G, Antzelevitch C, Medina-Malpica NA, Medina-Malpica OA, Droogan C, Kowey PR. Effect of epicardial or biventricular pacing to prolong QT interval and increase transmural dispersion of repolarization: does resynchronization therapy pose a risk for patients predisposed to long QT or torsade de pointes? Circulation. 2003;107:740-746.

12. Yokoshiki H, Kohya T, Tomita F, Tohse N, Nakaya H, Kanno M, Kitabatake A. Restoration of action potential duration and transient outward current by regression of left ventricular hypertrophy. J Mol Cell Cardiol. 1997;29:1331-9.

13. Rials SJ, Wu Y, Xu X, Filart RA, Marinchak RA, Kowey PR. Regression of left ventricular hypertrophy with captopril restores normal ventricular action potential duration, dispersion of refractoriness, and vulnerability to inducible ventricular fibrillation. Circulation. 1997;96:1330-6.

14. Rials SJ, WU Y, Ford N, Pauletto FJ, Abramson SV, Rubin AM, Marinchak RA, Kowey PR. Effect of left ventricular hypertrophy and its regression on ventricular electrophysiology and vul- 
nerablity to inducible arrhythmia in the feline heart. Circulation. 1995:91:426-30.

15. Peschar M. Vernooy K. Vanagt WYR. Reneman RS. Vos MA. Prinzen FW. Absence of reverse electrical remodeling during regression of volume overload hypertrophy in canıne ventricles. Cardiovase Res. 2003:58:510-517.

16. Peschar M. Reverse remodeling in bradycardia induced volume overload: the role of optimizing the pacing site. Thesıs. Maastricht University. the Netherlands: 2003.

17. Rıals SJ, XuX. Wu Y. Liu T. Marinchack RA. Kowey PR. Restoration of normal ventricular electrophysiology in renovascular hypertensive rabbits after treatment with losartan. J Cardiovasc Pharmacol. 2001:37:317-23

18. Van Opstal JM, Schoenmakers M, Verduyn SC. de Groot SH. Leunissen JD. van Der Hulst FF. Molenschot MM. Wellens HJ. Vos MA. Chronc: amodarone evokes no torsade de pointes arrhythmias despite QT lengthening in an animal model of acquired long-QT syndrome. Circulation. 2001:104:2722-7.

19. Huang B. Qin D. El-Sherif N Early down-regulation of $\mathrm{K}+$ channel genes and currents in the postinfarction heart. J Cardiovasc Electrophysiol. 2000:11:1252-61.

20. Kreher P. Ristori MT, Corman B, Verdelli J. Effects of chronic angiotensin l-converting enzyme inhibition on the relations between ventricular action potential changes and myocardial hypertrophy in aging rats. J Cardiovasc Pharmacol. 1995:25:75-80.

21. Wang Z. Kutschke W. Richardson KE. Karimi M. Hill JA. Electrical remodeling in pressure-overload cardiac hypertrophy: role of calcineurin. Circulation. 2001:104:1657-63.

22. Hiramatsu M. Furukawa T. Sawanobori T. Hiraoka M. Ion channel remodeling in cardiac hypertrophy is prevented by blood pressure reduction without affecting heart weight increase in rats with abdominal aortic banding. J Cardiovasc Pharmacol. 2002:39:866-74.

23. Sipido KR, Volders PG. de Groot SH. Verdonck F. Van De Werf F. Wellens HJ. Vos MA. Enhanced $\mathrm{Ca}(2+)$ release and $\mathrm{Na} / \mathrm{Ca}$ exchange activity in hypertrophied canine ventricular myocytes : potential link between contractile adaptation and arrhythmogenesis. Circulation. 2000:102:2137-2144

24. Verdonck F. Volders PG. Vos MA. Sipido KR. increased $\mathrm{Na}(+)$ concentration and altered $\mathrm{Na} / \mathrm{K}$ pump activity in hypertrophied canine ventricular cells. Cardiovasc Res. 2003:57:1035-43.

25. Pogwizd SM. Schlotthauer K. Li L. Yuan W. Bers DM. Arrhythmogenesis and contractile dysfunction in heart failure: Roles of sodium-calcium exchange. inward rectifier potassium current. and residual bela-adrenergic responsiveness. Circ Res. 2001:88:1159-67

26. Despa S, Islam MA. Weber CR. Pogwizd SM, Bers DM. Intracellular Na(+) concentration is elevated in heart failure but $\mathrm{Na} / \mathrm{K}$ pump function is unchanged. Circulation. 2002:105:2543-2548.

27. Vos MA. de Groot SH, Verduyn SC, van der Zande J. Leunissen HD. Cleutjens JP. van Bilsen M. Daemen MJ. Schreuder JJ. Allessie MA. Wellens HJ. Enhanced susceptibility for acquired torsade de pointes arrhythmias in the dog with chronic, complete AV block is related to cardiac hypertrophy and electrical remodeling. Circulation. 1998:98:1125-35.

28. Verduyn SC. Ramakers C. Snoep G. Leunissen JD. Wellens HJ. Vos MA. Time course of structural adaptations in chronic AV block dogs: evidence for differential ventricular remodeling. Am J Physiol Heart Circ Physiol. 2001:280:H2882-90. 
29. Schoenmakers M, Ramakers C. Van Opstal JM, Leunissen HD, Londono C, Vos MA. Asynchronous development of electrical remodeling and cardiac hypertrophy in the complete AV block dog. Cardiovasc Res. 2003;59:351-359.

30. Cerbai E, Crucitti A, Sartiani L, De Paoli P, Pino R, Rodriguez ML, Gensini G, Mugelli A. Longterm treatment of spontaneously hypertensive rats with losartan and electrophysiological remodeling of cardiac myocytes. Cardiovasc Res. 2000;45:388-96.

31. Molkentin JD, Dorn GW, 2nd. Cytoplasmic signaling pathways that regulate cardiac hypertrophy. Annu Rev Physiol. 2001;63:391-426.

32. Sugden $\mathrm{PH}$, Clerk A. Cellular mechanisms of cardiac hypertrophy. J Mol Med. 1998;76:725-46.

33. Matsumoto Y, Aihara H, Yamauchi-Kohno R, Reien Y, Ogura T, Yabana H, Masuda Y, Sato T, Komuro I, Nakaya $\mathrm{H}$. Long-term endothelin a receptor blockade inhibits electrical remodeling in cardiomyopathic hamsters. Circulation. 2002;106:613-9.

34. Moise NS, Gilmour RF, Jr., Riccio ML. An animal model of spontaneous arrhythmic death. $J$ Cardiovasc Electrophysiol. 1997;8:98-103.

35. Sosunov EA, Gainullin RZ, Moise NS, Steinberg SF, Danilo P, Rosen MR. beta(1) and beta(2)adrenergic receptor subtype effects in german shepherd dogs with inherited lethal ventricular arrhythmias. Cardiovasc Res. 2000;48:211-9.

36. Wu Y, Temple J, Zhang R, Dzhura I, Zhang W, Trimble R, Roden DM, Passier R, Olson EN. Colbran RJ, Anderson ME. Calmodulin kinase II and arrhythmias in a mouse model of cardiac hypertrophy. Circulation. 2002;106:1288-93.

37. Wu Y. Colbran RJ, Anderson ME. Calmodulin kinase is a molecular switch for cardiac excitation- contraction coupling. Proc Natl Acad Sci U S A. 2001:98:2877-81.

38. Wu Y, Roden DM. Anderson ME. Calmodulin kinase inhibition prevents development of the arrhythmogenic transient inward current. Circ Res. 1999;84:906-12.

39. Mazur A. Roden DM, Anderson ME. Systemic administration of calmodulin antagonist W-7 or protein kinase $A$ inhibitor $\mathrm{H}-8$ prevents torsade de pointes in rabbits. Circulation. 1999:100:2437-42.

40. Steinberg SF, Alcott S, Pak E, Hu D. Protas L, Moise NS, Robinson RB, Rosen MR. beta(1)Receptors increase cAMP and induce abnormal $\mathrm{Ca}(\mathrm{i}) \mathrm{cycling}$ in the German shepherd sudden death model. Am J Physiol Heart Circ Physiol. 2002;282:H1181-8.

41. Wehrens XH, Lehnart SE. Huang F, Vest JA, Reiken S, Mohler PJ, Sun J, Guatimosim S, Song L, Rosemblit N, D'Armiento J, Napolitano C, Memmi M, Priori S, Lederer WJ, Marks AR. FKBP12.6 deficiency and defective calcium release channel (ryanodine receptor) function linked to exercise-induced sudden cardiac death. Cell. 2003;113:829-840.

42. Anderson ME, Braun AP, Wu Y, Lu T, Schulman H, Sung RJ. KN-93, an inhibitor of multifunctional $\mathrm{Ca}++$ /calmodulin-dependent protein kinase, decreases early afterdepolarizations in rabbit heart. J Pharmacol Exp Ther. 1998;287:996-1006. 
Summary 
Cardiovascular diseases are the leading cause of death in the Netherlands. Although clinical symptoms of cardiovascular diseases may vary widely, sudden death is often the first manifestation. This sudden mode of death is mainly attributed to a cardiac arrhythmia. Susceptibility to (ventricular) arrhythmias has been associated with changes in cardiac structure, function, and electrophysiology, which are named remodeling processes. An important expression of structural remodeling is the development of left ventricular hypertrophy, which is regarded to be an adaptive response to an abnormal increase in cardiac work that can be evoked by mechanical overload. Patients with ventricular hypertrophy can have a compensated cardiac function for years (compensated hypertrophy), but if the stimulus for hypertrophy is sufficiently intense or prolonged ventricular dysfunction and heart failure may ensue. However, the exact relevance of the functional adaptations (contractile remodeling; either in compensated or decompensated contractile function) for arrhythmias is not yet clear. Moreover, the electrophysiological properties of the heart may change (electrical remodeling), which may lead to, e.g. prolongation of repolarization. Prolongation of ventricular repolarization (increased QT-time) has been attributed to an increased duration of the ventricular action potential, which is based on alterations in ion channels, pumps, and exchangers.

In chapter 1, the clinical background of the thesis is explained and the different types of cardiac remodeling in relation to susceptibility to ventricular arrhythmias and sudden cardiac death are discussed. In addition, animal models of different cardiovascular diseases in which ventricular remodeling and arrhythmogeneity have been studied are presented. The dog model of chronic complete AV block, which is a model of biventricular hypertrophy, heterogeneous prolongation of ventricular action potential duration (electrical remodeling), and susceptibility to class III-antiarrhythmic drug-induced torsade de pointes, is discussed in detail and introduced as a suitable model to study development of ventricular remodeling and arrhythmogenesis. Finally, the goals of the thesis are formulated.

In chapter 2, contractile remodeling in the chronic complete AV block dog and its relation to triggered arrhythmias are described. Creation of complete AV block in the dog leads to acute volume overload and an increase in stroke volume, which is not sufficient to maintain cardiac output. At chronic complete AV block, however, all systolic contractile parameters have increased, which is accompanied by normalization of cardiac output. At this time, positive inotropic interventions (poststimulus potentiation or ouabain administration) are related to induction of delayed afterdepolarization-related triggered arrhythmias, while negative inotropic interventions (fixed rate pacing or ryanodine administration) prevent them completely.

In chapters 3 and 4, the (asynchronous) time course of cardiac hypertrophy, electrical remodeling, contractile remodeling and susceptibility to drug-induced torsade de pointes up to 6 weeks complete AV block dog are presented. Electrical remodeling, contractile remodeling, and susceptibility to dofetilide-induced torsade de 
pointes are already present after 2 weeks complete AV block, while hypertrophy follows a slower time path. From this, one may conclude that ventricular hypertrophy is not a prerequisite for electrical remodeling, contractile remodeling (or compensated cardiac function), and susceptibility to drug-induced torsade de pointes in the model.

The relation of contractile adaptations and susceptibility to dofetilide-induced torsade de pointes is addressed in chapter 4. Chronic complete AV block dogs that are resistant to drug-induced torsade de pointes are characterized by a higher maximally attained poststimulus potentiation than the ones susceptible to torsade de pointes. Repolarization duration during dofetilide infusion and maximal potentation show a significant inverse correlation, in which susceptible dogs can be identified as having longer repolarization times during dofetilide and lower maximal poststimulus potentiation. It is suggested that dogs susceptible to dofetilide-induced torsade de pointes may have needed more contractile adjustments necessary to survive (sub)acute volume overload requiring more lengthening of the action potential, which is associated with lower maximally attained poststimulus potentiation and less repolarization reserve at chronic AV block as compared to the resistant ones.

In the chronic complete AV block dog there is a transient elevation of plasma (and tissue) components of the renin angiotensin system and the adrenergic system, which suggests a role of these neurohumoral systems in development of ventricular remodeling and arrhythmogenesis in the model.

In chapter 3 , the effects of chronic oral administration of the angiotensin II type-1 receptor blocker irbesartan are presented. Administration of irbesartan does not lead to prevention of electrical remodeling or ventricular hypertrophy, indicating that the angiotensin II type- 1 receptor does not play a role in ventricular remodeling in the chronic complete AV block dog.

Chronic oral administration of carvedilol, a non-selective adrenergic blocker, inhibits the hemodynamic compensatory response at acute AV block, independent of dose (chapter 5 ). This is associated with reduction of electrical remodeling and decreased susceptibility to dofetilide-induced torsade de pointes at 2 weeks complete AV block, only in the high dose group. Contractile remodeling, however, is not affected by either dose. This suggests that in the model, the adrenergic system contributes significantly to development of electrical remodeling and arrhythmogenesis.

This in contrast to calcineurin, which does not seem to play a role in electrical remodeling or arrhythmogeneity in the model, although it has been indicated in development of electrical remodeling after hemodynamic overload (chapter 6).

Finally, in chapter 6 findings of the thesis are discussed in broader perspective. 

Samenvatting 
De meeste mensen in Nederland sterven aan hart- en vaatziekten. Alhoewel de klinische symptomen van hart- en vaatziekten kunnen verschillen, is plotse hartdood vaak de eerste (en enige) uiting. Deze plotse manier van overlijden wordt vaak toegeschreven aan een hartritmestoornis. Een verhoogde gevoeligheid voor (kamer) ritmestoornissen wordt vaak in verband gebracht met veranderingen in de structuur, pompfunctie en elektrische eigenschappen van het hart. Deze veranderingen worden remodeleringsprocessen genoemd.

Een belangrijke vorm van structurele remodelering is de groei van hartspiercellen die leidt tot een toename van de linker kamermassa (linker kamerhypertrofie). Linker kamerhypertrofie ontstaat als het hart harder moet werken omdat er een mechanische overbelasting is, zoals bij hoge bloeddruk, na een hartinfarct, of bij een lekkende hartklep.

Mensen met kamerhypertrofie kunnen gedurende een lange tijd een normale pompfunctie van het hart hebben (gecompenseerde hypertrofie), maar als de mechanische overbelasting te groot is of te lang duurt kunnen er pompfunctiestoornissen optreden, die uiteindelijk zelfs in hartfalen kunnen overgaan (gedecompenseerde hypertrofie). Het is echter nog niet helemaal duidelijk wat de exacte relatie is tussen de veranderingen van de pompfunctie van het hart (contractiele remodelering; gecompenseerd ten opzichte van gedecompenseerd) en de verhoogde gevoeligheid voor kamerritmestoornissen.

Verder kunnen de elektrische eigenschappen van het hart veranderen (elektrische remodelering). Elke hartslag wordt voorafgegaan door een elektrisch stroompje, dat ontstaat in speciale pacemakercellen, en wordt voortgeleid over de boezems en de kamers van het hart. Na de elektrische activatie van het hart volgt een samentrekking (hartslag), waarna het hart terugkeert naar de elektrische rustfase (repolarisatie). Elektrische remodelering van het hart kan leiden tot een verlenging van de repolarisatieduur, dat op het ECG te zien is als een verlengde QT-tijd.

In hoofdstuk 1 wordt de klinische achtergrond van het onderzoek uiteengezet en worden de verschillende soorten remodeleringsprocessen in relatie tot de verhoogde gevoeligheid voor kamerritmestoornissen bediscussieerd. Verder worden verscheidene diermodellen voor hartziekten besproken waarin remodelering van de kamers van het hart en de gevoeligheid voor ritmestoornissen is onderzocht. Het hondenmodel met chronisch compleet AV-block wordt geintroduceerd en gepresenteerd als het juiste model om de ontwikkeling van kamerremodelering te onderzoeken en het ontstaan van de verhoogde gevoeligheid voor torsade de pointes (een soort kamerritmestoornis) te bestuderen. De chronisch compleet AV-block hond heeft: linker- en rechter kamerhypertrofie, een toegenomen repolarisatieduur die meer is toegenomen in de linker dan in de rechter kamer (repolarisatiedispersie) en een verhoogde gevoeligheid voor torsade de pointes, met name na toediening van repolarisatie verlengende medicatie. Daarnaast worden de doelen van het proefschrift geformuleerd. 
In hoofdstuk 2 worden de eigenschappen van contractiele remodelering in de chronisch compleet AV-block hond beschreven en de relatie met ritmestoornissen uiteengezet. Het induceren van een traag hartritme in een hond door middel van compleet AV-block leidt tot een acute volume overbelasting van het hart. In het chronische stadium is de pompkracht van zowel de linker als de rechter kamer toegenomen waardoor er een gecompenseerde functie is opgetreden. Dit is echter geassocieerd met een verhoogde gevoeligheid voor late nadepolarisaties en ritmestoornissen, met name na een verdere verhoging van de pompkracht (toediening van ouabaïne en het poststimulus pacing protocol). Terwijl een verlaging van de pompkracht deze ritmestoornissen laat verdwijnen (continu versneld pacen of toediening van ryanodine).

In de hoofdstukken 3 en 4 wordt de asynchrone ontwikkeling van structurele remodelering, contractiele remodelering, elektrische remodelering en de verhoogde gevoeligheid voor torsade de pointes in het chronisch compleet AV block hondenmodel gepresenteerd. Elektrische remodelering, contractiele remodelering en de verhoogde gevoeligheid voor torsade de pointes zijn al na 2 weken AV block aanwezig, terwijl structurele remodelering (hypertrofie van beide kamers) pas na 6 weken is ontstaan. Dit suggereert dat in dit hondenmodel, kamerhypertrofie geen voorwaarde is voor zowel contractiele remodelering, elektrische remodelering als voor de verhoogde gevoeligheid voor torsade de pointes.

De relatie tussen contractiele remodelering en de verhoogde gevoeligheid voor torsade de pointes in het model wordt uiteengezet in hoofdstuk 4. Chronisch compleet AV block honden die niet gevoelig zijn voor medicatie-geïnduceerde torsade de pointes worden gekarakteriseerd door een hogere maximale pompkracht dan honden die wel gevoelig zijn voor torsade de pointes. De repolarisatieduur tijdens de infusie van een repolarisatieverlengend medicament (dofetilide) en de maximaal behaalde pompkracht laten een negatief significante relatie zien, waarin de honden die gevoelig zijn voor torsade de pointes een langere repolarisatieduur hebben na dofetilide en een lager maximale pompkracht. In dit hoofdstuk wordt gesuggereerd dat honden die gevoelig zijn voor torsade de pointes meer volume overbelast zijn door acuut AV block, waardoor zij een grotere contractiele aanpassing moeten leveren zodat de actiepotentiaal meer verlengd wordt. In het chronische stadium uit zich dit in een lager maximaal behaalde pompkracht en een verminderde repolarisatiereserve, waardoor deze honden gevoelig zijn voor torsade de pointes.

$\mathrm{Na}$ het induceren van compleet $\mathrm{AV}$ block in de hond is er een tijdelijke stijging van factoren van het renine-angiotensine systeem en het adrenerge systeem in het bloedplasma (en hartweefsel) waar te nemen. Dit geeft aan dat deze neurohumorale systemen een belangrijke rol zouden kunnen spelen in de ontwikkeling van kamerremodelering en het ontstaan van de verhoogde gevoeligheid voor torsade de pointes in dit model. 
In hoofdstuk 3 worden de effecten van de chronisch en oraal toegediende angiotensine II type-1 receptor blokker irbesartan gepresenteerd. Irbesartan is niet in staat het ontstaan van elektrische en structurele remodelering te voorkomen, wat betekent dat de angiotensine II type-1 receptor geen rol speelt in het ontstaan van remodelering in de chronisch compleet $\mathrm{AV}$ block hond.

Chronische en orale toediening van carvedilol, een $\beta_{1_{1}}, \beta_{2^{-}}$en $\kappa_{1}$-adrenerge blokker, voorkomt de acute compensatoire response na het ontstaan van volume overbelasting na acuut AV block, onafhankelijk van de dosis (hoofdstuk 5). Dit is geassocieerd met een vermindering van elektrische remodelering en een verlaging van de gevoeligheid voor torsade de pointes in de hoog gedoseerde groep. De lage dosering carvedilol heeft geen effect op elektrische remodelering of de gevoeligheid voor torsade de pointes. Opmerkelijk genoeg heeft carvedilol geen enkel effect op contractiele remodelering. Deze resultaten geven aan dat het adrenerge systeem een belangrijke rol speelt in de ontwikkeling van elektrische remodelering van de kamers en het ontstaan van de gevoeligheid voor gevaarlijke ritmestoornissen.

Dit in tegenstelling tot calcineurine, dat geen enkele rol lijkt te spelen in de ontwikkeling van elektrische remodelering noch in de verhoogde gevoeligheid voor torsade de pointes, ook al wordt calcineurine als een belangrijke factor beschouwd in het ontstaan van remodelering na mechanische overbelasting in andere diermodellen (hoofdstuk 6).

Tot slot worden in hoofdstuk 6 de resultaten van dit proefschrift in een breder verband bediscussieerd. 
Dankwoord 
Het begin van mijn "onderzoeksloopbaan" begon meer dan zeven jaar geleden toen ik samen met Marc Vos de experimentele o.k. binnen stapte waar Marieke de Groot en Jet Beekman met een experiment bezig waren. Door hun gedrevenheid en enthousiasme èn mijn honger naar het nieuwe begon ik voor een halve dag per week als student-assistent bij Cardiologie. Een halve dag slechts, want studie, werken, sporten en uitgaan moesten mijns inziens allemaal doorgang kunnen vinden. Dat het onderzoek uiteindelijk wat verslavend heeft gewerkt ziet $u$ aan het voor $u$ liggende resultaat.

De inhoud van dit proefschrift is slechts een deel van wat ik in de afgelopen periode heb geleerd. Het doen van onderzoek heeft naast nieuw verworven kennis en kunde namelijk ook een grote bijdrage geleverd aan mijn persoonlijke ontwikkeling. In dit laatste maar essentiële hoofdstuk zou ik graag eenieder die belangrijk is geweest voor "mijn" onderzoek willen bedanken.

Prof. Dr. M.A. Vos, beste Marc, de afronding van mijn promotie vond plaats in een voor jou turbulente tijd als kersverse professor. Jouw doorzettingsvermogen en positieve geest zijn een stimulerende factor geweest op de momenten dat ik geen enkel lichtpuntje meer in mijn data zag. Jouw drang om elk klein en groot succes te vieren, heeft mij doen beseffen waar ik het allemaal voor deed. Daarnaast was je verantwoordelijk voor het groepsgevoel binnen de Experimentele Cardiologie. Jouw terugkerende vraag "wie is er aan de beurt voor een borrel?" zal me altijd bijblijven. Ik ben blij je eerste promovenda te mogen zijn en wens je veel succes als vakgroepvoorzitter van de Medische Fysiologie in het UMC te Utrecht.

De leden van de beoordelingscommissie, Prof. Dr. H.J.G.M. Crijns, Prof. Dr. M.A. Allessie, Prof. Dr. H.J.J. Wellens en Dr. K.R. Sipido wil ik bedanken voor het kritisch doorlezen van mijn manuscript en voor hun bereidheid te opponeren tijdens de verdediging van dit proefschrift. I would also like to thank Dr. M.E. Anderson for finding the time to review this manuscript and his willingness to be present at my thesis defense.

Ik wil ook mijn paranimfen Jet Beekman en Louise Sabelis van harte bedanken. Jet, als ik alle tijd op zou tellen die wij samen aan het onderzoek gewijd hebben, dan zou dat misschien wel een half jaar zijn! Behalve de spannende en onverwachte momenten tijdens de experimenten, zullen mij ook jouw trucs bij het pillen geven bijblijven. Nogmaals bedankt voor je hulp bij die ene echo om 7 uur 's morgens toen ik zonodig naar een schermtoernooi moest! Mede door jouw technische vaardigheid, zorgvuldigheid en lieve zorg voor de honden is het chronisch AV-block model zo succesvol geworden. Louise, vanaf de eerste dag van onze studie geneeskunde zijn we al bevriend. We hadden toen nog geen weet van wat ons allemaal te wachten zou staan, noch dat we beiden onderzoek zouden gaan doen of 
dat we in hetzelfde jaar ons proefschrift zouden gaan verdedigen. Samen met Martijn en Martin hebben we veel leuke uitstapjes gemaakt (hoogtepunt de "Superman" in Six Flags) en gezellige vakanties gehad (koekjes, vuurwerk en 1 konijn in "Rabbit Hill"). Misschien zou het leuk zijn een keer met zijn vieren op wintersport te gaan...

Mijn collega's van de Experimentele Cardiologie hebben me vaak geholpen en voor een vrolijke noot gezorgd. Roel, voor het draaien van de pillen, het maken van mooie plaatjes en het bakken van lekkere cakes. Jet, voor het snel uitwerken van data op het laatste moment en voor de wandelingen in de Ardennen. Jurren, voor het kritisch bekijken van mijn manuscripten en presentaties, voor de vele lange discussies over maatschappelijke issues en de humor. Dirk, voor het (wel erg) kritisch doorlezen van mijn manuscripten, jouw grote echokunde en de trotse papa verhalen. Morten, although your Dutch vocabulary is far from optimal (vlaai, beer, and gezellig is about it!), I really enjoyed the drinks after work, and your Italian and Danish cooking. Jérôme, voor de sarcastische noot, de lekkere whiskey's en de bioscoopjes. Chris, voor de sensationele rit op het dagje uit van Cardiologie, de grappen en serieuzere gesprekken. Maaike, voor de hulp tijdens de afronding van dit proefschrift, de kaars en de telefoontjes. Paul, voor de enorme kennis en de promotietips. Milan, for the helpful comments on my work, and the Czech cuisine. Verder hebben Marieke, Cora, Henny, Elke, Ferenc, Michiel, Camila en Mirella een belangrijke rol gespeeld.

Ook wil ik mijn collega's van de Cardiologie (m.n. Aimée, Suzanne en Henny van mijn tijd in de AlO-tuin; Vivian en Miriam voor de secretarïele ondersteuning) en Fysiologie te Maastricht en de Medische Fysiologie te Utrecht bedanken voor hun praatjes op de gang.

De Centrale Proefdier Voorzieningen onder leiding van wijlen Ton van den Boogaard zou ik willen bedanken voor de goede zorg voor de honden. Met name Monique heeft door haar betrokkenheid en enthousiasme een grote rol gespeeld. Theo, Ruud en Jo voor de hulp tijdens de experimenten èn voor de grappen.

Als ik na een dag onderzoek thuis kwam dan waren de telefoontjes, mailtjes, etentjes en bezoekjes van mijn lieve vrienden meer dan welkom. Annemieke, Birgitte, Dorry, Floor en Matt, Grit en David, Hannah, Hendra, Irma, Janneke, Louise en Martijn, Margo, Marjolein, Martijn, Mina en Garth ik hoop dat ik nu wat meer tijd voor jullie heb!

Mijn ooms, tantes, neven en nichten hebben altijd erg met mij meegeleefd, met name in voor mij moeilijke tijden. Ik wil jullie hiervoor bedanken.

Ook mijn "andere" familie: Ineke en Jan, Jan en Roelie, Anneke en Karl, Marco en Jacqueline voor de getoonde interesse en Carina voor de telefoonkusjes.

Hendrik, broer, onze band is in de laatste jaren erg hecht geworden, hiervoor wil ik 
je bedanken. Verder waardeer ik de directheid waarmee jij dingen kunt zeggen, dit zet me weer met beide benen op de grond.

Lieve Martin, jouw onvoorwaardelijke steun, nuchterheid en innerlijke rust waren essentieel voor de succesvolle afronding van mijn proefschrift. Ik hoop nog heel lang samen met jou van het leven te mogen genieten.

Papa en mama, jullie vormen de basis van mij en van dit proefschrift. Ik wil jullie bedanken voor alles wat jullie mij gegeven hebben. 
Curriculum Vitae 
Curriculum Vitae

28 oktober $1973 \quad$ Geboren te Breda

1986-1992

Gymnasium [3, Theresialyceum, Tilburg

1992-1996

Geneeskunde, doctoraalexamen, Universiteit Maastricht

1996

Wetenschapsstage Experimentele Neuroembryologie, University of Alberta, Canada

1996-1997

Student-assistent vakgroep Cardiologie,

Universiteit Maastricht

1997-1999

Vervolg studie geneeskunde, artsexamen,

Universiteit Maastricht

1999

Keuzestage tropengeneeskunde en A.I.D.S. preventie, Oyugis Integrated Project, Kenia

$1999-2003$

A.I.O., vakgroep Cardiologie, Universiteit Maastricht

Januari 2004-heden

Arts-assistent Cardiologie, Vie Curi Medisch Centrum voor Noord-Limburg, Venlo 
Publications 


\section{Articles}

- De Groot SHM, Schoenmakers M, Molenschot MMC, Leunissen JDM, Wellens HJJ, Vos MA. Contractile adaptations preserving cardiac output predispose the hypertrophied canine heart to delayed afterdepolarization-dependent ventricular arrhythmias. Circulation. 2000;102:2145-2151

- Van Opstal JM, Schoenmakers M, Verduyn SC, de Groot SHM, Leunissen JDM, van der Hulst FF, Molenschot MMC, Wellens HJJ, Vos MA. Chronic amiodarone evokes no torsade de pointes arrhythmias despite QT-lengthening in an animal model of acquired long QT syndrome. Circulation. 2001;104:2722-2727

- Sipido KR, Volders PGAV, Schoenmakers M, de Groot SHM, Verdonck F, Vos $\mathrm{MA}$. Role of the $\mathrm{Na} / \mathrm{Ca}$ exchanger in arrhythmias in compensated hypertrophy. Ann N Y Acad Sci. 2002;976:438-445

- Ramakers C, Vos MA, Doevendans PA, Schoenmakers M, Wu YS, Sciccitano $S$, lodice A, Thomas GP, Antzelevitch C, Dumaine R. Coordinated down-regulation of KCNQ1 and KCNE1 expression contributes to reduction of $1(\mathrm{Ks})$ in canine hypertrophied hearts. Cardiovasc Res. 2003;57:486-496

- Schoenmakers M, Ramakers C, van Opstal JM, Leunissen JDM, Londoño C, Vos MA. Asynchronous development of electrical remodeling and cardiac hyerptrophy in the complete AV block dog. Cardiovasc Res. 2003;59:351-359

\section{Book chapter}

Vos MA, Schoenmakers M, Peschar M, Prinzen FW. Regression of ventricular hypertrophy and its effect on electrical remodeling. In: Schalij MJ, Janse MJ, van Oosterom A, van de Wall EE, Wellens HJJ, eds. Einthoven 2002. 100 years of electrocardiography. Leiden, the Netherlands: The Einthoven Foundation; 2002: $415-420$

\section{Abstracts}

- De Groot M, Vos MA, Muller A, van Hardeveld C, Leunissen J, Schoenmakers $M$, van Zuidwijk M, Verduyn $C$, Wellens HJJ. Increased susceptibility for triggered arrhythmias in biventricular hypertrophy due to complete atrioventricular block. Heart Failure. 1997;349

- De Groot SHM, Vos MA, Schoenmakers M, Leunissen JD, Wellens HJJ. Adaptations in contractile function at chronic AV-block make the heart more susceptible to triggered arrhythmias. Circulation. 1997;96:I-239/I-240 
- De Groot SHMA, Vos MA, Schoenmakers M, Leunissen HDM, Wellens HJJ. The increased susceptibility to triggered arrhythmias of the heart at chronic complete AV block relates to adaptations in contractile function. Eur Heart $\mathrm{J}$. 1998: 19 suppl:79

- De Groot M, Leunissen J, Schoenmakers M, Vos M. Ouabain exhibits a proarrhythmic effect in the hypertrophied but not in the non-hypertrophied canine heart. J Mol Cell Cardiol. 1999;31:A65

- Schoenmakers M, van Opstal JM, Leunissen JDM, de Groot SHM, Spätjens RLHGM, Wellens HJJ, Vos MA. Ventricular hypertrophy is not a prerequisite for short-term functional adaptation, electrical remodelling and arrhythmogenicity in the chronic AV-block dog. PACE. 2001;24:572

- Van Opstal JM, Schoenmakers M, Verduyn SC, de Groot SHM, Leunissen HDM, van der Hulst FF, Molenschot MMC, Vos MA. Absence of torsade de pointes arrhythmias despite QT-lengthening after oral amiodarone treatment in an animal model of acquired long QT. Eur Heart J. 2001; 22:449

- Van Opstal JM, Schoenmakers M, Verduyn SC, de Groot SHM, Leunissen JD, van der Hulst FF, Molenschot MM, Wellens HJJ, Vos MA. Chronic amiodarone evokes no torsade de pointes arrhythmias despite QT-lengthening in an animal model of acquired long QT syndrome. Circulation. 2001;104:11-47

- Schoenmakers M, Leunissen JD, van Opstal JM, Wellens HJJ, Vos MA. Cardiac hypertrophy and electrical remodeling develop asynchronously in the chronic AV-block dog, independently of AT1 blockade. I Am Coll Cardiol. 2002;39:104A-105A

- Van Opstal JM, Truin M, Schoenmakers M, Thomson MB, Leunissen J, Vos MA. Sudden cardiac death and torsade de pointes arrhythmias in the chronic AVblock dog are associated with large temporal- and temporospatial repolarization variance. PACE. 2002;25:576

- Schoenmakers M, Beekman JDM, Spätjens RLHMG, Vos MA. Carvedilol reduces the susceptibility to drug-induced torsade de pointes in the complete AV block dog. Netherlands Heart Journal. 2003;11:9-10 